

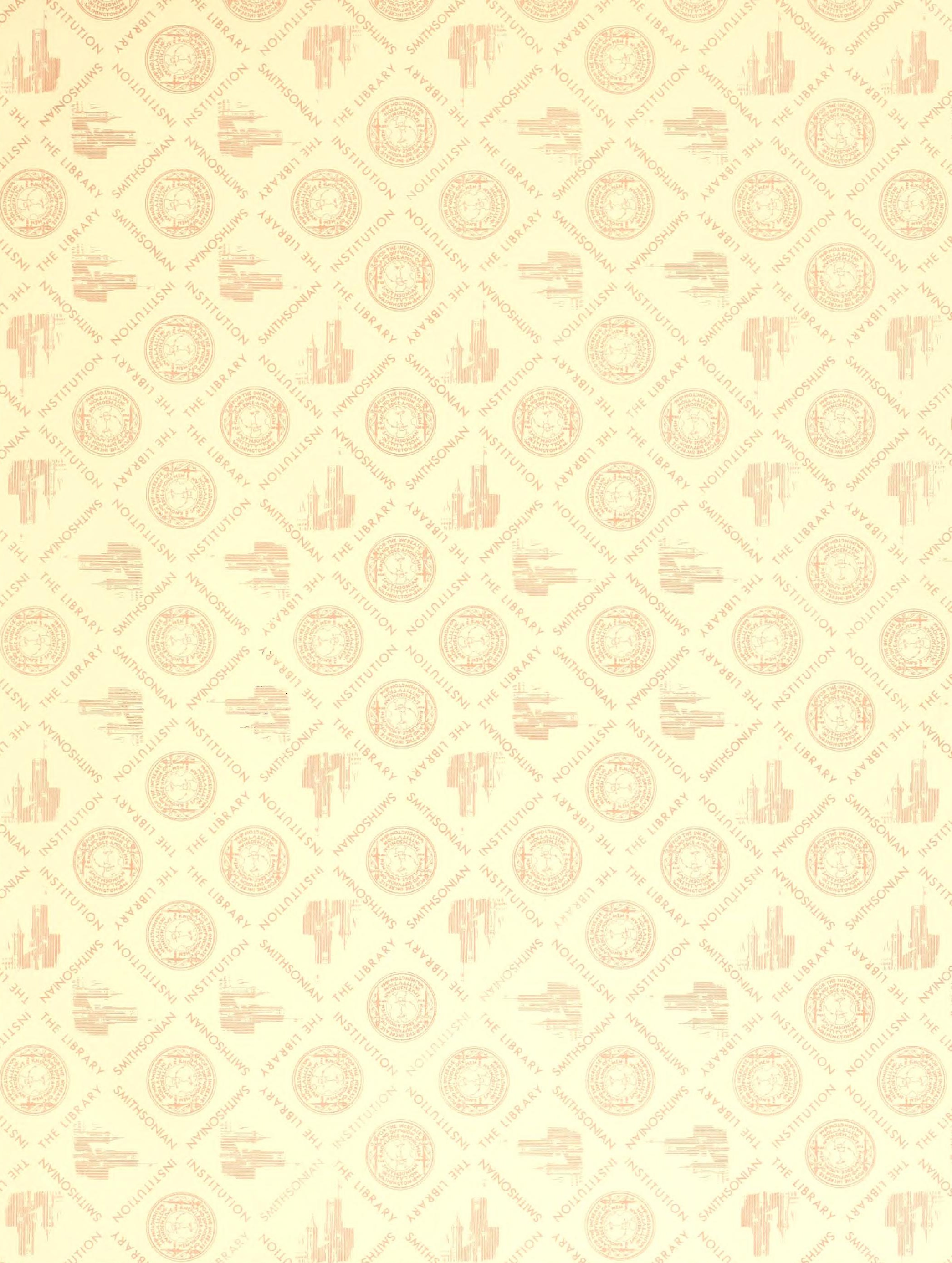





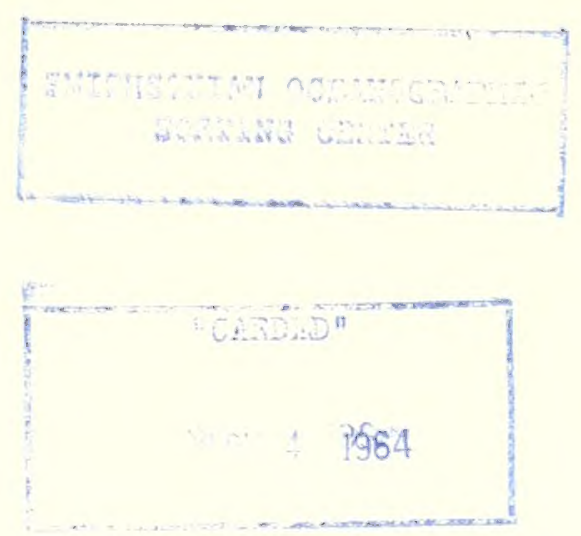





\title{
REPORT ON THE FISHES TAKEN BY THE BENGAL FISHERIES STEAMER "GOLDEN CROWN"
}

\author{
PART I.-BATOIDEI. \\ By N. Annandale, D.Sc., Superintendent, Indian Museum.
}

\section{INTRODUC'TION.}

The trawler "Golden Crown"' was purchased in England by the Bengal Government in the early part of the year Igo8 and commenced work in the Bay of Bengal at the beginning of the monsoon season in June of that year. Since then she has made numerous trips, most of which have been confined to the northern parts of the Bay. Her work has not been scientific, and she is not equipped for research of any kind; but the Commissioner of Fisheries has permitted me to retain for the Museum specimens of the fish captured on each trip. The collection thus obtained has served to supplement the ichthyological investigations of Lieutenant-Colonel A. W Alcock and his predecessors and successors as Surgeon Naturalist on the R.I.M.S "Investigator"'; for the trawl of the "Golden Crown,' being of the type commonly used in commercial fishing, is of a much larger size, and therefore capable of holding much larger fish, than any likely to be used for scientific purposes in Indian seas. It has, moreover, been used mainly in water of a depth between 20 and 30 fathoms, whereas the "Investigator"' dredges mainly, but not solely, at much greater depths. The collections obtained by the two vessels are therefore complementary to one another.

The "Golden Crown', has trawled along the greater part of the coast from Gopalpur in the Ganjam district of the Madras Presidency to Oyster Island off the coast of Burma, but mostly in Balasore Bay, off Konarak and Puri in Orissa, off the entrance to the Eastern Channel of the river Hughli, off the Mutlah Lightship at the entrance to the Mutlah river, and in the vicinity of Cox's Bazaar, Chittagong. Most of the ground covered has been muddy, but occasionally fine sand, coarse sand, and "coral grounds"' have been worked. The so-called coral grounds, however, have not been coral reefs but places where the bottom has become sufficiently solid to afford a support for sedentary organisms of various kinds. Off Gopalpur in about 24 fathoms, for instance, enormous numbers of Tenagodes shells were brought up in the trawl, interwoven into rock-like masses with a Lithistid sponge; off Konarak a recent conglomerate of sand and decomposed shells was found to afford a lodging to numerous Gorgoniids and Antipatharians, some of the latter reaching a gigantic 
size; while off the coast of Arakan true fossiliferous rocks, apparently of Miocene age, were encountered, their surface being densely coated with solitary corals and molluses of various kinds.

It has been decided that the Museum shall publish a report on the fish captured by the "Golden Crown," and the present paper is the first part of that report. Dr. $\int$. Travis Jenkins, Scientific Adviser on Fisheries to the Government of Bengal, and Mr. B. I. Chaudhuri, Assistant Commissioner of Fisheries, will deal with the Teleosteans, while the systematic study of the Elasmobranchs falls to me. Probably Dr. Jenkins and I will deal jointly with the Selachians, as soon as we feel that the collection is sufficiently representative to be treated in a satisfactory manner.

Since Dr. Jenkins came out to India, in November, I908, I have been indebted very greatly to him for selecting and preserving specimens and for information about specimens not preserved and the nature of the localities. It has not been possible for me to go out on the trawler myself, but Dr. Jenkins has done so regularly and, quite apart from his own work, has shown himself a most zealous coadjutor in the work of the Museum. Captain R. E. Lloyd, I.M.S., has also gone out on the trawler for one trip, and I am indebted to him for some interesting observations. I must express my obligations to the Commissioner of Fisheries for allowing me to retain specimens for the Museum and for obtaining a grant of Rs. 400 from the Government of Bengal towards the expense of illustrating the report; to Mr. B. L. Chaudhuri for much help as regards the collection, and to the skipper, Captain Mann, and European crew of the "Golden Crown.' To deal with large and powerful animals such as a full-grown saw-fish in such a way that they shall be suitable for scientific examination is a matter not devoid of difficulty and physical danger, and until November Igo8 I was dependent on Capt. Mann and his hands as regards the specimens retained for the Museum.

The Batoidei, being mostly bottom-haunting species, are more commonly captured in a trawl than any other large fish. Consequently it has been possible to obtain a fairly complete collection with great expedition. Indeed, between June Igo8 and March Igog about sixty per cent. of the forms now known to inhabit the seas of British India have been captured by the "Golden Crown," while of the remaining forty per cent. at least half of the species live either at great depths or on the surface of the sea and would not therefore be taken in a trawl except by accident.

In preparing the report on the Batoidei of the "Golden Crown"' I have made use not only of the old collection in the Indian Museum, but also of those in the Museum of Madras and Trivandrum, both of which, thanks to their respective heads, Mr. E Thurston and Lieut.-Col. F. W. Dawson, I have had the privilege of examining lately. The specimens from the "Golden Crown'" have been sent up to the Museum in ice, and I have thus had an opportunity, in many cases, of comparing them in a fresh condition with specimens long preserved dry or in alcohol. This has proved a very valuable opportunity, for it has been found almost impossible to identify certain species by means of the published descriptions on the basis of fresh material only. These 
descriptions, including the measurements given, have evidently, in many cases, been based solely on badly stuffed Museum specimens, and the figures reproduced have had the same foundation.

It may be well to give a definite statement as to the measurements recorded in this paper. Considerations of time and space have rendered them less complete than I would have liked, for expedition is necessary, as well as a considerable amount of spare room, if several large rays preserved in rapidly melting ice are to be measured in a tropical climate before they can go bad, especially if a proportion of them are finally to be preserved as museum specimens. Whenever possible, moreover, photographs and water colour sketches have been taken as well as the measurements, in order that an accurate record of the colours and outlines of the different species may be preserved. The measurements themselves have been taken with a tape across or along the specimens, - not from point to point. This method has been adopted as providing a more accurate standard for comparison than that of measuring from point to point. Fixcept when it is otherwise stated, the measurements have been taken on the fresh specimen before it has been dissected.

The illustrations, except when it is otherwise stated, are reproductions of photographs of frozen specimens.

The following list contains the names of the Batoidei as yet recorded or here mentioned as occurring in the seas of British India and Ceylon. I have not dealt further, however, with most of the deep-sea forms.

\section{LIST OF THE BATOIDEI RECORDED FROM INDIAN SEAS.}

The names of the species not examined in connection with this report are printed in italics. Those of species taken by the "Golden Crown"' are marked with a* ; those of species not described or recognized by Day in the "Fauna' with a \$; those species of which the types are in the Indian Museum with a $\dagger$.

\section{Family PRISTID无:}

I. Pristis cuspidatus.*

2. ,, perottetii.*

3. ,, pectinatus.*

3a. ,, , var. annandalei ${ }^{*} \xi \uparrow$

4. ,, zysron.*

Family RHINoBATID

5. Rhamphobatis ancylostomus.*

6. Rhinobatis djeddensis.*

7. ,, halavis

8. , granulatus.*

9. ", thonini.

IO. ,, columnæ.*

II. , schlegelii.*\$
Family RAJIDE.

I2. Raja mamillidens. $\$ \dagger$

I3. ,. johannis-davisi. $\$ \dagger$

I4. , reversa. $\uparrow \dagger$

I5. , sp. nov. $\uparrow$

I6. , powellii.\$†

I6a. , philipii (?) (=R. powellii). $§ \uparrow$

I7. Platyrhina schonleinii.

Family TRYGONID 王.

I8. Trygon microps. $* \$ \uparrow$

Ig. ,, uarnak.*

20. ,, gerrardii.*

2r. ,, favus, sp. nov.* I $^{2}$

22. ", bleekeri.* 
23. Trygon alcockii, sp. nov.*§†

24. , jenkinsii, sp. nov.*ร†

25. ', marginatus.*

26. ,, bennettii.

27. ,, imbricata.*

28. , zugei * $^{*}$

29. ,, kuhlii.*

30. Hypolophus sephen.*

3I. Teniura melanospilos.

32. Urogymnus asperrimus.*

33. , lævior, sp. nov. $\$$

34. Pteroplatea micrura.*

35. , $\quad$ zonura.*\$

36. ,, tentaculata.* $\$$

Family TORPEDINID As.

37. Torpedo marmorata. $\uparrow$.

38. Narcine timlei.*

39. ,, brunnea, sp. nov.*\$†

40. , mollis. $\$ \dagger$
4I. Benthobatis moresbyi. $\uparrow \uparrow$

42. Astrape dipterygia.*

43. Bengalichthys impennis, gen. et sp. nov.* $\xi \uparrow$

Family Mrimobatid 死。

44. Rhinoptera javanica.

45. ," adspersa.

46. Myliobatis nieuhofii.*

46a. ,, ,, var. cornifera.

47. ,, maculata.*

48. Aëtobatis guttata.*

49. ,, flagellum.* $\%$

Family CERATOPTERID死.

50. Dicerobatis eregoodoo.

5I. , , thurstoni.

52. ,, kuhlii.

53. Ceratoptera orissa.

- From this list it may be seen that of the fifty-three distinct species here recognized as occurring in Indian seas, no less than thirty-three have been taken during the past year by the "Golden Crown." Of the remaining twenty, seven probably live only in water deeper than that in which the operations of the fishery steamer have been conducted, while at least four (the members of the family Ceratopteridæ) are surface forms and would not usually be taken in a trawl. In the list there are twenty-one specific and two varietal names not to be found in Day's volume in the " Fauna," or there regarded as synonyms. Of these, nine belong to species described within the last few years by Alcock' or Iloyd" and, with two exceptions, taken in deep water by the " Investigator,' while twelve are here recorded for the first time or have recently been recorded for the first time in the Records of the Indian Musenm. A new genus, five new species and a new variety are described in this report.

\section{Suborder BATOIDEI.}

Family PRIS'TID A (Saw-fishes).

The saw-fishes, which abound in the Bay of Bengal and make their way up some of the larger rivers, are very destructive to edible fish. Their livers yield an oil which should prove valuable (see Mr. Hooper's analysis, postea) and the flesh of the young is edible, although there does not seem to be much demand for it.

Alcock, A Descriptive Catalogue of the Indian Deep-Sea Fishes (Calcutta, I899), and Illustrations of the Zoology of the R.I.M.S. "Investigator," Fishes, pls. viii, xxvi, xxvii.

Lloyd, Ann. Mag. Nat. Hist. (7), vol. xviii, p. 3 II (Igo6); Rec.Ind. Mus., i, p. 5 (I907), and Ill. Zool. "Investigator," Fishes, pls. xxxix-xli. Also " A Description of the Deep-Sea Fish caught by the R.I.M.S. "Investigator" since the year 1900," in Mem.Ind. Mus., ii, Igog (incd.). 
Only one genus can be recognized, namely Pristis, with five species, four of which cccur in the Bay.

\section{Key to the Indian Species of Pristis.}

I. Teeth absent from the base of the saw for a considerabie distance.

(a) From 25 to 35 teeth on each side of the saw. Anterior dorsal fin arising behind the root of the pelvic fins .. _. P.cuspidatus.

II. Teeth present on the base of the saw.

(a) Not more than 22 teeth on each side of the saw. Anterior dorsal fin in advance of the pelvic fins for the greater part of its length.

$P$. perottetii.

(b) Twenty-five or more teeth on each side of the saw. Anterior dorsal fin above the pelvic fins _.. $\quad \ldots \quad$.. P.pectinatus.

(c) Twenty-six or more teeth on each side of the saw. Anterior end of anterior dorsal fin distinctly behind the anterior end of the root of the pelvic fins ..

\section{Pristis cuspidatus, Latham.}

This species is easily distinguished from all others by the following characters :-

(a) The rostral teeth commence at a considerable distance from the base of the rostrum;

(b) Both edges of the rostral teeth are sharp, the hinder edge having a distinct barb in young individuals ;

(c) The lower lobe of the caudal fin is pointed and quite distinct.

(d) The teeth in the mouth are smaller and relatively broader than in the other species.

The broad groove which runs outwards and upwards from the outer edge of the nostril is also noteworthy, as well as the small size of the cutaneous fold on the anterior edge of the nostril.

Young specimens of this species have been caught by the "Golden Crown " on almost every voyage, but large ones are somewhat rare.

The following measurements are those of the largest specimen $(q)$ as yet taken, and of a large male. The former was captured at the beginning of August off Orissa, the latter in January off the mouth of the Ganges. The head, saw and fins of the female and the saw of the male are preserved in the Indian Museum.

Fixtreme length (including saw)

Length of saw

Breadth of saw at base

, , , , at tip

Distance of first rostral tooth from base of saw

Breadth across pectoral fin

Width of mouth

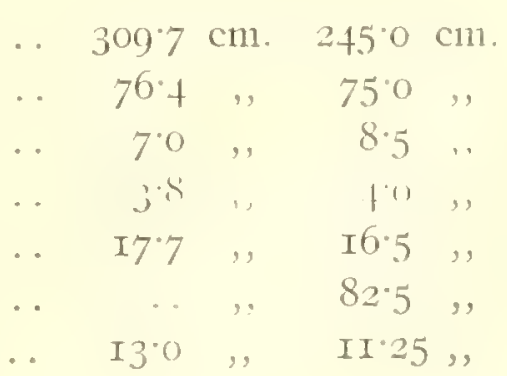


Breadth of pectoral fin

$$
\text { , , pelvic fin .. }
$$

Length of pectoral fin . .

$$
\text { , , pelvic fin .. }
$$

Breadth of first dorsal fin

$$
\text { ,. , second dorsal fin }
$$

Height of first dorsal fin

., , second dorsal fin

Length of dorsal lobe of caudal fin

Greatest breadth of dorsal lobe of caudal fin . .

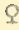

o

$\begin{array}{ccccc}\ldots & 39^{\circ} 9 & \mathrm{~cm} . & \ldots & \\ \ldots & 35^{\circ} 0 & , & \ldots & \\ \ldots & 32^{\circ} 5 & , & \ldots & \\ \ldots & 23^{\circ} 0 & , & \ldots & \\ \ldots & 35^{\circ} 5 & , & \ldots & \\ \ldots & 34^{\circ} 0 & , & \ldots & \\ \ldots & 35^{\circ} 0 & , & 27.5 & \mathrm{~cm} . \\ \ldots & 25^{\circ} 0 & , & 26^{\circ} 25 & , . \\ \ldots & 40^{\circ} 5 & , & 35^{\circ} 0 & , \\ \ldots & 27^{\circ} 0 & , & \ldots & \end{array}$

The rostral teeth are narrow in these specimens, measuring $10 \mathrm{~mm}$. in breadth at the base and $2 \mathrm{Imm}$. in length where they are not worn. They are very slightly retroverted and show no signs of a barb on the posterior edge, as the rostral teeth of all young examples of the species (=P. semisagittatus, Shaw) do (see Miiller and Henle, Syst. Beschr. d. Plagiostomen, pl. 60, I84I). The male has 27 teeth on either side of the saw; the female 27 on the right and 28 on the left.

The colour of young individuals is a dark leaden grey on the dorsal surface, fading to pale grey on the belly. The back of old specimens is considerably paler than that of the young and is tinged with green in life.

Pristis cuspidatus is confined to the seas of India and the Malay Archipelago. It is common at the mouths of the Ganges.

There is an interesting abnormal (stuffed) specimen of this species in the Museum. The anterior dorsal is entirely absent, but a slight scar on the skin of the back would suggest that it had been removed accidentally. In front of this scar there is a longitudinal band of small, broadly heart-shaped, flattened denticles, which is broadest posteriorly and becomes gradually narrower in front, reaching slightly beyond the anterior margin of the pelvic fins. The specimen is a young one, measuring about 80 cm. in length and was purchased in the Akyab markei in roo6.

\section{Pristis perottetii, Müller and Henle.}

This species is distinguished from $P$. pectinatus and $P$. zysron by the small number of its rostral teeth (not more than 22 pairs) and by the position of its first or anterior dorsal fin, which originates considerably further forward on the body than the pelvic fins.

This species is very common in the estuaries of the Ganges and Brahmaputra, which it ascends for at least a hundred miles, often being captured in fresh water. The following are the measurements of two large females taken by the "Golden Crown," A in November off Arakan and B in October off Orissa.

A. B.

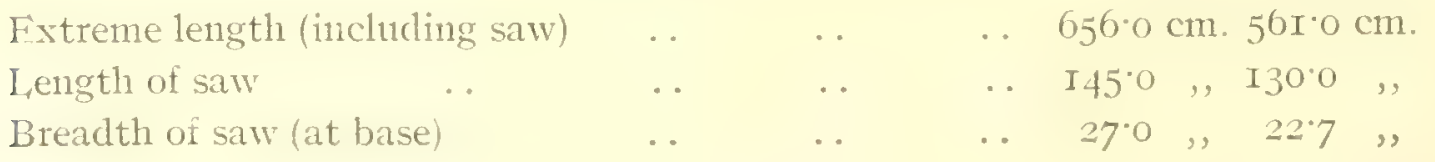




\begin{tabular}{|c|c|c|c|c|c|c|}
\hline Breadth of saw (at tip) & . & .. & . & II'2 & $\mathrm{cm}$. & $7 \cdot 8 \mathrm{~cm}$ \\
\hline Width of mouth & . & . & . & $45^{\circ} 6$ &, & . \\
\hline Breadth of pectoral fin .. & . & . & . & I $26 \cdot 6$ & .. & \\
\hline , , , pelvic fin .. & . & . & & 0,$3 ;$ & . & \\
\hline L.ength of pectoral fin & . & . & . & IOI 3 & , , & \\
\hline ,, , pelvic fin $\quad$. & . & . & . & $8 \mathrm{r} \cdot \mathrm{O}$ & , , & \\
\hline Breadth across pectoral fin & . & . & . . & $304^{\circ} 0$ & , & $228 \cdot 0$ \\
\hline Breadth of first dorsal fin & . & . & . . & $63: 3$ &, & \\
\hline , , , second ,. .. & . & . & & 353 & ,. & \\
\hline Height of first dorsal fin & . & . & . & $63 \cdot 3$ & , , & . \\
\hline , , secomol , , , & . & . & . & $6,3: 3$ & , & \\
\hline
\end{tabular}

It will be seen from these measurements that the proportionate length of the saw varies considerably. In specimen $A$ it is slightly over $\frac{1}{5}$ of the total length, while in $B$ it is just about ${ }_{-1}^{1}$. The teeth in these specimens are very stout, with the posterior edge strongly grooved. They measure in A $27 \mathrm{~mm}$. in breadth at the base and from $73-78 \mathrm{~mm}$. in length, in B I $-20 \mathrm{~mm}$. in breadth at the base and $50-68 \mathrm{~mm}$. in length. The teeth at the tip bend forwards slightly in each case. A has I7 and $B$ I8 pairs. The number on the sides of the saw, however, is not always the same I have examined specimens with 22 teeth on one side of the saw, but none with so many on both sides. Several have 20 on one side and $2 \mathrm{I}$ on the other.

The adult female of this species is dull grey on the dorsal surface, almost white on the belly, and the male does not appear to differ from the female in coloration.

Pristis perottetii is found in all tropical seas and estuaries and is closely related to $P$ antiquonm of the Mediterranean and Atlantic, from which it may be distinguished by the fact that in the latter the first dorsal fin is situated immediately above the pelvic fins.

\section{Pristis pectimatus, Lathan.}

This species is easily distinguished from $P$. perottetii by the larger number of its rostral teeth $(25-3+$ pairs $)$. From $P$. zysron it may be distinguished by the fact that the anterior edge of the first dorsal is situated almost immediately over that of the pelvic fins.

The saw is short and tapers considerably, but Day is not correct in saying that it is always twice as broad at the base as at the tip, the proportion being sometimes about 4 to 3 . The rostral teeth are rather slender and are grooved posteriorly; at the base of the saw they are, in old specimens, three or four times as distant from one another as they are at the tip. I have not seen a specimen in which they had the same number on both sides of the saw. The true teeth, in the mouth, resemble those of $P$. perottctii. The head and forepart of the body are flatter in $P$. pectinatus than in any other species I have seen. The second dorsal fin is always slightly smaller than the first.

Although this is caommon species in the estuaries of the Ganges and is well represented in the collection of the Indian Museum, I have found no complete specimens 
of the typical form among those sent me from the "Golden Crown." A number of severed saws, however, appear to belong to this form.

\section{Pristis amandalei, Chaudhuri. (P1. v, fig. 4.)}

P. annandalei, Chandhuri, Rec. Ind. Mus., ii, P. 39I, text-figure.

I do not now think that this form is more than a variety of $P$. pectinatus, if, indeed, it is not the typical adult male of that species. The main difference lies in the coloration, and this is not only a character that is lost in dried specimens, but is also one that may very well be sexual or even seasonal. In all the species of the genus variation occurs as regards the exact proportions and outlines of the fins and saw, and I do not think, after comparing dried specimens, that the structural features which separate $P$. annandalei from the specimens of $P$. pectinatus in the Museum, are beyond the limits of such variation, although I agreed with Mr. Chaudhuri at the time he described his species that it was new. When fresh it exlibited a brilliancy of coloration much superior to anything that I have seen in any other specimen of the genus. The back was of a bright ashy grey, which faded into blue on the sides and then changed to pale yellow. The anterior margins of the dorsal fins were bluish grey, but the body of all the fins was orange-yellow suffused with red. The claspers were of a bright brownish red, and there was a conspicuous orange-red line running down each side of the saw and interrupted by each tooth. The following are the measurements of this specimen, which was taken in July off the coast of Burma in shallow water.

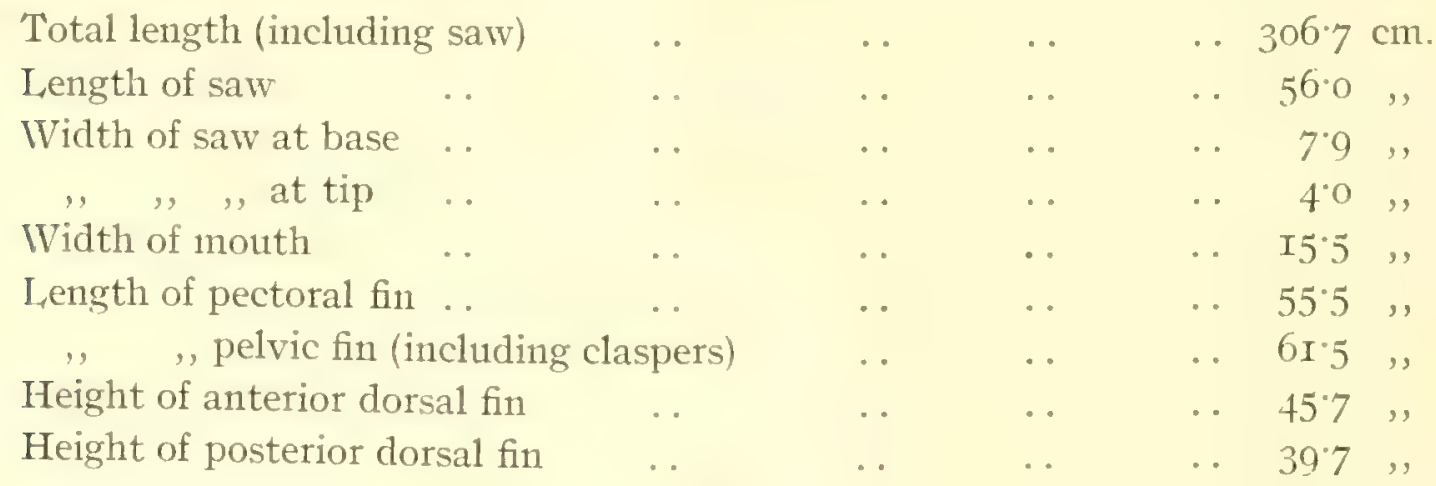

The rostral teeth are slender, measuring only from 7 to $8 \mathrm{~mm}$. in width at the base and from $2 \mathrm{I}$ to $26 \mathrm{~mm}$. in length. There are 24 on the right and 25 on the left.

A successful cast of this specimen was made and was coloured from a water-colour sketch of the fresh specimen. Figure 4 , plate $v$, is a reproduction of a photograph of this cast. The skeleton and part of the skin have also been preserved in the Indian Museum, the number in the Museum register of fishes being $\mathrm{F} \underline{2} \frac{3}{1} \underline{9} \underline{3}$.

Pristis zysron, Bleeker.

The rostrum in this species is longer in proportion to the body than that of $P$. pectmatus; the rostral teeth are stouter, and in old specimens they are often as much as 
ten times as distant from one another at the base as they are at the tip of the saw. They frequently have the same number on the two sides of the saw. The posterior dorsal fin is usually rather larger than the anterior one. There is a narrow yellowish streak along the side of the saw in large individuals of this species, as there is in all adult specimens of $P$. pectinatus, but even in the males the colours are dull.

Day says that $P$. zysron is perhaps mote common in the seas of India than $P$.cuspidatus, but this remark probably applies to the Arabian Sea rather than the Bay of Bengal. Several large specimens have, however, been taken by the "Golden Crown." The measurements of two males are as follows :-

Total length (including saw)

\section{Length of saw}

Width of saw at base

,, , , , , , tip

Breadth across pelvic fin

$\begin{array}{ll}\ldots & \ldots \\ \ldots & \ldots \\ \ldots & \ldots \\ \ldots & \ldots\end{array}$

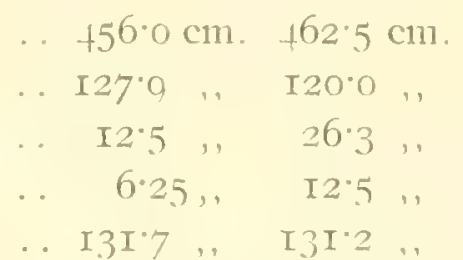

The second of these specimens has 28 pairs of rostral teeth, the first has 25 on one side and 26 on the other. I slould not be surprised ultimately to obtain a series of specimens linking $P$. pectinatus and $P$.zysron together. Undoubtedly there has been much confusion as regards the two species, and I am by no means satisfied that the are distinct. The large size of adult specimens and the difficulty with which they are preserved, however, militate against the acquisition of such a series. All the ordinary specimens of $P$.pcctinatus I have seen have been less than Io feet long with the saw, while the two of $P$. zysron $\mathrm{I}$ have examined in detail have been over $\mathrm{I} 5$ feet. I doubt whether either form grows as large as $P$. perottetii.

\section{Family RHINOBATIDA (Guitar-Fishes, Spear-Sharks).}

Shark-like rays (having the gills on the ventral surface) with the anterior part of the body depressed but comparatively little expanded and the pectoral fin-rays not extending forwards to the sides of the head. The snout rounded or produced. without rostral teeth. No electric organ. Two dorsal fins, without spines.

This family is divided by Güther, as by most other ichthyologists, into three genera, viz., Rhynchobatus, Rhinobains and Trygonorhina. Trygonorhina, which is distinguished from Rhinobatus by having the anterior nasal valves confluent, is only known from the S. Pacific, but Rhynchobatus and Rhinobatus are both well represented in Indian seas. Two very dissimilar species, however, are held by most authors to constitute the former genus, although they differ from one another considerably not only in the shape of the snout but also in the structure of the head. These two species are $R$. ancylostomus and $R$. dicddensis. The former in my opinion is not congeneric with the latter and as Gill's generic name Rhamphobatis is available for it, I have placed it in that genus. As regards $K$. djeddensis, moreover, I have been confronted with a difficulty in the matter of the proper genus to which it should be assigned. It is supposed to be distinguished from the species of Rhinobatus by certain rather ill-defined 
characters, which are discussed bejow. I cannot regard it as generically distinct from its allies usually placed in Rhinobatus.

The two Indian genera recognized in this paper are, therefore, Rhamphobatis, Gill (I86I), and Rhinobatis, Floch and Schneider (I80I).

\section{Genus Rhamphobatis, Gill.}

Head rounded in front, not produced into a rostrum. Back bearing large compressed bony tubercles arranged in rows. Teeth lozenge-shaped, transverse, with many sinuous, parallel transverse ridges.

I have made a careful comparison between the skull of the one species of this genus and that of Rhinobatis djeddcnsis. The cranial cartilages are scmewhat different in the two species. In the latter a single rostral cartilage projects forward between the nasal capsules; its ventral surface is hard, solid and undivided, but there is a broad and lengthy longitudinal depression on the dorsal surface. In Rhamphobatis, on the other hand, a pair of rostral cartilages, which are much broader and flatter than the single one in Rhinobatis and only joined to one another at the base by membrane, arise in the same position and only unite as cartilages near the tip of the snout. The condition in Rhinohatis gramulatus, $R$. schlegclii and $R$. halavi is exactly the same as in $R$. djoddensis.

There is, moreover, a distinct difference between the teeth of Rhamphobatis and those of all the species of Rhinobatis I have examined. In the latter genus, although the teeth differ considerably in the different species, they may be described in all cases as having a single transverse ridge, which sometimes is raised in the centre so as to be almost conical. In Rhamphobatis, on the other hand, the teeth bear numerous wavy transverse ridges, none of which is much better developed than the others.

\section{Rhamphobatis ancylostomus (Bloch and Schneider). (P1. v, fig. 5.)}

Pectoral fins with the anterior margins not joined by skin to the sides of the head. A median dorsal ridge of large, compressed, irregular tubercles rumning from just behind the spiracles a little more than half way to the first dorsal fin; a similar ridge on either side running along the internal margin of the orbit and spiracle and. continued in a somewhat less conspicuous fashion round the anterior margin of the former; a patch of similar tubercles in front of each of these lateral ridges, which are continued posteriorly, after a considerable interruption, by short and feeble ridges in a straight line with them; a still shorter and feebler outer lateral ridge on either side parallel to the main one. The two dorsals and the caudal fin about equidistant from one another; the posterior rather smaller than the anterior; the lower lobe of the caudal long and pointed. A strong ridge on the side of the tail. Mouth strongly undulated, the two downward projections on the upper jaw and the three upward projections on the lower jaw approximately equal; the teeth lozenge-shaped, the breadth $\frac{5}{6}-\frac{6}{6}$ the length; ten distinct ridges on the unworn teeth; teeth much smaller on the excavations of the jaw, than on the projections. 
There is a cast of a young specimen coloured from life in the Trivandrum Museum. It is of a bright salmon-pink body colour with numerous, narrcw, irregular black transverse bars. In older individuals the pink fades to a dull greenich shade, while the black bars become fainter and anastomoye into a more or less regular reticulation, at first enclosing round white spots and fnally becoming almost obliterated, so that only a faint marbling persists. In old specinens, however, scme dark linear markings usually remain on the base of the pectoral fins. In the male figured on plate $\mathrm{V}$, fig. 5 , these markings took the exact form of a ? symmetrical on the two sides.

Five specimens have been taken to my knowledge by the "Golden Crown," four of them fully adult. One $(q)$ was captured in Octoler off the Orissa coast, and two $(\sigma, q)$ in December off the mouth of R. Hughli. The measurements of the former and of one of the latter were as follows:-

Total length

Breadth across pectoral fins

Mouth to vent

Width of mouth . .

Distance between eyes

Anterior border of pectoral fins

Anterior border of Ist dorsal . .

Anterior border of and dorsal. .
Anterior border of pelvic fins . .

Length of upper lobe of caudal fins

\begin{tabular}{|c|c|c|c|c|c|}
\hline & & f & & $\sigma$ & \\
\hline & . & $204^{\circ} 0$ & $\mathrm{~cm}$. & $206 \cdot 0$ & cm. \\
\hline$\cdots$ & . & $\mathrm{I} 3 \mathrm{I}^{\circ} \mathrm{O}$ & ," & $\mathrm{I} 34^{\circ} \mathrm{O}$ & , , \\
\hline & & & & $73^{\circ} 0$ & ,' \\
\hline & . & $\cdots$ & & $25 \cdot 3$ & , \\
\hline & . & $25: 3$ & & $27 \cdot 8$ & , , \\
\hline & & $35^{\circ} 4$ & , & $45^{\circ} 6$ & ,' \\
\hline & & $22 \cdot 8$ & ," & 13.9 & , , \\
\hline & & $32 \cdot 9$ & ", & $24^{\circ} 0$ & \\
\hline & $\cdots$ & $25 * 3$ & , & $17 \% 7$ & , \\
\hline & $\cdots$ & 443 & , & $30 \% 5$ & ," \\
\hline
\end{tabular}

Day's figure (Fishes of India, vol. ii, pl. cxciii, fig. 3) is evidently taken from an immature specimen. I therefore reproduce a plotograph of the male whose measurements are given above.

\section{Genus Rhinobatis, Bloch and Schneider.}

Head produced into a more or less elongated and narrow rostrum without lateral teeth. Back bearing tubercles of various kinds in rows, or uniformly covered with granular denticles. 'Teeth lozenge-shaped or almost circular, with a single transverse ridge or a central conical projection. Anterior nasal valves not confluent.

Miuller and Henle in separating "Rhynchobutns" from the species they included in "Rhimobatus" relied mainly (see Syst. Beschr.d. Plagiostomon, pp. III and II3) on the shape of the nasal valves, the position of the spiracles relative to the eyes and the outline of the anterior part of the body, while Guinther (Cat. Fishes, viii, pp. $44044 \mathrm{I}$ ) and Day (Fam. Brit. Ind., Fishes, i, p1. 39, fo, 42) lay great stress on the fact that the anterior margin of the pectoral fin is quite free in Rhynchobutis and is joined to the snout by a membrane in Rhinohutis. Day also notes that the anterior dorsal fin is opposite the pelvic fins in the former genus and far behind them in the latter.

The differences noted by Miiller and Henle undoubtedly exist, but they seem hardly to be of generic value, considering the variation that occurs within the limits of the genus Rhinobatis (sensu stricto), nor does the difference in the position of the 
dorsal fins seem to be of very great importance; in some species (e.g., P. schlegelii) the first dorsal is much nearer the pelvic fins than it is in others (e.g., $R$. gramulatus). As regards the freedom or otherwise of the anterior border of the pectoral, I fail to see any absolute difference at all in fresh or well-preserved specimens. Undoubtedly, however, there is a certain gradation in respect of this character; in $R$. djeddensis the fin projects more freely than it does in $R$. gramulatus, but in $R$. gramulatus it projects more freely than in $R$. halavi. The fact that the lower lobe of the caudal is distinct in $R$. djeddensis and not so in the other species would not be regarded as a generic difference in other families of the suborder. Indeed, "Rhynchobatus " seems to me to be less widely separated from such a form as Rhinobatis gramulatus than Pristis cuspidatus is from such a form as $P$. perottctit.

\section{Key to the Indian Species of Rhinobatis.}

I. Anterior dorsal fin above pelvic fins. Tail with a distinct lower pointed

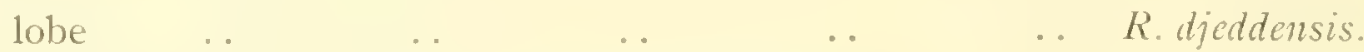

II. Anterior dorsal fin wholly behind the pelvic fins.

A. No fold of skin on the interval between the anterior angles of the nostrils.

$A^{\prime}$. Interval between the posterior angles of the nostrils not markedly less than the length of one nostril.

(a) A row of sharp spines running down the centre of the back. Snout acutely pointed .. . . R. gramulatus.

$\left(a^{\prime}\right)$ An interrupted row of obtuse spines on the back. Snout $\begin{array}{llllll}\text { obtuse } & \ldots & \ldots & \ldots & & \end{array}$

$A^{\prime \prime}$. Interval between the nostrils posteriorly less than half the length

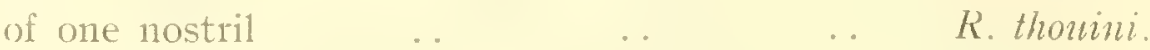

13. The anterior nasal valve on each side continued as a fold of skin extending towards the other nostril.

(b) Back with a inedian row of large, smooth tubercles crossed by a vertical line of similar tubercles on the shoulder $R$. columnce.

$\left(b^{\prime}\right)$ Back finely granular with faint indications of a mid-dorsal row of enlarged tubercles _. . . R. schlegelii.

Of the six species enumerated in this key four have been taken by the " Golden Crown,' while a fifth is fairly well represented in the old collection of the Indian Museum. I have not seen R. thomini. R. schlegelii is here recorded from Indian seas for the first time; $R$. djeddensis has been taken in very large numbers, while $R$. gramulatus is represented by a single specimen in the "Golden Crown' collection and by several in that of the Indian Musenm; of $R$. colmmu several specimens have been taken by the trawler.

6. Rhinobutis djeddensis (Forskål).

Rhynchobatus djeddensis, Gimther, op. cit., p. $+f I ; D a y$, op. cit., p. to.

Snout pointed, measured from the mouth between $\frac{1}{5}$ and $\frac{1}{4}$ of the total length; the concavity on the dorsal surface extending forwards for a considerable distance. 
Back in the adult bearing several rows of regular, compressed bony tubercles, which also surround the anterior margin of the orbits. The ventral lobe of the tail almost equal to the dorsal lobe in the young, relatively smaller in the a dult. The posterior dorsal fin smaller than the anterior, which is situated over the pelvic fins. There are two conspicuous ridges on the posterior margin of the spiracle. The jaws have each a single undulation, which is not very deep. The teeth are large, suboval transversely, and bear a single transverse central ridge, which becomes obsolete as they are worn, the breadth of each tooth is to the length as 5 to 3 or 3 to 2 ; the teeth on the central concavity of the upper jaw are smaller than the others.

In the young the back is of a rather pale greyish olive-green, which takes a bluish tinge on the eyelids. The lateral and caudal fins and the greater part of the snout are pink. On each side, near the centre of the base of the pectoral, there is a large round black spot, which is surrounded by much smaller white spots. Numerous similar white spots are scattered on the sides of the body and a few appear on the pectorals. In older specimens the olive-green becomes darker and greyer, the spots tend to disappear, although perhaps they never become quite obsolete, and the pink changes to grey.

It is unnecessary to describe this common and well-known species at any great length. It is by far the most abundant species of its family in the catches of the "'Golden Crown,', whose trawl brings up numerous examples on every trip. 'The largest specimen I have seen measured $8 \mathrm{ft}$. 9 inches $(258 \mathrm{~cm}$.). It was a female with seven fully formed young ones in one oviduct, the other oviduct being empty and its corresponding ovary containing large eggs.

The unborn young measured $34 \mathrm{~cm}$, in length and bore yolk-sacs, which were smaller than those of some young ones captured free. In the case of the latter the yolk-sac was as big as a small orange. There does not appear to be any arrangement for supplying the unborn young with maternal nourishment in the case of this species. Day mentions that the young are very common off the Coromandel coast about March; they are also abundant at the head of the Bay of Bengal in September and Octoher.

\section{Rhinobatis halavi (Forskäl).}

Rhinobatus halavi and Rh. obtusus, Gthr. op. cit., pp. $++2,++3$; Rh. halavi, Day, op. cit., p. 43 .

I have not the material on which to base a fresh description of this species, as regards the synonymy of which I merely follow Day. No specimens have been taken by the "Golden Crown' ' and there are only dried or immature specimens in the Museum. A stuffed female measures i $28 \mathrm{~cm}$. in total length, and we have a much smaller one in spirit, as well as several other skins. The short, obtuse snout is characteristic.

The teeth resemble those of $K h$. gramulatus but their transverse ridge is not so strongly convex. 


\section{Rhinobatis gramulatus.}

Rhinobatus granulatus, Gthr., op. cit., p. $4+3$; Day, op. cit., p. +2 .

Snout pointed, variable in length, as a rule from $4^{\frac{1}{2}}$ to $5^{\frac{1}{2}}$ times in the total length; the dorsal concavity triangular, narrow. The interval between the nostrils posteriorly not or hardly greater than the length of the nostril; the anterior nasal valve variable in size, usually small, not produced inwards beyond the limits of the nostril. The two dorsal fins situated considerably behind the posterior margin of the pelvic fins, equal or subequal, separated by rather more than the length of anterior fin. 'The lower lobe of the caudal rounded, not distinctly marked off from the dorsal lobe.

'The back, the central ridge of the snout and the antetior part of each dorsal fin covered in the adult with somewhat irregular, granular or obtusely pointed, small denticles, which become smaller from the mid-dorsal line outwards. There is a distinct row of sharp retroverted spines extending along the mid-dorsal line from a little behind the spiracles to the anterior dorsal fin, and as a rule there are several similar spines on the anterior margin of the orbit. The lateral fins and the sides of the snout are naked. In the young (=Rhinobatus philippi, Müller and Henle) there are two sharp, retroverted spines on either shoulder, forming with the slightly enlarged denticles which surround them a line crossing the mid-dorsal line at right angles. On either sicle of the rostral ridge there is a line of similar spines; the dorsal line extends backwards between the two dorsals.

'The colour of the adult is described by Day as "reddish grey superiorly, becoming dull white beneath."' The young is greenish grey on the back; the snout pure white, with the exception of the central ridge, which is of the same colour as the back.

The jaws are very feebly undulated, and it is not possible to recognize definite upward and downward projections and corresponding concavities in them. The teeth are small, transversely rhomboid, but with the four angles somewhat rounded. The transverse ridge runs across the tooth near the inner margin and is markedly convex in its centre, so that the exposed surface of the tooth as a whole has a tubercular appearance. There is no marked difference in the size of the teeth at different points on the jaw

Only one specimen of this species appears to have been taken by the "Golden Crown," a young female from off the Orissa coast. There are, however, several other specimens in the Museum collection. The largest (stuffed) measures $185 \mathrm{~cm}$. in totai length.

\section{Rhinobatis columna. Bonaparte.}

Rh. columna, Bonuparte, Fauna Italica, Pesci, No. I52, plate.

? Rh. horkelii, Müller and Henle, op. cit., p. I22, p1. 4 I.

snout sharply pointed, about $6 \frac{1}{2}$ times in the total length; the distance between the onter angles of the nostrils rather more than $\frac{1}{2}$ and less than $\frac{2}{3}$ of that between the mouth and the end of the snout. The anterior nasal valve produced 
into a fold which does not reach or barely reaches the lateral margin of the nostril. The back very flat; the breadth across the widest part of the pectorals $2 \frac{1}{2}$ times in the total length. Pectoral fins broadly rounded; tip of pelvic fins nearly reaching base of first dorsal, which is separated from second dorsal by more than twice its own length. Rostral ridges narrowly separated. Back minutely granular with a row of smootl, rounded tubercles extending down the centre from a short distance behind the eyes to the posterior dorsal fin; a semicircle of similar tubercles extending round the inner margin of each orbit, and a short interrupted row crossing the mid-dorsal line at right angles in the scapular region. Colour of young dark greyish brown with indistinct marblings of a darker shade and with numerous somewhat obscure, round, whitish spots; edges of snout white in smaller specimens; all the fins becoming pale at the edge; ventral surface white. The larger specimens I have examined are darker than the smaller ones have less white on the snout, which in some is of the same colour as the back.

The mouth is straight; the teeth are small and almost flat, the ridge across them being feebly developed. They are of the same size on all parts of the jaw.

Several specimens of this species were obtained off the entrance to the Eastern Channel of the mouth of the river Hughli by the "Golden Crown "' in February, Igog. The largest, a male with the claspers evidently immature and not reaching the tip of the pelvic fins, measured $420 \mathrm{~cm}$. in lengtl. Except as regards colour, these specimens agreed closely with Mizlier and Henle's figures of $R$. horkclii, which appears to be separated from $R$. undulatus mainly on account of its darker snotit. A pale snout is characteristic of the young, however, not only in $R$. colmmne but also in $R$. djeddensis, $R$. halavi, $R$. schlegclii and $R$. gramulatus. The same is true as regards white spots, at any rate in the case of $R$. djeddensis and $R$. schlegclii.

Both Günther and Day state that in $R$. columnce ${ }^{\prime}$ the continuation of the anterior nasal valve almost meets its pair on the other side. In Bonaparte's original figure, however, this is not represented as being the case. My specimens agree much more closely with Günther's description of $R$. undulutus than they do with his description of $R$. columne, but I feel bound to follow Bonaparte's figure in my identification. Some confusion probably exists between these two species, but I have not the material to clear it up.

\section{Rhinobatis schlcgclii, Miiller and Henle.}

Rhinobatus schlegelii, Gthr., op. cit., p. +45

Snout long, pointed, but shorter than that of R. gramulatus; the central concavity of the rostral ridge elongated and narrow. The two ridges on the posterior border of the spiracle very strongly developed. Anterior nasal valve produced into a flap which extends beyond the edge of the nostril inwards towards the middle line but does not nearly meet its fellow of the opposite side. Posterior nasal valve

I Since the above was written I have been able to examine a small Italian specimen of $R$. columna preserved in sp rit. It appears to bs browner than my In lin specimens and lacks all trace of white spots. Otherwise it agrees with them very closely, except that perhaps the tubercles on the back and round the orbits are a little less prominent.-1 pril I $8 t h$, Igog. 
strongly dilated on the margin of the nostril. Anterior dorsal fin slightly behind the pelvic fins, the claspers reaching as far as its anterior margin in the male; both dorsal fins short and high, subequal, separated by several times the length of the anterior fin. Denticles minutely granular all over the dorsal surface, barely enlarged on the mid-dorsal line.

Colour of the dorsal surface uniform brownish grey or olive-green in the adult; sides of the snout pale in young specimens; numerous faint white spots all over the dorsal surface of the body in the unborn young.

Jaws nearly straight. 'Teeth small, with the transverse ridge so strongly convex that when viewed in profile they apjear to be almost conical with a flattened base.

Several adult specimens of this species were obtained by the "Golden Crown" off the entrance to the Eastern Channel of the river Hughli in a depth of about 30 fathoms in February, I909, and a small male, which was presented by Mr. J. H. Row and identified by Col. Alcock, has been in the Museum for some years. It was taken in the Mutlah river, which connects the Salt Lakes near Calcutta with the sea. Guinther mentions an adult female of $700 \mathrm{~mm}$. and an adult male of $750 \mathrm{~mm}$. from Japan. A female from the Eastern Channel with five young in its oviduct measured $500 \mathrm{~mm}$., while an apparently adult male measured $336 \mathrm{~mm}$. The transverse diameter across the pectoral fins was in the former case $187.5 \mathrm{~mm}$. The young from the oviduct of this specimen measured I $20 \mathrm{~mm}$. in length and $44 \mathrm{~mm}$. across the disk. Their snouts, although produced, terminated much more abruptly than was the case in the adult, the two sides being nearly parallel. In the mother the length of the snout (measured from the eyes) was contained 5.62 times in the total length, while in the young it was contained 6.66 times.

$R$. schlegclii has been recorded from the east coast of Africa as well as from Chinese and Japanese seas.

\section{Family RAJID王 (Skates).}

Head and body forming a rhombic disk, much flattened; the pectoral fins extending to the snout; tail quite distinct. Skin usually bearing spines and large denticles. Tail with a longitudinal fold on each side and a caudal fin, which is degenerate in some genera; dorsal fins present. No electric organ. No serrated caudal spine.

In Day's works on Indian ichthyology only one member of this family is recorded as occurring in Indian seas, viz., Platyrhina schonleinii. In recent years, however, six species of Raja (of which four are markedly distinct from one another, although each species is founded on a single specimen) have been described by Alcock or Lloyd. A specimen which I take to belong to Alcock's Raja powellii was recently taken in shallow water off Trivandrum on the west coast of India and has been presented to the Indian by the Trivandrum Museum; but the members of the family belong essentially, so far as Indian seas are concerned, to the deep-sea fauna. Captain R. E. Lloyd has therefore dealt with them in a paper (to be issued in the Momoirs of the Indian Musenm almost simultaneously with this one) on the deep-sea fishes taken by the "Investigator ' since the publication of Col. Alcock's monograph. No Rajidx have been taken by the "Golden Crown.' 
Family TRYGONID E (Sting-Rays and Butterfly Rays).

Head and body forming a thombic or subc rcular disk; pectoral fins meeting in front of the snout; tail quite distinct. Tail without longitudinal folds, sometimes with dorsal and ventral cutaneous, rayless flaps; dorsal fins absent or very small, a recumbent serrated spine usually present on the tail. No electric organ. Of the true rays this family is the best represented in the Indian seas, in which it is practically confined to shallow water. Four genera and twelve species are recorded by Day; to these, seven species are here added, one having recently been! described and three being described below for the first time, while three were previously known but had not been found (or recognized) in Indian seas. One of the forms regarded by Day as distinct is here regarded as synonymous with another. Fifteen species have been taken by the "Golden Crown."

The 'Trygonidæ, although their flesh is coarse, are eaten by many castes of Indians, who attribute to them certain tonic and aphrodisiac qualities. The tails of the larger species are made into whips and walking.sticks, and there is no doubt that an extremely valuable oil could be manufactured out of their livers (see Mr. Hooper's analysis, postea). The fishery or estuarine species in the river Hughli, however, which is referred to by Blyth (Joum. A siat. Soc. Bengal, xxix, ). 35, I860), appears to have completely died out.

The five Indian genera may be distinguished as follows :-

\section{Key to the Indian Genera of Trygonide.}

I. 'Tail with a serrated spine, without cutaneous folds or with them rudimentary and not reaching the tip. Teeth flattened, with a transverse ridge or (rarely) with a sharp cusp; jaws not angular ... . Trygon.

II. Tail with a serrated spine, with a cutaneous fold several times as deep as itself but not extending nomally to the tip. Teeth flat, without a transverse ridge; jaws angularly bent $\quad . \quad \ldots \quad \ldots \quad \ldots$... Hypolophus.

III. Tail without a serrated spine. Teeth without a definite transverse ridge Urogymnus.

IV. Tail with a serrated spine and a cutaneous fold extending to the tip Trenima.

V. Disc very broad and short, angular. Tail feeble, with or without a small dorsal fin, normally with a serrated spine. Teeth saddle-shaped, with one or more

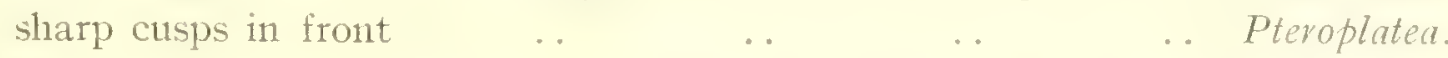

The first four genera in this key are very near one another and should perhaps be regarded as subgenera. In Trygon the serrated spine is occasionally absent, while in Hypolophus individuals occur in which, probably oring to injury in early life, the cutaneous fold extends to the extremity of the tail.

In diagnosing the species of this family it is particularly important that attention should be paid to fresh specimens. Many species grow to so large a size that it is practically impossible to preserve then in alcolol, while the characteristic markings disappear and the natural proportions are distorted in stuffed skins.

With reference to measurements it is necessary that an exact statement should be made as regards the methods adopted, for there are several different ways in which 
each of the more important measurements might be taken. So far as the Trygonidæ are concerned I have measured the length of the disk from the tip of the mouth to the base of the tail and have not included the length of the pelvic fins. A more exact measurement might be obtained on the ventral surface, but for diagnostic purposes the one adopted is sufficiently accurate. The breadth of the disk has been measured across the back with a tape, not from point to point. 'This method gives a more accurate idea of the bulk of a flat fish than that of measuring from point to point, but of course it makes the deeper species, such as Trygon microps, appear to have a larger expanse of pectoral fin than is actually the case. The snout has been measured from a point just in front of the eyes, the interorbital space from the inner margin of one orbit to that of the other, the tail from the posterior end of the disk.

The genera of Trygonidx are, for the most part, sufficiently defined in the above key, so far as the Indian forms are concerned. Urolophus, which is recorded from Java and may very probably occur within our area, is distinguished from Trygon by the possession of a rayed cauda! fin and, in some species, a rudimentary dorsal one.

Genus Trygon, Adanson.

Disk distinct from tail (which is always powerful), more or less flattened, never very much broader than long. No rayed caudal or dorsal fins; at least one serrated caudal spine, except in abnormal specimens; a rayless caudal fold sometimes present on the dorsal or ventral surface of the tail, or on both surfaces, but never much deeper than the tail itself. Teeth as a rule flat with a transverse ridge, rarely bearing a sharp spine.

In the genus Trygon, an important specific character consists in the number, proportion, and outline of the cutaneous processes on the floor of the mouth behind the cutaneous fold that hangs down from the roof. These can only be investigated properly by dissecting out the mouth. Although they are not absolutely constant in any one species, the evidence they afford as to the distinction between allied species such as $T$. uamak and $T$. favus is very valuable, for the differences they display are often strongly marked in allied species. The character of their variation is best illustrated by examples. In T.gcrrardii (plate ii, fig. 6) there are usually four processes, the two central ones being much stouter and longer than the two lateral ones. As a rule the central ones are pointed, but in one specimen dissected (plate ii, fig. $6 a$ ) they are blunt and fringed at the tip. In another specimen the two lateral processes are absent. In what seems to be a normal specimen of $T$. microps there are three central processes joined together at the base so as to form a deeply serrated ridge, but in three out of the five individuals I have dissected the arrangement of these processes is not quite symmetrical, while in one there are four central processes with traces of a fifth.

$$
\text { Koy to the Indian species of Trygon. }
$$

I. I arge species (adults over to $\mathrm{cm}$. across the disk, young over $\mathrm{I}_{5} \mathrm{~cm}$. ) as a rule with a single large serrated spine ${ }^{1}$ on the tail; cutaneous caudal fold, if present, inconspicuous.

'There is usually a second, smaller one concealed under the first. 
A. All the denticles with stellate bases.

(a) Distance between the eyes less than half the length of the snout. Base of tail broad and flat .. .. T. microps.

B. All or most of the dorsal denticles with round or polygonal bases.

(a) Dorsal denticles forming a regular wine-glass-shaped figure with well-defined borders.

$\left(a^{1}\right)$ Distance between the eyes less than half the length of the snout .. $\quad . . \quad$.. T. bleckeri.

$\left(a^{2}\right)$ Distance between the eyes more than half the length of the snout . . . n . . gerrardii.

(b) Denticles not forming a regular figure on the back.

$\left(b^{1}\right)$ Dorsal denticles, if present, confined to the middle line. Dorsal surface pink or red .. . T. bemettii.

$\left(b^{2}\right)$ Dorsal denticles absent from the pelvic fins, flat and rounded. Dorsal surface olive-brown with faint pale spots scattered all over the disk T.alcockii, sp.nov.

$\left(b^{3}\right)$ A row of sharp spines running down the middle of the back and the base of the tail. Dorsal surface olive-brown, without spots .. T.jenkinsii, sp. nov.

$\left(b^{*}\right)$ Flat dorsal denticles irregularly interspersed with small stellate ones on the body; the pectoral fins covered with small stellate denticles. Dorsal surface grey-

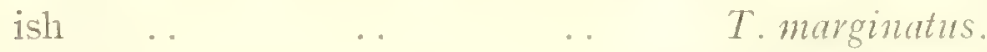

$\left(b^{5}\right)$ Flat dorsal denticles irregularly interspersed with small stellate ones, which are absent from the pectorals. Dorsal surface of adult pale brown with darker markings; of young white with black spots T. uamak.

$\left(b^{5}\right)$ No stellate denticles. Dorsal surface of adult dark brown with a bold honeycomb pattern of dull yellow.

T. favus, sp. nov.

II. Small species (adults less than to cm. across the disk, young not more than Io $\mathrm{cm}$.).

A. Distance between the eyes about one-third the length of the snout. Dorsal surface dark brown ..

T. zugci.

B. Distance between the eyes less than half the length of the snout. Dorsal surface pale brown _.. $\quad . \quad T$. imbricuta.

C. Distance between the eyes almost as great as the length of the snout. Dorsal surface grey with bluish spots ..

T. kuhlii.

The only species named in the key I have not seen is Trygon bennettii. Duméril (Nat. Hist. Poissons, i, p. 596, I865) records a specimen of this species measuring 43 cm. across the disk, while one of Henle and Müller's was rather larger ! 'Plagiostomen,' p. I6I). All the figures I have seen, however, look as though they represent young 
individuals. The adults of the other species included in Section I of my key grow over 2 feet $(60 \mathrm{~cm}$.) in diameter, but $T$. gcrrardii does not greatly exceed this limit.

Trygon microps, Annandale. (Pl. iv, fig. I ; pl. ii, figs. 3 , 3a; pl. iii, fig. I.)

T. microps, Amandale, Rec. Ind. Mus., ii, p. 393, pl. xxvii.

Size large (large female over $222 \mathrm{~cm}$, across the disk, large male over Igo $\mathrm{cm}$. .).

Colour white; the dorsal surface of the disk suffused with rose-pink, without definite markings ; tail grey above, becoming darker distally.

Disk rhombic, wider than long by more than one-quarter of the width; the pectoral angles rather greater than right angles. Snout rounded as a whole, but with a small terminal projection which is covered with enlarged denticles. Distance from eyes to tip of snout greater than that from eye to eye; length of snout $3 \frac{1}{2}$ to $+\frac{1}{2}$ in length of disk.

Eyes very small, dark in colour, little prominent; spiracles large, without dorsal flaps, their area more than eight times that of the eyes.

Tail without cutaneous fins, not longer than disk, consisting of a broad, flat, proximal part about half as long as the disk, and a slender, cylindrical distal part of approximately the same length, a single massive spine borne at the junction of the two parts; a very low ridge on the ventral surface of the distal part.

skin soft and delicate, without enlarged tubercles on the disk, bearing numerous minute, spiny denticles (pl. ii, figs. 3, $3 a$ ), all of which have stellate bases. The denticles larger on the tip of the snout and the region surrounding the eyes and spiracles than elsewhere, sometimes extending to the ventral surface at the edge of the pectoral fins. The proximal part of the tail armed with much larger denticles, which are largest on the sides and only bear very short stellate spines on the ventral surface; distal part densely clothed with denticles similar to but smaller than those on the sides of the proximal part.

Month large; upper jaw undulating slightly, lower jaw practically without undulation; a coarsely digitate cutaneous flap hanging down from the roof of the mouth; usually five short finger-like processes on the floor of the mouth, three in the centre joined together at the base and one at either side (pl. iii, fig. I). Teetl white; the transverse ridge very conspicuous in the unworn teeth, the part anterior to it being slightly concave and considerably greater in area than that posterior to it, which is convex.

Two specimens, both females, have been taken by the "Golden Crown," one (the type) off the coast of Chittagong in $\mathrm{I} /$ fathoms in August, and a second, larger specimen off the coast of Orissa in October. In all the specimens examined, the tail looks as though it had been mutilated, but I cannot be quite sure that it is not in its normal condition. The larger specimen gave birth to a young one on board the trawler, but the young one was unfortunately thrown overboard. Owing to a clerical error, which I lave been able to rectify by measuring a cast of the type specimen, the tail was represented in my original description of the species as being two feet longer than was actually the case. 
I909.7

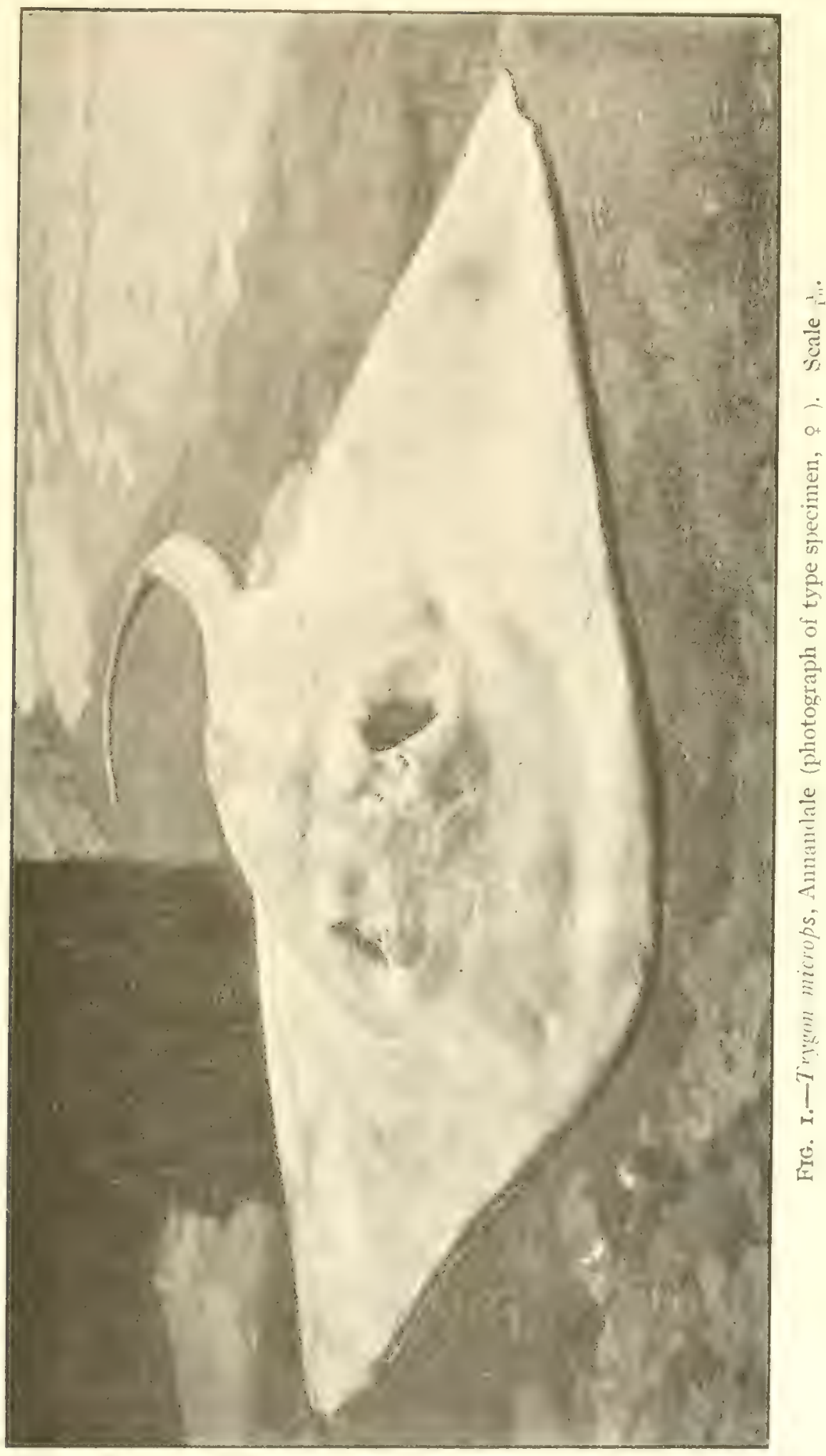


Since this was written three other specimens, including two males, have been taken in 24-27 fathoms off the Ganjam coast (March I909). The claspers of the male are remarkably short. The following are the measurements of two males and two females :-

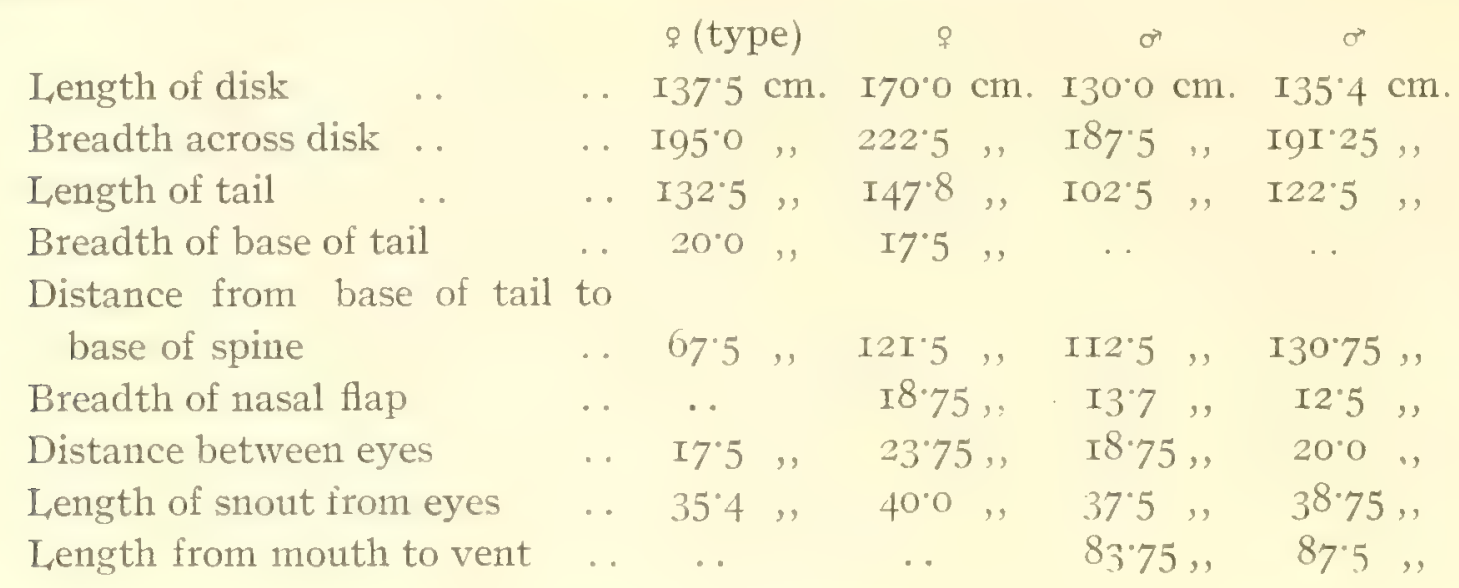

From these measurements it is clear that the proportions are somewhat variable in this species, the relative lengths of the tail and the disk especially being very different in the different individuals. It is very unfortunate that the young one was not preserved.

This is not only the largest species of the genus I have seen, but it differs from the other Indian forms in the shape of the tail and in the fact that all the denticles have stellate bases. The photograph reproduced on plate iv, fig. I, is of the type, and was taken as soon as the specimen was brought ashore. It shows the peculiarities of the tail very clearly.

The type specimen (skin and skull dried, mouth in spirit) is numbered F 241 in the registers of the Indian Museum.

Trygon narnak (Forskal). (P1. i, figs. I, 2 ; pl. ii, figs. I, Ia ; p1. iii, fig. 2.)

T. uarnak, Gimther, op. cit., p. 473.

T. punctata, id., ibid., p. 474 (young).

Size large (over $157 \mathrm{~cm}$. across the disk in large individuals, not less than $23 \mathrm{~cm}$. in young).

Colour in young white; the dorsal surface covered with large round or oval black spots; the pectoral and pelvic fins edged with pink in life; the tail boldly ringed with black. As the fish grows, the white ground of the dorsal surface gradually changes first to grey and then to pale brown, the spots become dark brown in colour and coalesce in various ways to form larger spots or complicated figures. A similar change as regards colour takes place on the tail, but the dark rings remain distinct. There is often a dark margin to the ventral surface of the disk.

Disk with the lateral angles broadly rounded; the length, considerably less than the transverse diameter. In the young the broadest part of the disk is situated at a point not much more than half the distance between the base of the tail and the 
tip of the snout; while in the adult this point is situated at nearly four-fifths of the distance. All the proportions of the disk, however, are variable. The angle of the snout is rather variable but in fresh specimens it is, as a rule, slightly less than a right angle; in the unborn young it is, at any rate in some specimens, obtuse. The length of the snout, measured from the eyes, is about $\frac{1}{5}$ of the total length of the disk in the adult and between $\frac{1}{3}$ and $\frac{1}{4}$ in the young. The outline of the front of the disk is somewhat sinuous in the adult but forms almost a simple concave curve in the young.

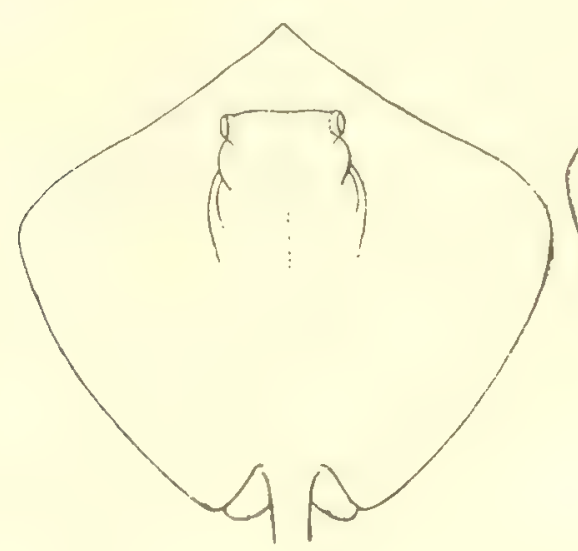

A.

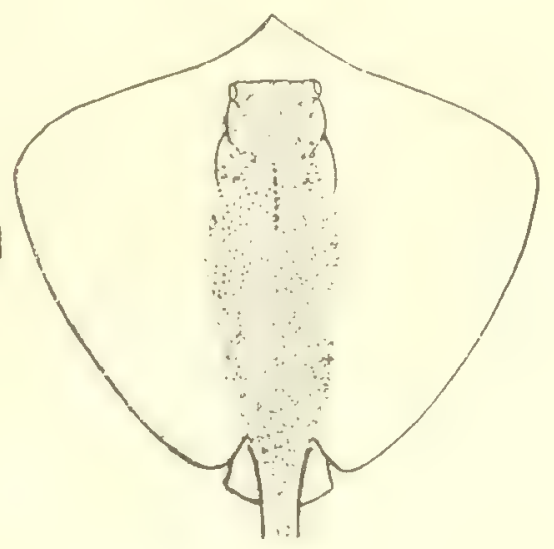

B.

FIG. 2.-Diagram showing the difference in outline between the young $(A)$ and the adult $(B)$ of Trygon uarnak.

Eyes large and prominent, especially in the young. The dorsal wall of the spiracle forming a convex longitudinal flap.

Tail' more than twice as long as the disk, cylindrical, tapering, armed with a single rather slender serrated spine, which is situated much nearer the base than the tip of the tail. No cutaneous folds above or below.

Skin tough. In the young there are as a rule several relatively large rounded tubercles in the mid-line of the scapular region, and these, although at first they are sometimes practically alone, are usually surrounded by smaller, heartshaped, nearly flat denticles which have the narrower end pointing backwards. In the adult the middle of the back is somewhat sparsely covered with similar but relatively smaller denticles, with which are interspersed numerous small, spiny ones with stellate bases. These become more numerous on the posterior part of the disk and the base of the tail, which is completely surrounded by little almost granular denticles with the spiny denticles scattered among them. This arrangement is continued for the whole length of the tail. There are no denticles on the periphery of the disk or on the ventral surface, but those on the back do

In a large proportion of the larger specimeus of the genus Trygon the tail is mutilated; it is often difficult to tell whether mutilation has occurred or not. 
not disappear abruptly as the bare area is reached, but gradually become smaller and form no definite outline to the area they cover.

Mouth large. The jaws are almost straight. The teeth are large, usually more or less deeply tinged with brown in fresh specinens; in the back of the jaws, where they are not worn, each has two distinct transverse ridges, a secondary shorter one running parallel to the median ridge and in front of it. There are normally four processes on the floor of the mouth, subequal in size, the two lateral ones being only smaller than the two median, and situated at about an equal distance apart. A somewhat similar process projects into the mouth from the cutaneous fold which covers the inner base of the teeth of the lower jaw; the fold which hangs down from the roof of the mouth is somewhat coarsely digitate.

Two colour varieties of $T$. uamak can be distinguished-

Var. a. Anterior part of the disk spotted in the adult, the spots combining on the posterior part into irregular blotches or figures.

Var. b. The whole of the dorsal surface of the disk covered in the adult with an irregular network of dark lines, often with dark spots or streaks in the centre of the meshes.

Var. a must be considered the typical form of the species as Forskal says in his original description " tota maculata" (Descr. Anim., 1. I8, No. I6b, I775).

Var. $b$ may be identical with $T$. undulatus, Bleeker. According to Blyth it is identical with McClelland's $T$. variegatus, but I have not seen any specimen on which the markings were so scanty and so open as they are represented in the figures published by the latter author (cf. Blyth, Joum. A siat. Soc. Bengal, xxix, p. 43, and McClelland, Calc. Joum. Nat. Hist., i, p. 66, p1.2, fig. 2).

Day, judging from his description (Malabar Fishes, 1. 277; Fishes of India, vol. ii, p. 735 ; and Fanm. Brit. Ind., Fishes, vol. i, p. 53), had seen the true T. uarnak, but unfortunately his figure in the Fishes of India (p). cxciv, fig. I) represents not this species but $T$. gerrardii, a smaller and otherwise different species which has been confused with T. namak by several authors, notably by Müller and Henle ("Plagiostomen, ' p. I59, vars. I and 3).

I have been able to examine a very large series (some hundred specimens) of this species, representing every stage between the unborn young and the adult over five feet in diameter. Specimens have been taken practically every trip by the "Golden Crown,'” but Dr. Jenkins tells me that large individuals are particularly abundant in about 30 fathoms of water off the mouth of the river Hughli on a muddy bottom.

$$
\text { Trygon gerrardii, Gray. }
$$

'. gerrardi, Gïnther, op. cit., P. 474 .

'T. uarnak, Day, Fishes of India, vol. ii, pl. cxciv, fig. I.

'To describe this species it is only necessary to indicate the points in which it differs from $T$. warmak.

Size moderate (largest specimen $67^{\circ} 5 \mathrm{~cm}$. across the disk).

Disk shaped and proportioned much as in the young of T. unrmak. 
Colour of the dorsal surface of the young brownish slate-colour without spots, the tail being banded with black and white; the edge of the pectorals pale. As the fish grows, the colour darkens to a warm brown, and large, round, widely separated cream-coloured spots appear on the posterior part of the disk and on the pelvic fins. In still older specimens the ground colour darkens considerably, the cream-coloured spots become obsolete, and the banding on the tail disappears.

The skin is tough as in T. uarnak, but the arrangement of the clenticles is quite different, at any rate in the adult. In the young they resemble those of the adult of $T$. uamak, except that none of them have stellate bases or spiny processes. In adult and half-grown fish, however, they form a compact pavement-like surface. which occupies the middle of the disk from the head backwards and has welldefined limits, towards which they are little smaller than they are elserhere. The outline of this surface resembles a wine-glass or flower-vase with the mouth directed forwards. On the tail this figure is continued, representing here the stem of the vase; but it ends, in front of the serrated spine, in a point. The denticles are confined to the dorsal surface of the base of the tail and do not extend either to the ventral surface of the basal part or beyond the spine on the dorsal surface.

Mouth. - The central part of both jaws is practically straight, but on either side of it on the upper jaw there is a distinct concavity, corresponding to a similar convexity of the lower jaw. The teeth are nearly white; a single stout transwerse ridge runs across the centre of each (unworn) tooth, separating two equal conver surfaces, each of which is strongly corrugated longitudinally. There are normally four processes on the floor of the mouth as in T. mamak, but the two central ones are much stouter than the lateral ones and somewhat widely separated from them.

Although I have not been able to examine so large a series of this species as I have been able to examine in the case of $T$. mamak, I liave seen a considerable number of specimens. T. gerrardi is well represented in the collection of the Indian MIuseum and is commonly sold in the Burmese coastal markets during the winter months. A considerable number of specimens was taken off the coasts of Burma, Chittagong and Orissa by the "Golden Crown'" in the late summer and antumn of last year and in the winter of this. Apparently the species is only taken in shallow water, at any rate in ivinter.

$$
\text { Trygon favus, sp. nov. (Pl. i, fig. 3; pl. iii, fig. Io.) }
$$

Closely allied to $T$. narnak, from which it may be distinguished by the following characters :-

Size moderately large (type ( $f$ ) I30 cm. across the disk).

Disk very flat, with the pectoral fins even more broadly rounded than in $T$. unmak, and the snout somewhat more produced; its length alout $3 \frac{3}{5}$ in the total length of the disk. Eyes widely separated, small.

$T$ uil rather less than twice as long as the disk.

Colom.-Dorsal surface very dark brown with a bold reticulation of dull vellow. which becomes less regular on the fore part of the disk than it is on the hind part. 
A yellow spot or streak in the middle of most of the meshes of the reticulation. Ventral surface white.

Skin devoid of denticles with stellate bases.

Mouth large. Jaws as in $T$. gerrardii. Teeth white; the transverse ridge feeble even

on the unworn teeth. On the floor of the mouth there are two bluntly triangular processes with irregularly serrated margins and joined together by a similarly serrated ridge.

I have only seen two specimens of this species, both females. They were taken together off the coast of Orissa in October by the "Golden Crown." In spite of their striking coloration I was inclined to regard them as representing a variety of T. uarnak, until I came to examine the interior of their mouths and to analyse the measurements of both forms. Unfortunately only the two mouths and the skin of the back of one specimen could be preserved. One of the mouths, and this piece of skin, therefore, constitute the "type," which is numbered $F 2 \pm 11$ in the registers of the IIuseum.

A good photograph of the specimen of which these relics have been kept is given on pl. i, fig. 3 .

\section{Trygon bleekeri, Blyth. (P1. iii, fig. 9.)}

T. bleekeri, Day, Fishes of India, vol. ii, p. 738, pl. cxcv, fig. 3 ; Fum. Brit. Ind., Fishes, 1. 54 .

Size fairly large (adults II2-II9 cm. across the disk).

Disk slightly broader than long. 'The snout narrow, acutely pointed, strongly produced, measuring more than $\frac{1}{3}$ of the total length of the disk and twice as long as the distance between the eyes.

Colour.-Dorsal surface dark brown, unspotted. Ventral surface in young white with a broad margin of dark brown. As the fish grows, this margin becomes broader and finally occupies nearly the whole of the disk. In some adult specimens a distinct streak remains in the middle of the disk; in others this is more or less obscured by dark blotches or disappears almost completely. There are no pale rings on the tail.

Skin.-The scales closely resemble those of $T$. gervardii in structure and arrangement.

Mouth.-Jaws distinctly undulated, the central part of the upper jaw forming a narrow, conical downward projection, and the lower jaw having a corresponding concavity in the middle. Teeth dark reddish brown, having a single transverse ridge, which is very distinct on the unworn teeth and divides them into two equal convex surfaces marked with longitudinal corrugations. On the floor of the mouth there are two long finger-like processes nearer one another than either is to the angle of the mouth but rather widely separated (pl. iii, fig. 9).

This species is allied to $T$. gerrardii (which it resembles in the nature and arrangements of its denticles very closely) even more nearly than it is to $T$. mamak. As regards the processes in the mouth the latter species seems to be at one extreme of a series of which $T$. bleckeri is at the other. 
A considerable number of specimens of $T$. bleekeri were taken by the "Golden Crown " in October off the coast of Burma and Orissa. Most of the specimens I have seen have been females, as is also the case as regards $T$. mamak. The two species are often taken together. Both seem to be commoner in the northern parts of the Bay than off the Madras coast. This is especially the case as regards T. blcekcri, which, indeed, has not been taken by the "Golden Crown'" except in the north. Both species apparently prefer a muddy bottom.

\section{Trygon alcockii, sp. nov.}

Size considerable (adult female $\delta_{5} \mathrm{~cm}$. across the disk).

Disk slightly broader than long, with the pectoral angles rounded; the length from the maximum diameter to the tip of the snout contained about $2 \frac{1}{4}$ times in the length of the disk. The snout pointed, forming approximately a right angle, by no means strongly produced but considerably longer than the interorbital distance; its length contained nearly $4 \frac{1}{2}$ times in the length of the disk.

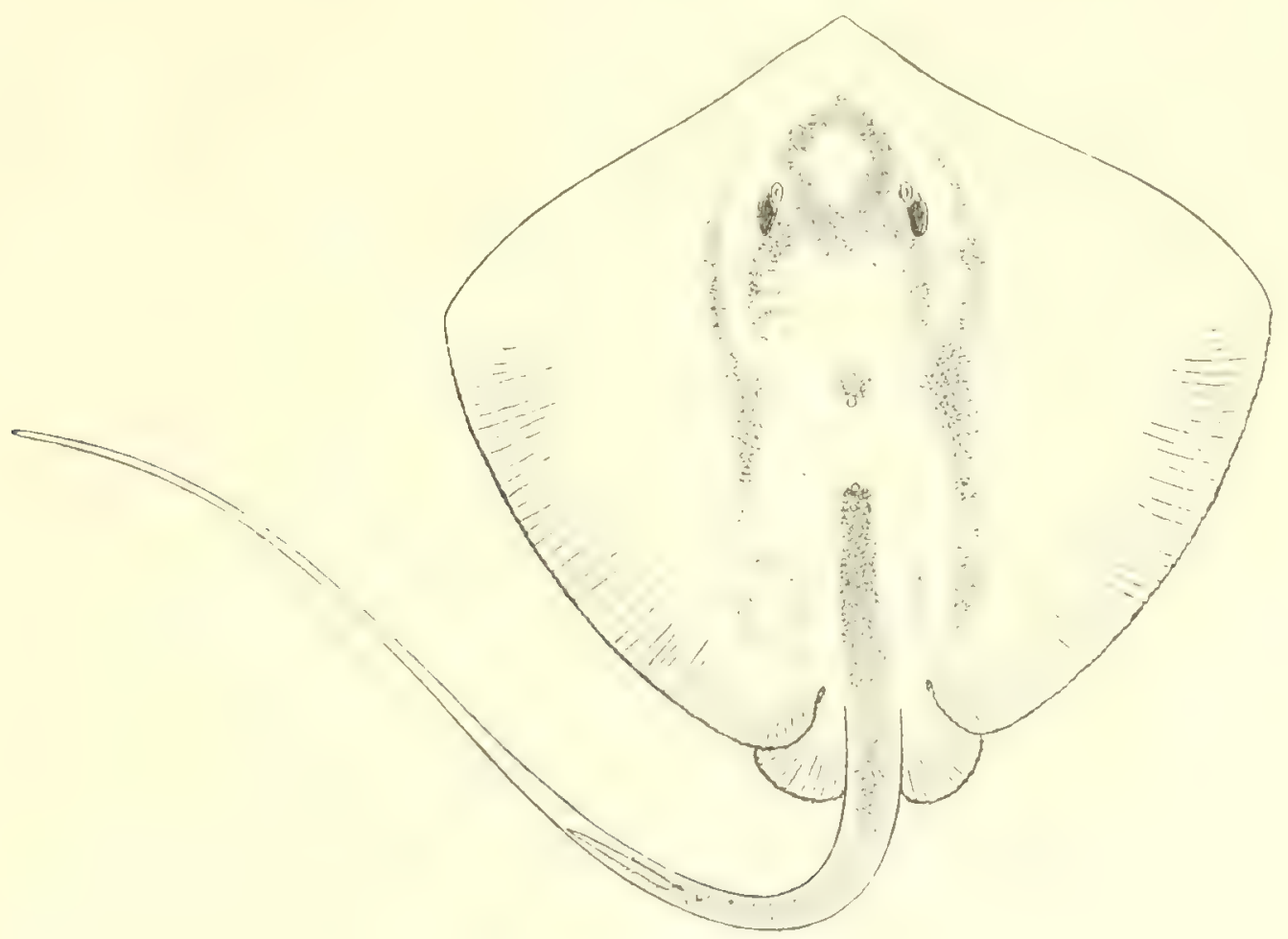

FIG. 3.-Outline of Trygon alcockii, $\times$ c. $\frac{1}{111}$.

Tail nearly cylindrical but somewhat flattened above at the base, tapering, not twice as long as the disk, without cutaneous folds, bearing a single large spine.

Colour.-Dorsal surface dark olive-brown with small, obscure, pale spots scattered all over the disk and the base of the tail; the edges of the fins purplish; the dorsal and lateral surfaces of the tail brown, without markings except at the base. Ventral surface (including base of tail) white, suffused with pink; a rather broad purplish lateral margin marbled with white. 
Skin tough. The scales flat and nore or less rounded, differing greatly in size on different parts of the head and body, to which they are confined on the disk : the largest occurring in a small patch behind the shoulder girdle; those between the eyes and on the middle of the posterior part of the back and the base of the tail larger than those on the central part of disk, where they are so small and so deeply sunk in the skin that they are almost invisible in the fresh specimen; the tail completely covered with flat scales except as regards the ventral surface of the part anterior to the spine; this surface, the pectoral and pelvic fins bare.

Mouth small; the jaws distinctly but not strongly undulated. The teeth white, with a single distinct central transverse ridge, larger on the upper jaw at the sides than in the middle, not occupying the whole of the exposed surface of either jaw.

Two individuals were taken in a seine-net at Puri on March 2 Ist during a short visit to the Orissa coast made by Dr. Jenkins and myself. One had already been cut up before the specimen could be secured, but the other (a female) has been preserved. It is the type of the species, and is numbered $\mathrm{F} 27 \pm \mathrm{in}$ the books of the Indian Museum.

This ray is distinguished from $T$. jenkinsii by its flat scales, by its proportions, and by its coloration. The difference as regards the last point is not, however, very marked, for the pale spots are faint and soon disappear in preserved specimens, while the coloration of the ventral surface was perhaps due to some extent to suffused blood. From $T$. gerrardii, $T$. alcockii is distinguished by its larger size, shorter and stouter tail, and differently proportioned disk, as well as by the fact that its spots are scattered on the anterior as well as the posterior part of the body.

As regards the processes on the floor of the mouth in $T$. alcocki, I am not in a position to give a description of their normal characters, because in the one specimen I have examined they are markedly asymmetrical. I may say, however, that there are, in this specimen, four blunt processes situated at about equal distances from one another. One of them is much longer than the others.

The type of the species was certainly mature and had probably just given birth to a young one as the nutritive filaments in one uterus were highly developed.

\section{Trygon jonkinsii, sp. nov.}

Sizc moderately large (adult male I0.375 $\mathrm{mm}$. across the disk).

Disk considerably broader than long. The pectoral angles rounded; the length from the greatest diameter to the tip of the snout $2 \frac{1}{2}$ times in the length of the disk. The snout sharply pointed, not much produced, longer than the distance between the eyes, which are large and prominent; the length of the snout contained $3 \frac{1}{2}$ to 4 times in the length of the disk.

Tail cylindrical throughout, without a trace of a cutaneous fin, not much longer than the disk is broad, sometimes bearing two serrated spines, which arelong and slender. Colour.-Dorsal surface reddish olive, becoming paler at the edge of the fins, without definite markings. The tail dark grey, mottled on the ventral surface with brown and white at the base. The ventral surface of the disk dead creamy white. 
Skin fairly tough. A' few enlarged rounded denticles in the scapular region followed posteriorly by a single row of stout, short, retroverted spines with flat bases, the row extending on the tail to the base of the anterior spine; the middle of the back occupied by a pavenent of small, flat, round scales, which gradually become smaller towards the periphery. 'The pectoral and pelvic fins naked; the tail covered with small, bluntly spinous tubercles.

Mouth.-Jaws feebly undulated; teeth white, practically uniform in size, each with a low transverse ridge situated near the posterior margin and with a distinct trans-

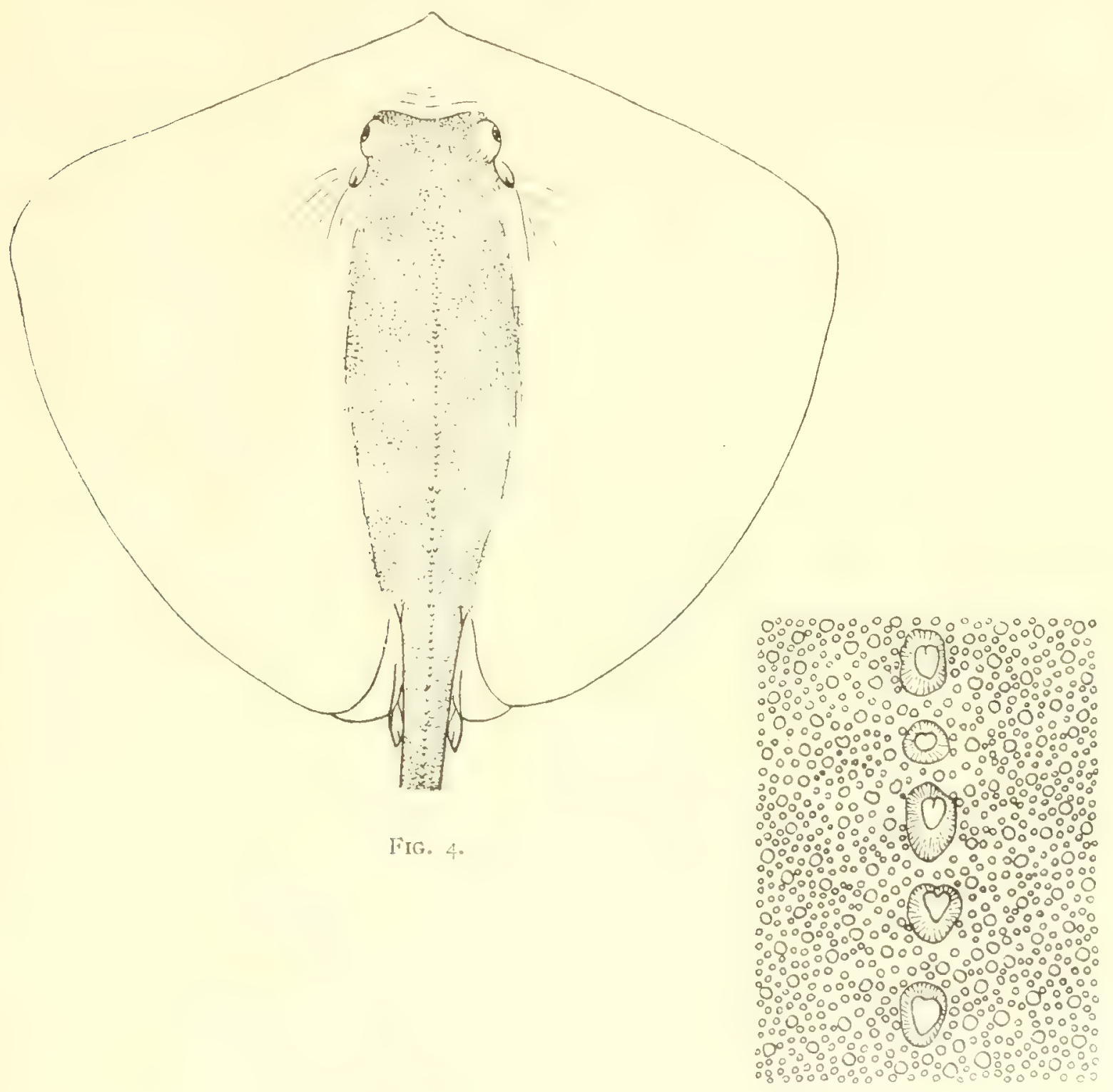

FIG. 4 a

FIG. 4.-Outline of fresh specimen of $T$. jenkinsii, $\times \quad c \cdot \frac{1}{9}$.

,4a.-Scales on the middle of the posterior part of the back of the same specimen, $X I_{: 2}^{1}$.

verse depression in front. Processes on the floor of the mouth four in number, resembling those of $T$. gerrardii but with the two central ones a little further apart. 
This species appears to resemble $T$. akajei in several respects but to differ in size, in the proportions of the disk and tail, lepidosis and character of the teeth and jaws. Possibly it may be identical with Bleeker's Trygon dadong, but on the whole I think this improbable.

Two adult males were taken by the "Golden Crown "' off the Ganjam coast in 23 to 27 fathoms in March, rgog. The type (dried skin, mouth in spirit) is numbered $F 247 s$ in the Museum registers.

To facilitate comparison I give the measurements of specimens of the six allied species, Trygon uarnak, Trygon gerrardii, Trygon favns, Trygon bleekeri, Trygon alcockii and Trygon jenkinsii together. The specimen indicated with a was measured in spirit.

\begin{tabular}{|c|c|c|c|c|c|c|c|c|c|c|c|c|c|}
\hline Name of species. & \multicolumn{2}{|r|}{ Sex. } & $\begin{array}{c}\text { Length } \\
\text { of } \\
\text { disk. }\end{array}$ & \multicolumn{2}{|c|}{$\begin{array}{l}\text { Width } \\
\text { of } \\
\text { disk. }\end{array}$} & \multicolumn{2}{|c|}{$\begin{array}{c}\text { Length } \\
\text { of } \\
\text { tail. }\end{array}$} & \multicolumn{2}{|c|}{$\begin{array}{l}\text { Nasal } \\
\text { flap. }\end{array}$} & \multicolumn{2}{|c|}{$\begin{array}{c}\text { Distance } \\
\text { between } \\
\text { eyes. }\end{array}$} & \multicolumn{2}{|c|}{ Suout. } \\
\hline Trygon narnak & . & d & $122.5 \mathrm{~cm}$. & $\mathrm{I} 50^{\circ} \mathrm{O} \mathrm{Cl}$ & cni. & $132 I .25 c$ & cin. & I $2^{*} 75$ & $\mathrm{~cm}$ & $25^{\circ} \mathrm{OC}$ & $\mathrm{m}$ & $37.5 \mathrm{c}$ & c1n. \\
\hline, & $\cdots \mid$ & $q$ & I20 & I52 5 & , & $438 \cdot 75$ & , & $15^{\circ} \mathrm{O}$ & , & $23 \cdot 75$ & , & $32 \cdot 5$ & . \\
\hline , & $\cdots 19$ & (juv.) & $23 \cdot 75$ & $40 \cdot 0$ &, & $80^{\circ} 0$ &, & $2 \cdot 5$ & $"$ & $6 \cdot 25$ & $"$ & & \\
\hline ," & .. $1 * q$ & $\begin{array}{l}\text { f (en. } \\
\text { bryo). }\end{array}$ & $23: 5$, & $20 \cdot 5$ &, & $67 \cdot 8$ & , & $2 \cdot 9$ & , & 4.5 & , & $6 \cdot 7$ & \\
\hline Trygon gerrardii & . & $\rho$ & $55^{\circ} \mathrm{O}$ & $67 \cdot 5$ &, & $150^{\circ} 0$ &, & $5 \cdot 02$ & ," & IO'O & , & I $5^{\circ} \mathrm{O}$ & . \\
\hline Trygon favus (type) & $\cdots !$ & & II $5^{\circ} \mathrm{O}$, & $130^{\circ} 0$ & ,' & $207 \cdot 5$ &, & $\cdots$ & & $30 \%$ & 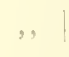 & $36 \cdot 25$ & $\cdots$ \\
\hline Trygon bleekeri & $\cdot \cdot 1$ & Q & II8:75, & II 755 &, & $202 \cdot 5$ & , & $8 \cdot 75$ & , & $15^{\circ} \mathrm{O}$ &, & $32 \cdot 5$ & . \\
\hline , , & $\cdots \mid q$ & (juv.) & $4 I \cdot 25$, & $46 \cdot 25$ &, & $138 \cdot 75$ &, & $5^{\circ} 0$ &, & 7.5 &, & $\mathrm{I} 5^{\circ} \mathrm{O}$ &, \\
\hline Trygon alcockii (type). & $\cdots$ & 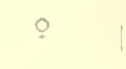 & $73^{\circ} 0$ & $85 \cdot 0$ & , & $\mathrm{IO}^{\prime} 5$ & , & $7^{\circ} 0$ & $"$ & I I*O & , & I $6 \cdot 5$ & , \\
\hline Trygon jenkinsii & . & $c^{2}$ & $78 \cdot 75$ & I $03 \cdot 75$ & , & Iro.o & , & $8 \cdot 75$ & , & I $6 \cdot 25$ &, & $22 \cdot 5$ & , \\
\hline (type) & & 8 & $80^{\circ} 0$, & $103^{\circ} 75$ &, & II 2.5 & ," & 75 & , & $\mathrm{I} 5^{\circ} \mathrm{O}$ & , & $20^{\circ} 0$ & , \\
\hline
\end{tabular}

Trygon marginatus, Blyth. (P1. iii, fig. 2.)

T. marginatus, Blyth, Joum. Asiat. Soc. Bengal, xxix, p. 38 (т86I); Day, Fam. Brit. Ind., Fishes, p. 54.

Disk broader than long, with the pectoral angles somewhat narrowly rounded. 'The snout rounded as a whole, but sometimes with a short terminal projection; length of snout $3 \frac{4}{5}$ to $4 \frac{1}{2}$ times in length of disk. Eyes small.

Tail much longer than disk, without caudal folds. There is only one large serrated spine. Colour.-Dorsal surface grey, with a distinct blackish tint and without any tinge of brown. In the male a series of livid bluish marks of an irregularly crescentic outline runs round the disk at some little distance from the margin. Ventral surface white with a broad blackish margin laterally and posteriorly; this margin sometimes indistinct. Tail blackish. 
Mouth rather small; the lower jaw more distinctly undulated than the upper, which is nearly straight. Teeth faintly tinged with brown. The unworn teeth are distinctly but minutely ridged longitudinally; the transverse ridge is strong, and there is a well-marked concavity on the surface in front of it. There are two short processes on the floor of the mouth, one situated near each angle.

Skin.-The skin is delicate, but not so soft as in $T$. microps. The head and the centre of the back are covered with closely set, rounded, almost flat denticles, which on the tail are intermixed with stellate spines. On the back the denticles become

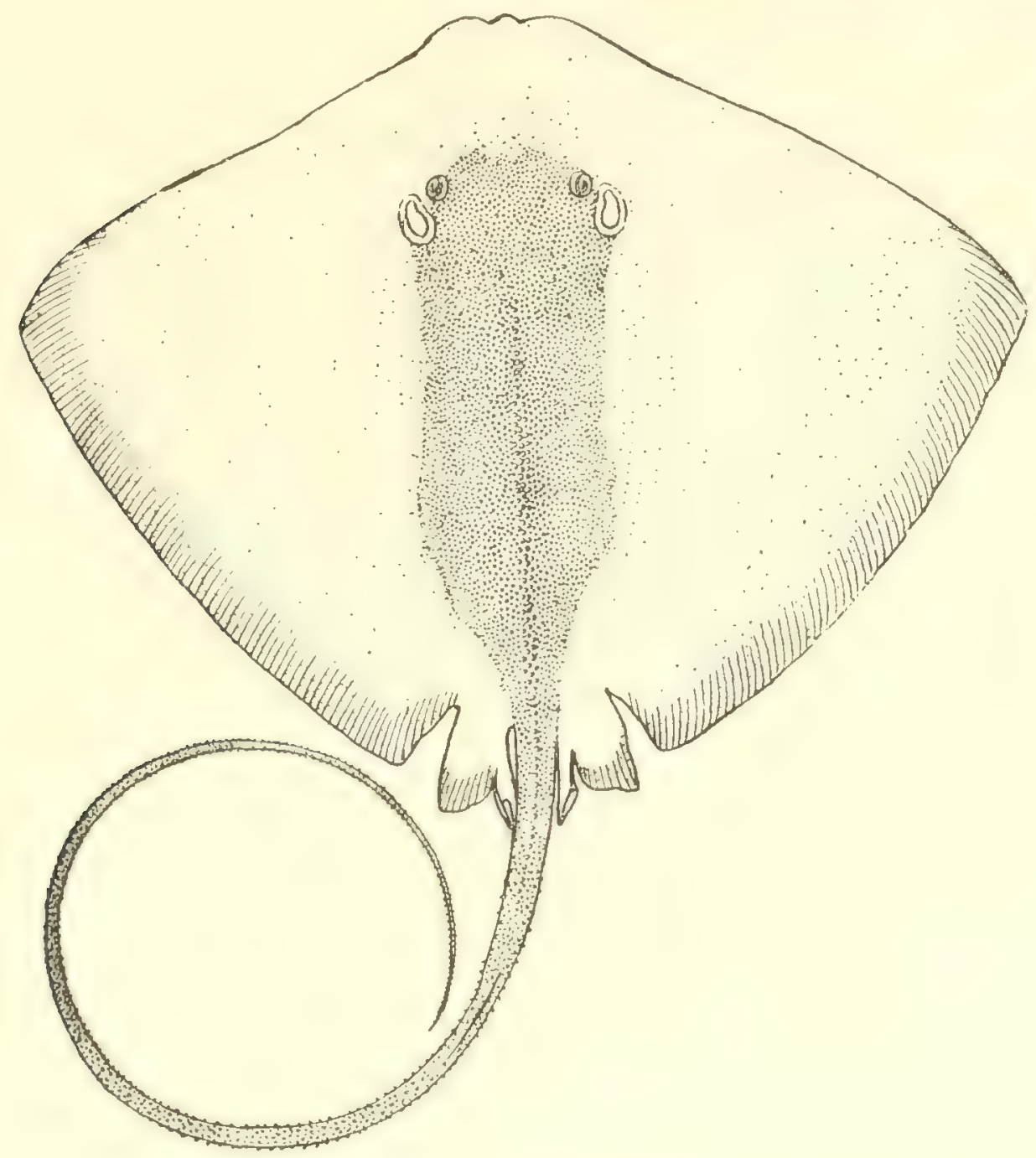

FIG. 5.-Trygon marginatus, $\sigma^{*}, \times c_{0} \frac{1}{1 T}$. (From stuffed specimen.)

gradually smaller from the middle outwards and do not form a clearly defined figute on the area they occupy. Externally, on either side, some of them have stellate bases - a character which becomes more marked as regards those that occur on the pectoral fins, on which they show a tendency to be arranged in longitudinal lines. They extend to the margin and sometimes over it on to the ventral surface. This description is based on a large male taken by the "Golden Crown' in October off the coast of Burma and a still larger female captured in March off the coast of 
Ganjam in about 24 fathoms. Although they do not agree in every respect with Blyth's description of the species I think these specimens must belong to it. Blyth's specimens appear to have perished and there are no others, except the ones described, in the Indian Museum, or, indeed, so far as I can discover, in any other collection. The measurements of my specimens were as follows :-

Length of disk

Breadth of disk

Length of tail

Length of snout from eyes

Distance between eyes

Nasal flap . .

Mouth to vent

\begin{tabular}{|c|c|c|c|c|c|}
\hline - & $\cdots$ & . & $\ldots I 47^{\circ} 5$ & $\mathrm{~cm}$. & IO2.5 \\
\hline . & . & . & .. I788.75 & , , & I36·25 \\
\hline & $\cdots$ & . & . I975 & , & $220 \cdot 83$ \\
\hline & . & . & .. 375 & , , & $25^{\circ} \mathrm{O}$ \\
\hline & $\cdots$ & $\cdots$ & $\cdots \quad 26.5$ & , & $2 I^{\prime} 25$ \\
\hline & . & . & $\ldots \quad I 6.25$ & , & $15^{\circ} \mathrm{O}$ \\
\hline & . & .. & $\ldots \quad 06 \cdot 25$ & & - \\
\hline
\end{tabular}

Trygon imbricata (Bloch and Schneider).

T. imbricata, Mïller and Henle, op. cit., p. I6+; Day, op. cit., p. 52.

T. walga, Wiuller and Henle, op. cit., p. I59, pl. 5 I ; Day, op. cit., p. 55.

Size small (adults $210-220 \mathrm{~mm}$. across the disk, young $90-100 \mathrm{~mm}$.).

Disk about as long as broad in the adult, broader in the young, always with the pectoral fins broadly rounded; the snout not greatly produced, occupying about onethird of the disk, forming an angle which is nearly a right angle; its length from the eyes about $2 \frac{4}{5}$ times the distance between the eyes. Eyes nearly as large as spiracles, not very prominent.

Tail variable in length, sometimes barely as long as the disk, sometimes twice as long or even longer, proportionately longer in the young than in the adult. On either side there is always a thick but low ridge, while along the mid-dorsal line a narrow groove can generally be detected. Sometimes this groove contains a low fold, which is much lower than the tail and is more strongly marked on the distal half of the tail than it is on the basal, although it does not reach the tip. More rarely there is a corresponding fold on the ventral surface, but even when both are present they are low and inconspicuous. As a rule there are two narrow serrated spines on the tail.

Colour.- Ventral surface white. Dorsal surface of brownish clay-colour, occasionally with obscure darker spots and usually becoming paler on the edge of the fins. The lateral ridges on the tail white.

Skin.-The lepidosis is as variable as are the proportions of the tail, but the two characters are not correlated. In many adult individuals the back and head (but not the pectoral fins) are covered with small flattened denticles which do not differ from one another markedly as regards size or shape. There are sometimes, however, several enlarged tubercles on the midline of the scapular region, while often a row of denticles bearing backwardly directed spines can be detected in the middle line at the posterior end of the disk and on the base of the tail. They vary in size and development. Sometimes, even in adults, the disk is almost naked. 
Month.-The jaws are somewhat curved as a whole and regularly but not very strongly undulate. The teeth are small and white; the transverse ridge is low and

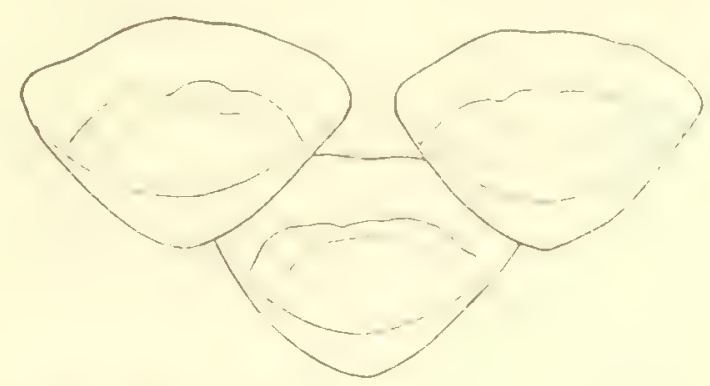

Fis. 6. - Teeth of Trygon imbricata (enlarged). From preparation in canada balsam.

somewhat irregular, the surface of the tooth posterior to it being decidedly concave. There are two short processes on the floor of the mouth, occasionally with a minute papilla between them. They are situated much nearer to one another than either is to the angle of the mouth.

At first sight the form described by Bloch and Schneider as Raja imbricata is very distinct from Müller and Henle's Trygon walga. Indeed, so long as I had only examined a comparatively small series of specimens, I was prepared to regard them at least as distinct varieties. Recently, however, I have had an opportunity of examining a large number of living specimens, among which I find every gradation between the two forms. Shortness of tail is not invariably or even usually correlated with any peculiarity in the denticles, nor is the exact form of the disk correlated with either character. Every possible gradation is found between a distinct caudal fold and a complete absence of any such character. Nor is any one peculiarity peculiar to either sex. Except that the young has a relatively wider disk, a longer tail and a paler colour, and usually fewer denticles on the disk, than the adult, there is no external difference between them, and I have seen two embryos from one mother which differed considerably as regards length of tail.

T. imbricata appears to be, in the strict sense of the plurase, a littoral and estuarine species. Few specimens have been taken in water even so deep as $\mathrm{I}_{5}$ fathoms by the " Golden Crown,' but large numbers are captured in the winter season on the Orissa coast at Puri by means of seine-nets worked from the shore. The flesh is only eaten by the lowest castes of the Hindus.

\section{Trygon zugci (Miiller and Henle).}

Size small (largest specimen 3 I cm. across disk, smallest $8.5 \mathrm{~cm}$.).

Disk slightly broader than long; the pectoral angles broadly rounded; the greatest transverse cliameter situated about half way between the base of the tail and the tip of the snout, which is sharply pointed and much produced, its length from the eyes being more than three times as long as the distance between the eyes. Eyes nearly as large as the spiracles. 
Skin smooth, richly provided with mucous glands. Sometimes a few rudimentary denticles can be detected on the posterior part of the disk and the base of the tail, but as a rule the skin is naked except for a single mid-dorsal line of large denticles with sharp spines directed backwards. Sometimes this line is only developed on the base of the tail, sometimes it extends from a point close behind the spiracles.

Tail with low dorsal and ventral folds, which commence close behind the spine and run for about a third of the length of the tail; the tail from one-and-a-half to nearly three times as long as the body.

Mouth broadly arched as a whole; the jaws slightly sinuous. The teeth white. Each

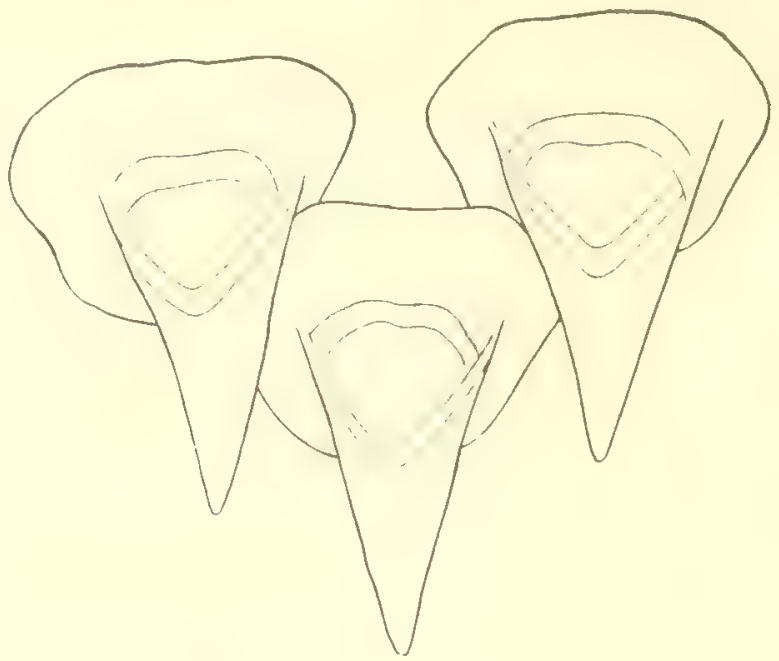

Fig. 7.-Teeth of Trygon zugei, or (enlarged). - From preparation in canada balsam.

in the male with a roundish base and a long, slender, tapering cusp, which ends in a sharp point; in the female a triangular ridge takes the place of the cusp.

Colour.-Dorsal surface dark blackish brown, no paler at the edge of the fins than on the middle of the disk. Ventral surface white, often blotched or suffused with dark pigment. Young paler above than the adult, with the edges of the pectoral fins black on both surfaces.

$P$. zugei does not appear to be common in the northern parts of the Bay of Bengal but a few specimens have been taken by the "Golden Crown" off the coasts of Burma and Orissa, as well as a considerable number (in February) off that of Madras. The photograph reproduced on plate iv was taken from one of the former while it was still fresh. The freezing to which it had been subjected, however, had caused the skin to shrivel a little.

\section{Trygon kuhlii (Müller and Henle).}

Size small (male $30 \mathrm{~cm}$. across the disk, female $32 \mathrm{~cm}$.).

Disk slightly broader than long: the pectoral angle rounded, the broadest diameter being considerably nearer the tip of the snout than the base of the tail. The snout 
rounded, not produced, its length from the eyes not much greater than the distance from eye to eye. Eyes very large and prominent. Spiracles narrow, extending along the outer margin of the eyes.

Tail considerably longer than the disk, armed with two or more long, slender serrated spines and bearing a long, well-developed ventral cutaneous flap and a much shorter dorsal one.

Colour.-Dorsal surface pale slate-colour onnamented with a variable number of round, bluish, black-edged spots scattered irregularly, and sometimes with smaller black spots. Ventral surface white. The proximal part of the tail rather darker than the ground of the dorsal surface of the disk, without markings ; the distal part boldly banded with black and white.

Skin almost naked, sometimes bearing numerous minute rudimentary denticles on the tail and in the middle of the back. A row of large denticles with stout spines directed backwards sometimes present in the mid-dorsal line, but, at any rate in young individuals, not always present.

Mouth--Straight as a whole; the jaws distinctly undulate. The teeth resembling those of $P$.zugei but with a considerably stouter cusp in the male. 'The nasal flap straight, fringed, with a longitudinal central groove on the surface.

No specimens of this species have been taken by the "Golden Crown " in the northern part of the Bay of Bengal, but a large pair $(\sigma, q)$ and several smaller specimens were captured in February, I909, off Gopalpur (Madras Coast) in 24 fathoms and a considerable number of specimens of different sizes off the same coast in March. Both $P$.zugei and the present species have a wide range, the former being distributed from the Arabian Sea to Japan, while the latter occurs not only in Japanese waters but also on the East Coast of Africa.

Genus Hypolophus, Müller and Henle.

Distinguished from Trygon by the form of its tail, jaws and teeth.

\section{Hypolophus sephen (Forskål).}

Trygon sephen, Day, Faun. Brit. Ind., Fishes, i, p. 5I, figs. 2I, 22.

Size large (adult $5_{52} \mathrm{~cm}$. across the disk).

Disk slightly broader than long, with the pectoral angles obtusely rounded; the broadest transverse diameter widely separated from the anterior end of the disk. Snout forming an angle greater than a right angle; not produced. Eyes large and prominent.

Colon?.-Dorsal surface reddish brown in the young, bluish grey in the adult, without spots; the margins of the fins and the tail (except the base) darker than the centre of the disk.

Tail.-I onger than disk in normal specimens, with a broad cutaneous flap running along the ventral surface from a point near the insertion of the serrated spine (or spines) for about one quarter of the length of the tail, its distal extremity being widely separated from the tip. Two serrated spines are usually present. 
Skin tough. 'The head, back and base of tail are covered with closely set, flat or nearly flat denticles, usually with three or more enlarged tubercles in the scapular region. The tail is covered for the greater part of its length with small spiny denticles, which also occur scattered on the cutaneous flap.

Mouth.-The jaws are bent almost angularly, this being particularly noticeable as regards the upper jaw, in the middle of which the teeth are smaller than they are elsewhere. The middle part of the upper jaw is deeply concave from below. 'The teeth are white; their surface is nearly smooth and the transverse ridge is practically obsolete. Where they are quite unworn, however, it is possible to see that the surface is divided into two areas; a posterior one, of which the outline is rounded and the surface obscurely sculptured, and an anterior one with an angular outline and marked with distinct longitudinal grooves. On the floor of the mouth there are three long slender processes situated close together in the middle, and another near each angle.

This species represents the genus Hypolophus of Miiller and Henle and is certainly very distinct from any other. I am doubtful as to the necessity for recognizing subgenera in the fishes, otherwise I would certainly recognize Miiller and Henle's name as that of a sub-genus.

There are several small specimens in spirit in the collection of the Indian Museum, but the only fresh one that I have seen was a male measuring $I 5 I \cdot 8 \mathrm{~cm}$. across the disk which was taken by the "Golden Crown'" in August off the Burmese coast. This specimen exhibited an interesting abnormality, lacking the distal part of the tail completely. The cutaneous flap ran to the extreme tip, becoming gradually lower towards this point. The tail, however, was no longer than the disk, and I have little doubt that it had been accidentally abbreviated, although the wound had completely healed without even leaving a scar at the tip. A photograph of this specimen is reproduced on plate $v$, fig. I.

\section{Genus Urogyanus, Müller and Henle.}

Tail very distinct from the disk, without a serrated spine. Disk stout, elliptical or subcircular. 'l'eeth flattened, without a distinct transverse ridge but with the inner margin raised. Other characters as in Trygon.

Hitherto only one species of the genus has been known, namely Urogymmus usperrimus (Bloch and Schneider), but a second is here described. Unfortunately I have only seen one fresh individual of the former, which was mutilated, and have not been able to exanine the latter except as a stuffed nuseum specimen. The differences, however, are so very clearly marked that I do not hesitate to describe the new species.

'The two species may be distinguished as follows :-

A. Pectoral fins covered with spiny denticles which have Hat circular bases - U. asperrimus.

B. Pectoral fins covered wlth small rounded denticles, which at the periphery are almost granular $\ldots U$. lavior. 


\section{Urogymmus asperrimus (Bloch and Schneider).}

Disk slightly broader than long, broadly arched in front but with a somewhat projecting snout, very thick vertically in the middle, sloping up abruptly from the anterior part of the pectoral fins to the top of the head.

Tail longer than disk, sometimes with a low cutaneous fold on the ventral surface.

Colour uniform greyish brown on the dorsal surface.

Skin tough, very richly supplied with slime-glands. 'The head, back and tail are densely covered with prominent bony tubercles, among which are scattered numerous spiny denticles with more or less stellate bases. 'These are particularly numerous on the tail and on the superciliary part of the head. The pectoral fins are covered with spiny denticles which have smooth circular bases. In the dried skin the area on which the bony tubercles are present is clearly marked off from that occupied by the spines with circular bases, but in the fresh specimen the bases of all the scales are more or less completely concealed in the epidermis and in the enormous amount of slime with which the skin is coated.

Mouth.-The upper jaw is divided by a shallow concavity on either side into three nearly equal convex projections. The middle part of the lower jaw, however, is nearly straight, there being a slight concavity on either side. The teeth are of a dark purple-brown; they are nearly oval (transversely) in shape and have the exposed surface minutely but deeply sculptured. On the floor of the mouth there are three long finger-shaper processes situated close together in the middle.

The only specimen I have seen fresh was captured by the "Golden Crown ', in August, Igo8, off Chittagong, but there are several stuffed ones in the Madras Museum. 'The one taken by the "Golden Crown" ' had lost the greater part of its tail owing to what appeared to be a slanting cut from above as with an axe. The wound had, however, healed. 'The following are the measurements of this specimen, which was a female :-

Length of disk . .

Diameter across disk

Distance between eyes

Tip of swout from eyes

$\ldots$ II 2.5
$\ldots 97.5$
$\ldots 23.75$
$\ldots 23.75$

Urogymmus lovior, sp. $110 \mathrm{v}$.

[Description of type (a stuffed skin) in the Madras Muscum.]

Disk broadly oval if the pelvic fins are included, alnost as wide as long without them, truncated in front as a whole, but with a short projecting snont.

Tail longer than disk, without cutaneous folds.

Skin.-Dorsal surface of pectoral fins, head and anterior part of body covered with small, round, blunt tubercles, which become gradually smaller from the centre of the body outwards towards the edge of the pectoral fins, where they are almost granular. Behind the scapular region these tubercles are mixed with short spines, which have stellate bases and become nore numerous on the base 
of the tail, where they greatly outnumber the rounded tubercles and finally take their place altogether. The whoie of the tail is covered with spines of various sizes.

Month.-Upper jaw more distinctly undulated than the lower. Teeth white, practically lozenge-shaped.

This specimen was taken near the shore at Malpe, S. Canara, on the Malabar coast. Mr. F. Thurston has kindly given me the following note as to its history :"I was summoned from the dinner-table to inspect the carcase of an immense skate, whose last act, as she lay dying on the shore, was to continue the species by bringing forth twelve young ones, who were promptly salted."'

Genus P'teropratea, Müller and Henle.

Disk very broad in comparison with its length, lozenge-shaped, flat. Pectorals united in front. Tail feeble, normally with a serrated spine, without a rayed caudal fin, a small rayed dorsal fin sometimes present. Teeth with a saddleshaped base and one or more backwardly-directed, sharp cusps. No processes on the floor of the mouth. Nasal valves coalescent. Slin naked or nearly so.

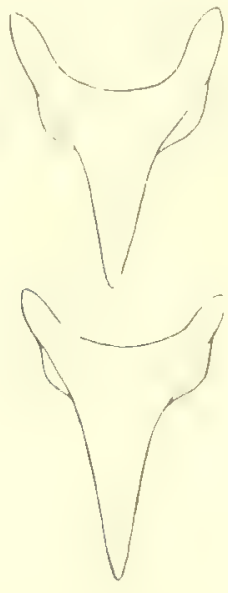

A.

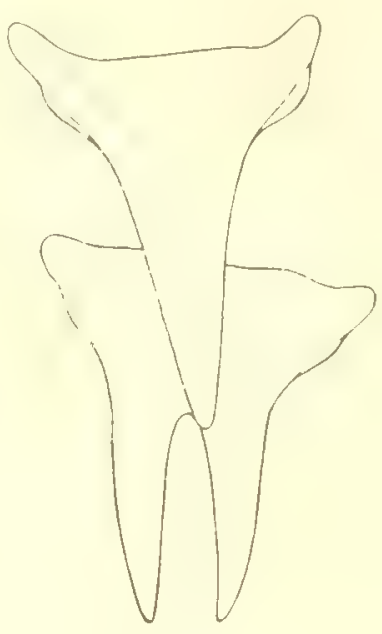

B.

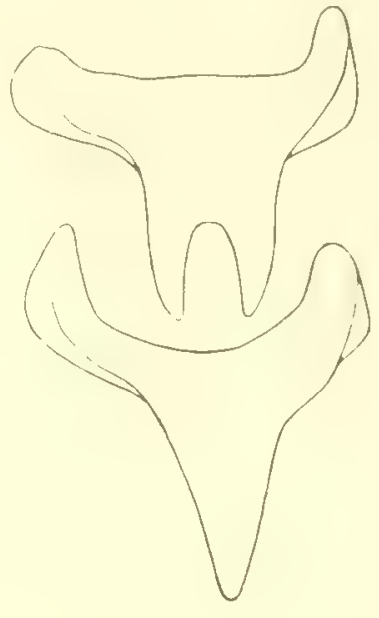

C.

Fig. 8.- T'eeth of Pteroplatca (enlarged) : A, P. micrura; B, P. zomura; C, P. tentaculata.

Day describes only one Indian species of this genus, but three are common in the Bay of Bengal, namely, $P$. micmu, $P$. zomma and $P$. tentaculata. They may be distinguished as follows:-

I. No dorsal fin.

A. No tentacle on the posterior margin of the spiracle. Dorsal surface uniformly coloured in the adult .. . . P micrura.

II. A small dorsal fin on the tail.

A. No tentacle on the margin of the spiracle. Dorsal surface minutely dotted with dark green and boldly spotted with greenish yellow $P$.zonura.

B. A small tentacle present behind the spiracle. Dorsal surface spotted and blotched with greenish yellow $\quad \ldots \quad \ldots \quad \ldots \quad P$. tentaculata. 
In general form and structure all the species of the genus are very much alike. In the Indian species at any rate the structure of the mouth and teeth differs little. The mouth is nearly straight and bears no processes on its floor or cutaneous flap on its roof. The teeth have been briefly described by several anthors; Günther (Cat. Fishes, viii, p. 486) says that they are "very small, uni- or tricuspid"'; Mïller and Henle describe them as "mit I-3 Spitzen" (Syst. Beschr.d. Plagiostomen, p. I68) ; Jordan and Everman (Fishes of North America, i, p. 86) do not mention them in their account of the North American species. They are so small in the Indian forms that it is impossible to examine them properly without dissecting them out and mounting them for microscopic investigation. The figure reproduced on page 38 gives an outline of teeth of $P$. micrura, $P$. zonura and $P$. tentaculata. In the two latter species teeth with one cusp are mingled indiscriminately with teeth bearing two cusps; but apparently in $P$. micrura all the teeth have one cusp. In the two former species the unicuspid teeth are much more numerous than the bicuspid ones.

I have not detected any rudimentary denticles in the skin of the Indian forms.

-The species of Pteroplatea are eaten by some castes of Hindus but rejected by others and by Mahommedans as being " fish without fins."

\section{Pteroplatea micrura (Bloch and Schneider).}

Size moderate (adult females $7+-82 \mathrm{~cm}$. across disk, males (?) smaller, young $\mathrm{r} 6 \mathrm{~cm}$.).

Disk as a rule rather less than twice as broad as long, with the pectoral angles subacute in the adult, distinctly rounded in the young. The snout hardly projects at all, the anterior margin of the disk forming a very obtuse angle. The distance between the eyes considerably greater than the length of the snout measured from thenı. The nasal flap distinctly emarginate, delicately fringed.

Tail variable in length, sometimes longer than disk, as a rule shorter, but always more than half as long, without dorsal fin or cutaneous folds; serrated spine usually present in the adult but absent or concealed in the young.

Coloum.-The dorsal surface of the new-born young is of a pale greenish grey profusely covered with small, round, blackish spots and with more sparsely scattered and larger white ones. The ventral surface and the tail are white, but there is a row of relatively large, longitudinally oval, blackish spots on the dorsal surface of the latter. Soon after birth the spots disappear from the body, while those on the tail coalesce in pairs and grow round the greater part of the circumference of the tail. A white spot is, however, left in the middle of each of the double black ones on the tail. As the fish grows older the tint of the dorsal surface darkens to deep slate-colour or brownish grey, the spots on the back having completely disappeared before this happens although those on the tail become more distinct and more extensive with age.

This species is more commonly captured by the methods employed by Indian fishermen than its two congeners, because it is mainly a littoral form. Iarge numbers of small individuals were taken at Puri in January and February practically on the beach.

Day states, on the authority of Jerdon, that $P$. micnura grows to 6 feet across the disk (Fishes of India, ii, p. 74I); but in the large series of specimens taken by the 
"Golden Crown" the gravid females have measured less than 3 feet across the disk, while the adult males have all been smaller. The members of the genus are so closely allied that it is not improbable that a large species not yet described exists in Indian seas. Day refers also to a drawing in Sir Walter Elliot's collection of an example covered all over with small brown spots. Probably the original of this drawing was a young specimen of P.zomura.

$P$. micmra appears to be common off the coasts of Burma, Chittagong and Orissa at all seasons, but always to remain in very shallow water. Like its two Indian congeners it is gregarious; so far as can be judged from the specimens in the "Golden Crown " collection sent to the Museum, the shoals of the three species keep separate from one another. P. micrura is rather widely distributed in Indo-Malayan seas.

$$
\text { Pteroplatea zonura (Bleeker). (P1. iv, fig. 4.) }
$$

Size moderate (adult females $85 \mathrm{~cm}$. across disk, males slightly smaller).

Disk.-Proportions almost asin P. micmur. Nasal flap almost straight, barely fringed.

Disk often with a distinct though short projection in front.

Tail variable, often more than half as long as disk but probably never quite so long. Dorsal fin twice as long as high, about a third as long as the free part of the pelvic fins; its anterior border situated slightly in front of the distal border of these fins. Serrated spine minute or absent. A low cutaneous fold sometimes present on the ventral surface.

Colour.-Dorsal surface olive-green, minutely and closely speckled with dots of a darker shade, boldly marked with large round or irregular spots of greenish yellow and often joined together by irregular lines and blotches of the same colour, sometimes ocellate. In the young the dark spots are paler and less numerous, while the spots are less irregular and have a brownish colour. The ventral surface is devoid of pigment. 'Tail coloured like that of $P$. micrura.

This fish is evidently common on the Orissa coast in depths of from I5 to 20 fathoms. Numerous individuals of both sexes have been taken there by the "Golden Crown " at different seasons, especially in winter. I saw a young female taken in the seine-nets on the beach at Puri in Fiebruary.

The species was originally described from Java.

$$
\text { Pteroplatea tontaculata (Müller and Henle). (P1. iv, fig. 4.) }
$$

Size moderate (adult females $73 \mathrm{~cm}$. across the disk).

Disk a little less than twice as broad as long in the adtult, more than twice as broad in the young; the pectoral angles somewhat rounded in both. The distance between the eyes as a rule nearly the same as (a little greater than) the length of the snout measured from them. The snout has a distinct though short projection. The tentacle at the posterior angle of the spiracle is variable in length, always slender and pointed.

Tail variable in length, as a rule less than half as long as the disk in the adult, sometimes with faint dorsal and ventral cutaneous folds. The dorsal fin about 
twice as long as high, more than half as long as the inner edge of the pelvic fins; its anterior border situated nearer the base than the distal end of the pelvic fins. Serrated spine minute or absent.

Colour.- In the young the dorsal surface of the disk is of a greenish slate-colour, marked with irregular roundish spots of a dark brown, and with a faint and close reticulation of a paler shade of brown. This reticulation separates closely set roundish areas of the ground colour. As the fish grows, the brown spots enlarge and assume a greenish colour, finally becoming dark olive and occupying the greater part of the surface. The faint reticulation disappears and large spots and blotches of yellowish green are developed. The tail is faintly barred at all ages. The coloration of the adult, therefore, differs from that of the adult $P$. zonura, so far as the dorsal surface is concerned, in the absence of minute dark dots and in the faint markings of the tail. The ventral surface of the young is white, but in the adult it is marbled and clouded with dark pigment.

This species is probably confined to water from. I5 to 30 fathoms deep. A considerable number of specimens were taken together in about 30 fathoms at the mouth of the Eastern Channel of the river Hughli in February, Igog. Others were taken off the Orissa coast in the autumn of Igo8, but never many at a time; several were taken off the Ganjam coast in from 24 to 27 fathoms in March.

The species probably is widely distributed in the Red Sea and the Indian Ocean.

\section{Family TORPEDINIDE.}

Naked Batoidei with a broad, flat, circular or elliptical disk. At least one dorsal fin usually present (absent in one genus). A honeycomb-like electric organ developed between the head and the pectoral fins.

Two genera of Torpedoes are recorded by Day as occurring in Indian seas, while a third has since been described by Alcock. Two more are here added, one being new and the other represented by a species not hitherto recorded with certainty from the Indian Ocean. The following key will serve to separate the Indian genera :-

I. Two dorsal fins on the tail.

A. Eyes well developed.

(a) Spiracles distinctly separated from the eyes ..

(a') Spiracles not distinctly separated from the eyes

. Torpedo.

B. Eyes degenerate.

(a) Pectoral fins feebly developed .. .. Benthobatis.

.. Narcine.

II. One dorsal fin on the tail.

A. Pectoral fins moderately well developed ... .. Astrape.

B. Pectoral fins reduced externally to mere rudiments Bengalichthys.

III. No dorsal fin

Temera.

I include in this key the genus Temera because it will probably be found in Indian seas, having been originally taken at Penang. There is a very small specimen (of 
T. hardwickii?) in the collection of the Indian Museum, but unfortunately I have not been able to trace its history or provenance. The specific characters of the only known species of the genus are so imperfectly recorded that I hesitate to identify the specimen, which is both immature and faded.

Benthobatis is a deep-sea genus, but the relations between it and Narcine correspond so closely with those between my new genus Bengalichthys (which is a shallow-water genus) and Astrape, that I am obliged to discuss it at some length.

Both the species and the genera of the family are in some cases closely related, and it is often difficult to distinguish between them unless fresh or well-preserved material is used. This is particularly the case as regards the genera Narcine and Torpedo. Stuffed skins of these forms are practically useless for purposes of identification, unless the greatest care has been taken to preserve the natural features. The naked, glandular skin is particularly liable to become distorted, while the colour, although sufficiently permanent in spirit unless the specimens are exposed to a strong light, invariably darkens in skins, so that all the markings disappear.

The ridges or processes on the roof and floor of the mouth form in some genera as useful a diagnostic character as is the case in certain genera of Trygonida, but one that can only be investigated properly by dissecting out the mouth.

The Torpedoes do not appear to be used as food in India, at any rate habitually. Those caught in the seine-nets at Puri are invariably thrown away.

\section{Genus Torpedo, Duméril.}

Disk distinct from tail, which is stout, bears a well-developed caudal and two dorsal fins and has a fold on either side. Pectoral fins well developed; pelvic fins not joined behind the anus. Eyes distinctly separated from spiracles. Nasal valves confluent into a quadrangular flap. Teeth pointed, with a single cusp and a flat base; cleft of mouth wide and U-shaped.

Only one species has as yet been found in Indian seas, or at any rate definitely identified. I am much indebted to Mr. Boulenger for examining photographs of an Indian specimen of this species and confirming my identification.

$$
\text { Torpedo mamorata, Risso. (Pls. iiia, fig. 4, and v, fig. 3.) }
$$

T. galvanii, Bonaparte, Fann. Ital., vol. iii, Pesci, plate (I832-4I).

T. marmorata, Gïnther, op. cit., p. +50.

Disk broadly truncated in front, broader than long, rather longer than the tail. The latter very broad at the base. The dorsal surface covered with minute wrinkles, which run longitudinally on the anterior part of the disk and transversely on the posterior. The eyes nearly as large as the spiracles, from which they are separated by a distance less than their own diameter. The posterior and lateral margins of the spiracles provicted with a row of somewhat stout, irregular, conical processes.

The mouth is situated between two deep, rather lengthy longitudinal folds, which approach one another posteriorly and diverge anteriorly. The teeth occupy nearly 
the whole of the mandibular surface ; their cusps are long and very sharp, directed obliquely backwards. There is a low cutaneous ridge behind the teeth on either jaw but no outstanding processes.

Colour.-The colour is variable in European specimens; in the three Indian ones I have seen the dorsal surface was of a peculiar livid dark purple-brown, densely spotted with purplish buff. These markings extended over to the ventral margin of the pectoral fins; but the greater part of the ventral surface was dull white.

The only specimen I have examined in detail is one brought by Dr. Travis Jenkins in December, Igo8, from Puri, where it had been taken in a seine-net worked from the shore. In November of the same year, horvever, I saw a very similar specimen, which had been captured in the same way, at Quilon on the Travancore coast. Dr. Jenkins's specimen measures (in spirit) $245 \mathrm{~mm}$. across the disk, which is $227 \mathrm{~mm}$. long; the tail is $173 \mathrm{~mm}$. long, the total length being thus foo mm. The specimen is a female and contained ripe ovarian eggs; a good photograph is reproduced on p1, v, fig. 3 .

\section{Genus NARCine;, Henle.}

Disk longer than broad, distinct from tail, which bears two dorsal fins and has a fold of skin along each side. Pectoral fins well developed; pelvic fins not united behind the anus. Eyes close to the spiracles, well developed. Nasal valves confluent. Mouth tubular and protrusible; its cleft narrow and straight. Teeth pointed, with a single cusp, which is directed backwards and in some species feebly developed.

At first sight this genus is very near Torpcdo, from which Giinther says that it " differs in having the spiracles almost immediately behind the eye." He also says that the teeth sometimes have a median point, which, however, does not project. I cannot, however, see any real difference between the two genera in respect to the teeth ; whether the "median point" projects or not is due to the position of the mouth and to the angle at which the teeth' are examined, while the absence of a median point is often due to its being worn away. So far as the Indian species are concerned, there is a very marked difference between the two genera in respect to the shape of the mouth, which in Torpedo is evidently capable of being widely opened, although it appears to be somewhat protrusible, while in Norcine it can be thrust out bodily as a tubular structure with a narrow, transverse, slit-like aperture.

Narcine has long been known to be represented in Indian seas by two shallowwater forms, which Day regarded as mere colour varieties, while Lloyd has recently described a deep-sea species. I feel obliged to separate the two former from one another as distinct species for reasons given below. Here I may say that Lloyd's $N$. mollis is closely related to the form I have described as $N$. brmnea, although clearly distinct from that form. It is distinguished by the uniform dark colour of its dorsal and

In comparing the teeth of these genera great care must he taken to select teeth from the back of the jaws, where they have not been worn. Some of Dumeril's figures (Nal. Hist. I'oiss., pl. xi) rather suggest that he did not adopt this precaution. 
ventral surfaces, the flabby consistency of its muscular tissue, and the structure of the interior of its mouth and teeth, the cusp of the latter being very wide transversely and forming a flat triangle rather than a spine-like process.

The Indian species may be recognized as follows :-

I. Dorsal surface spotted. Dorsal fins subequal .. . N. timlei.

II. Dorsal surface brown; ventral surface white. Dorsal fins sub$\begin{array}{llllllll}\text { equal } & . & & \ldots & \ldots & & \end{array}$

III. Dorsal and ventral surfaces dark brown, unspotted. Dorsal fins

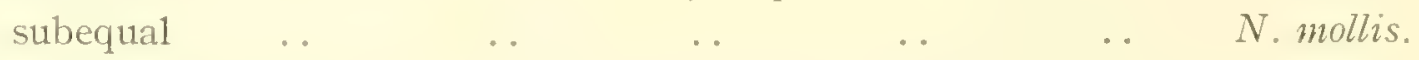

The eyes in all the Indian species are large, and the margins of the spiracles are smooth.

$$
\text { Narcine timlei (Bloch and Schneider). (P1, iii a, fig. I.) }
$$

$\mathrm{N}$. timlei and N. indica, Henle and Müller, op. cit., p. I30.

N. timlei, Giinther, op. cit., p. +52 ; Day, op. cit., vol. i, p. 45 (in part, not the figure); Fishes of India, vol. ii, p. 733 (in part).

Disk variable in outline, sometimes regularly oval and only slightly broader than long,

sometimes considerably narrower, sometimes with the pectoral fins projecting in such a way that it becomes, even in fresh specimens, almost rhomboidal. The tail strongly developed, depressed, nearly as long as or longer than the disk; the two dorsal fins subequal, separated by about the length of one of them; the posterior margin of the pelvic fins reaching or nearly reaching the anterior border of the first dorsal. Extent backwards of the pectorals variable; sometimes they fall short of the anterior margin of the pelvic fins, sometimes reach it, and frequently overlap it.

Colour.-Dorsal surface chocolate-brown (which sometimes turns to purplish grey in preserved specimens) profusely marked on the back, lateral fins and tail with large spots of a dark purple-brown colour. In the young these spots are surrounded by rather indefinite pale rings, which sometimes persist in the adult, giving them an ocellate appearance. The posterior margins of the dorsal and caudal fins are somewhat broadly, the anterior margins narrowly edged with white. Ventral surface dead white, sometimes clouded with dark pigment in large individuals.

The mouth can be protruded as a depressed tube measuring, in the case of a large individual, $35 \mathrm{~mm}$. in length, $15 \mathrm{~mm}$. in transverse diameter at the distal extremity, and $8 \mathrm{~mm}$. longitudinally. The teeth occupy about a third of each jaw; they have long, narrow, acutely pointed inner projections, which (in the unworn tooth) are nearly as long as the transverse diameter of the bases. On the roof of the mouth behind the teeth there is a pair of irregular, distinctly separated, compressed vertical processes, and on the floor a similar pair; in both pairs the inner margins are emarginate on the basal half. The nasal flap straight, very finely and shortly fringed, with a narrow, smooth stretch in the middle. 
Adult specimens measure about $3+\mathrm{cm}$. in total length and about $\mathrm{I} 7 \mathrm{~cm}$. across the disk.' Numerous specimens have been taken off the Orissa coast by the "Golden Crown,' and I have recently had an opportunity of examining many living ones on the beach at Puri, where large numbers are caught daily in seine-nets worked from the shore during calm weather. Two points at once become clear as a result of the examination of fresh specimens, (I) that it was impossible to separate Henle's Narcine indica from $N$. timlei, Bloch and Schneider, on the ground of the shape of the disk, and (2) that the specimens examined fell into two very distinct groups separated from one another not only by colour but also by size.

As regards the first of these points, the variation in the outline of the disk is remarkably wide and does not appear to be correlated with any difference in size, sex, or coloration. It is due mainly to differences in the development of the pectoral fins, the rays of which vary greatly not only in length but also as regards their position on the body.

Another point in which variation is very marked is the size of the eyes as compared with that of the spiracles. Occasionally the eyes are nearly as large as the spiracles, sometimes they have not more than half the superficial area of these structures.

The size and proportions of the dorsal and caudal fins are also variable.

As regards the important question of coloration, variation exists as regards the size and regularity (or otherwise) of the spots on the dorsal surface, which in one set of specimens are always present.

Day, in the "Fauna"' and in the Fishes of India, remarks that some specimens have no spots on the dorsal surface and that the absence of spots is not due to age, sex or locality. These statements are fully borne out by the large series of living and preserved specimens I have seen; but I do not think that the two forms are specifically identical and have therefore been forced to describe the immaculate one as a new species. Unfortunately it is the one figured by Day as typical of $N$. timlei.

Narcine timlei is very sluggish in its movements. I have failed repeatedly to induce it to give an electric shock even when it was in a bucket of sea-water

$$
\text { Narcine brumnea, sp. nov. (P1. iiia, fig. 2.) }
$$

N. timlei, Day, Fishes of India, pl. cxcii, fig. 3; Fann. Brit. Ind., Fishes, vol. i, fig. I $8, \mathrm{p} .45$.

Closely related to $N$. timlei, from which it differs in the following characters: (I) coloration, (2) size, (3) form of the teeth, (4) outline of the free edge of the nasal flap, and (5) form of the processes in the mouth.

(I) 'The dorsal surface is of a warm chocolate-brown without spots, the ventral surface creamy white. A narrow margin of the latter shade runs round the disk, being more distinct anteriorly than posteriorly : the dorsal and caudal fins, as well as the lateral ones, are edged with greyish white.

1 Day's statement that this species grows to at least is inches in tota! length (Fishis of Indiu, vol. ii, p. 733) is perhaps due to a confusion with some species of Torpedo. Judging from old specimens in the Indian Nuseum, such a confusion acttally existed in his diagnoses. 
(2) Iarge individuals of either sex measure about $22 \mathrm{~cm}$. in length and II $\mathrm{cm}$. in breadth across the disk.

(3) 'The posterior projection of the teeth is much shorter than the transverse diameter of the base, broader and blunter than is the case in $N$. timlei.

(4) The free edge of the nasal flap has a distinct projection in the middle line.

(5) On the roof of the mouth, behind the teeth, a cutaneous ridge with irregular serrations occurs, while on the floor there is a similar ridge, with or without a notch in the middle line, but never divided into two distinct processes.

The difference in colour between this species and $N$. timlei is constant in fresh specimens, although naturally difficult to detect in faded ones. The difference in size exists as regards the smallest specimens I have seen. 'There are in the Indian Museum, from different localities, seven examples of $N$. brmmea which measure between $55 \mathrm{~mm}$. and $70 \mathrm{~mm}$. in length, and between $30 \mathrm{~mm}$. and $35 \mathrm{~mm}$. across the disk. None of these specimens exhibits any trace of spots on the dorsal surface or retains any external rudiment of the yolk-sac. The smallest specimen of $N$. timlei I have seen was taken by the "Golden Crown' at the mouth of the river Hughli in January, Igog. It measures $80 \mathrm{~mm}$. in length and $50 \mathrm{~mm}$. across the disk and has numerous large ocelli on its dorsal surface. There is a yolk-sac $23 \mathrm{~mm}$. long attached to the belly, and from the general appearance of the specimen I think that it was probably borm prematurely.

The structural differences between $N$. brumea and $N$. timlci are of considerable interest, but they can only be seen distinctly if the specimens examined are dissected.

\section{Genus BenTroBaTIS, Alcock.}

This genus, which is known from several specimens of a single bathybial species, differs from Narcine mainly in the degeneracy of the eyes, a character of which no trace can be detected in the only known deep-sea species ( $N$. mollis) of the latter genus. The teeth are not very different from thase of some species of $N$ arcinc.

Genus Astrape, Müller and Henle.

Tail with one dorsal fin. Eyes small but not markedly degenerate. Teeth neariy flat, with a broad, backwardly directed ridge, which is very bluntly pointed. Mouth protrusible but not tubular, the cleft nearly straight. Other characters as in Narcine.

Only two species of this genus are recorded by Giinther: Astrape capensis, from the coast of S. Africa and Madagascar, with the tail distinctly shorter than the disk, and $A$. dipterygia, from the seas of India, China and Japan, with the tail and disk of about the same length.

$$
\text { Astrape upterygia (Bloch and Schneder). (P1. iiia, fig. 6.) }
$$

A. dipterygia, Day, Famn. Brit. Ind., Fishes, p. f6, fig. I9.

Disk longer than broad, of approximately the same length as the tail, somewhat truncate in front. 'The pectoral fins well developed, especially posteriorly, thin 
and distinct from the trunk. Fyes about half as large as the spiracles, protuberant in life, separated by a concave interspace about half as long as their distance from the anterior border of the disk. Margins of spiracles smooth. Mouth surrounded posteriorly by a semicircular fold, about half as wide as its distance from the anterior border of the disk, provided with thick, tuberculate lips, which are discontinuous in the middle of the anterior border. Teeth occupying nearly the whole of the mandibular surface, with a broad, bluntly pointed transverse ridge. A bilobed, prong-like, vertical process on the roof of the month and a similar one on the floor. Nasal flap with a distinct median longitudinal groove and a median process on the free edge.

Colour.- Dorsal surface dull chocolate colour with a purplish tinge. Ventral surface, edge of disk and fins, a large oval spot on each side of the back some distance in front of the posterior margin of the pelvic fins, and a forwardly directed streak on each side of the anterior part of the tail, cream colour.

This species exhibits much the same variation as $N$ arcine timlei and $N$. brumea in respect to its fins. It has been taken by the "Golden Crown'" in considerable numbers off the Orissa coast and appears to be common all over the Bay in shallow water. It is not so common as $N$. timlei and $N$. brumea, however, and perhaps inhabits slightly deeper water.

I arge specimens measure $16 \mathrm{~cm}$. in total length and $9 \mathrm{~cm}$, across the disk.

Genus Bengalichthys, gen. nov.

Closely allied to Astrape, from which it is distinguished by its thick, fleshy disk, rudimentary pectoral fins, and degenerate eyes.

I think it well to separate a form represented by two individuals in the "Golden Crown " collection from Astrape as a distinct genus, in order to emphasize the peculiar manner in which this form has become adapted for a more or less sedentary existence. In several respects the adaptation is of a nature closely similar to that which has brought about the evolution of Benthobatis from Narcine, although the environment in which this evolution has taken place is not the same in the two cases. Benthobatis, as I have already pointed out, is a deep-sea form-it occurs at depths from about 400 to about 700 fathoms - and, like many deep-sea forms, has degenerate eyes. The disk, moreover, is thick and muscular and bears on the dorsal surface numerous little glandular pits; the pectoral fins are not clearly marked off from the body. In all of these points the species of Bengalichthys to be described immediately resembles Benthobatis, although it is not a deep-sea form, having been taken in only I5 fathoms. In two striking characters, however, it differs from Benthobatis, viz., in coloration and in the number of the dorsal fins. The former difference is probably due to its environment, the latter to its ancestry; in other words, the former is an adaptive character, the latter a morphological one. A character common among deep-sea fish of all kinds is a dark and uniform coloration of both the dorsal and the ventral surface, while among the rays of shallow water it is unusual for the ventral surface to be dark, although this is the case 
in a few species. The only known species of Benthobatis has a dark ventral surface, the only known species of Bengalichthys a pale ventral surface. The genera of the Torpedinidæ, on the other hand, fall naturally into several groups separated by the number (or absence) of their dorsal fins. Benthobatis belongs to one of these groups, Bengalichthys to another. There can be little doubt, therefore, that the two genera have not had the same ancestry but have become like one another owing to parallel or rather convergent lines of evolution. Although Bengalichthy's does not live in the clark abysses of the sea, we may suppose that its mode of life is very similar to that of Benthobatis. Neither can be a powerful swimmer, but both, judging from the manner in which the muscles of the disk are developed, must be powerful wrigglers and squirmers. It must be remembered in this connection that the flabbiness of the flesh (i.e., the muscles) of deep-sea fish which have been brought to the surface is mainly an artificial condition, ' not one that would be apparent if it were possible to examine the fish in their natural environment. Now, quite apart from the question of the depth at which a fish lives, it is quite clear that eyes may be inconvenient to an animal which wriggles about in the mud at the bottom of the sea, and I have little doubt that both the fish under discussion live in this way, perhaps actually burrowing into the mud, through which the movements of their disks assist them to make their way. Their mouths, like those of their nearest allies in both cases, are feebly developed and probably suctoria! in function. Neither they nor their allies can attack large organisms of any kind, and it is clear that their electric organs must be weapons of defence rather than offence. Perhaps both Benthobatis and Bengalichthys have become more perfectly adapted for obtaining their food by sucking it from the mud owing to the degeneracy of certain organs that are of no use for this particular purpose.

$$
\text { Bengalichthys impennis, sp. nov. (P1. iiia, fig. 7.) }
$$

Disk stout and muscular, pear-shaped, the broader end being in front; the anterior margin broadly convex; the length about the same as the maximum transverse diameter. Numerous white glandular pits are present on the dorsal surface, on which they are arranged in much the same way as on that of Benthobatis moresbyi. Pectoral fins consisting externally of a fringed ridge $2-3 \mathrm{~mm}$. broad near the edge of the dorsal surface of the posterior half of the disk.

Tail stout, longer than the disk; the caudal fins rounded posteriorly; the dorsal small, situated about half-way between the posterior border of the pelvic fins and the caudal. The pelvic fins distinct from the disk and apparently situated on the sides of the tail.

Colour. - Dorsal surface of disk and tail deep buff clouded with dark brown. Ventral surface, margin of disk and fins, a large oval spot on each side of the back in front of the root of the tail, a forwardly directed streak on each side of the tail, in front

1 The muscles of Torpedo mamorata. however, which is not a deep-sea fish, are much more flabby than those of any species of Narcine (except. Varcine mollis), Astrape or Bengalichlhys with which I am acquainted. 
of the dorsal fin and a backwardly directed streak on the base of the disk at either side, cream colour.

Eyes minute, deeply sunk, colourless, close to the spiracles, which have smooth edges. Mouth closely resembling that of Astrape dipterygia externally; the teeth with the triangular transverse ridge somewhat more pointed than in that species. I somewhat narrow, long rectangular process on the roof of the mouth, directed backwards rather than vertically downwards, and having its distal edge sinuous but not bilobed; a similar but smaller process on the floor of the mouth.

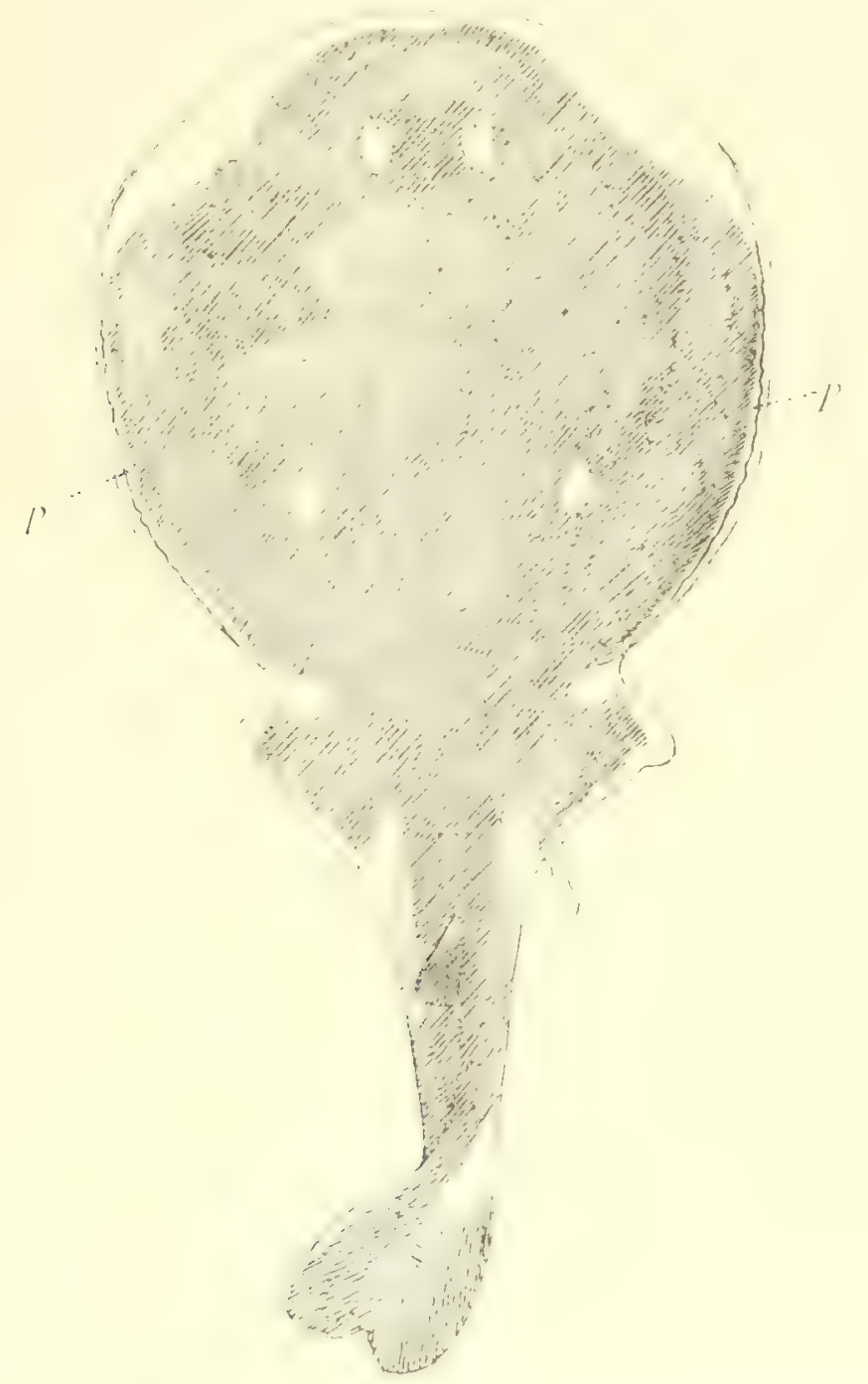

FIG. 0.-Bengalichthys impennis, nat. size: $p .=$ pectoral fin.

This species is represented by two specimens (a male and a female) taken by the "Golden Crown ' in about I 5 fathoms of water in Balasore Bay on the coast of Orissa in October, Igo8. The following measurements are taken from the specimens after preservation in spirit:-

Total length

Length of disk

$$
\begin{aligned}
& \text {. } \quad \ldots \quad \quad \ldots \quad I 75^{\circ} 0 \mathrm{~mm} \text {. I } 25^{\circ} \mathrm{O} \mathrm{mm} \text {. }
\end{aligned}
$$

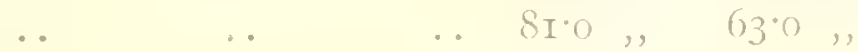


Length from anterior border of anus to anterior border of $\sigma^{\circ} q$ dist

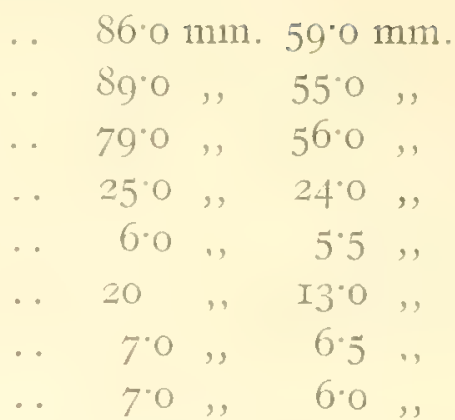

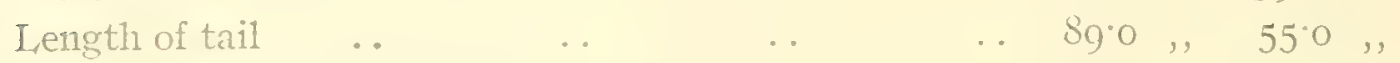

Maximum width of disk $\quad \ldots \quad \quad \quad \ldots \quad \quad \ldots 79^{\circ} 0$, , $56^{\circ} 0$,,

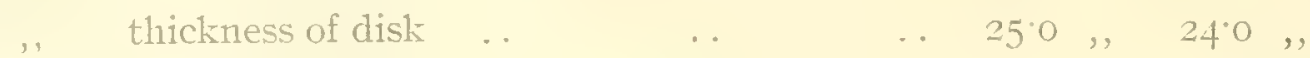

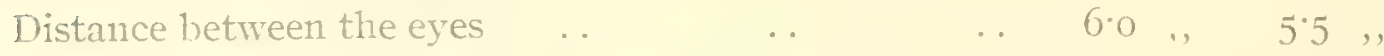
," from eyes to anterior border of disk $\quad . \quad 20 \quad$,. $23^{\circ} 0$,,

$\begin{array}{llllll}\text { Height of dorsal fin } & \ldots & \ldots & \ldots & 7^{\circ} 0, & 6.5, \\ \text { Length of dorsal fin } & \ldots & \ldots & \ldots & 7^{\circ} 0, & 6.0,\end{array}$

Owing to the strong muscles of the disk, it is liable to undergo great changes in shape; the two specimens I have examined exhibit this very clearly. The degeneracy of the pectoral fins causes the disk to terminate, when viewed from above, some little clistance in front of the anus.

The mouth, as in Astrape, is to some extent protrusible, but cannot be thrust out bodily as a tubular structure like that of $N$ arcine.

The number of the type $(s)$ in the Museum register is $F, \frac{2}{3} \underline{5} \overline{7}$.

\section{Family MTYLIOBATID死.}

Head distinct from disk, with a prominent snout or a pair of processes on the front of the head supported by two groups of cartilaginous jointed rays (cephalic fins) ; skull rectangular and box-like. Teeth flat, rectangular and pavement-like, large. Disk wide in proportion to its length. Tail long and thin, with a dorsal fin at its root, with or without a serrated spine.

Taking into consideration the great differences between the skull and teeth of the "Myliobatina", and the "Ceratopterina," I think it as well to follow Müller and Henle, and also Jordan (Guide to the Study of Fishes, rol. i, pp. 55I, 559, I905), in regarding them as distinct families, although I have not adopted the American name "Mobulicire" for the latter group.

The Myliobaticie, if this view be accepted, consist of the genera Rhinoptera, Iytiobutis and Aëtobatis, each of which is represented by at least two species in Indian seas. Of Rhinoptera I lave only seen the skeleton and teeth, and $\mathrm{I}$ do not, therefore, propose to discuss its Indian representatives. Of Myliobatis and Aëtobatis, however. the "Golden Crown "' has obtained large numbers of specimens, which have afforded invaluable material for the elucidation of several doubtful points. The three genera may be distinguished by the following characters:-

I. Head provided with a pair of distinct rayed appendages (cephalic fins) on the ventral surface. Teeth tesselated, in five or more series, the central one being the broadest and the others decreasing in breadth from within out-

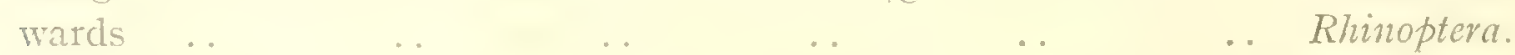

II. Cephalic fins encased in muscle and skin to form a single more or less conical snont. 
A. Teeth in a single broad series .

.. Aëtobatis.

B. Teeth in several series, of which the lateral ones are much narrower than the central one Myliobatis.

\section{Genus Myriobatis, Cuvier.}

This genus is sufficiently defined in the description of the family and the generic key printed above. At least two species occur in Indian seas and have been taken by the "Golden Crown," namely, M. nicuhofii and M. maculata. A new variety of the former is described below.

\section{Myliobatis nieuhofii (Bloch and Schneider).}

Size moderately small (adults $+2-6+\mathrm{cm}$. across the disk, young about $\mathrm{I}_{5} \mathrm{~cm}$.).

Disk considerably more than twice as long as the distance between the mouth and the

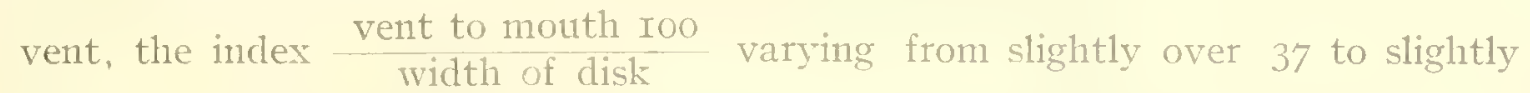
over +3 , but usually being between to and $4 \mathrm{I}$. The pectoral fins acutely pointed, their anterior margin nearly straight, their posterior nargin broadly concave. Snout (measured from anterior borders of skull) $-\frac{1}{13}$ to $-\frac{1}{0}$ as long as the distance between the mouth and vent and from $\frac{1}{2}$ to $\frac{5}{7}$ as 1 ong as broad at the base, not sharply pointed.

Tait much longer than disk, without a serrated spine. The dorsal fin arises nearer the base of the pelvic fins than their distal margin and does not reach, or barely reaches, the level of that margin posteriorly.

Colour. - The fresh fish has the dorsal surface of a bright greenish golden colour with five broad cross-bars of a darker and more livid shade across the disk, and two across the head. Not only do these marlings disappear in spirit or even in ice, but they are very superficial, and any rotgh handling causes the tissues which contain them to be rubbed away. The ordinary spirit specimen of the adult has the dorsal surface of a dark slate-grey. The cross-bars are more conspicuous in the young and remain visible longer in spirit. The ventral surface is white.

Skin soft and at first sight naked. The back, however, is more or less completely covered with minute, star-shaped denticles buried in the skin and sometimes extending on to the ventral surface. They can usually be felt by drawing the tip of the finger across the back of the disk.

Mouth nearly straight. The teeth truncate in front and not projecting from the jaw. Their proportions are very variable and the number of series of smaller teeth at the sides of the broad central one is not always the same on the two sides of one jaw. The nasal flap is always straight.

As this is one of the most variable species with which I am acquainted, I have examined and measured a large number of specimens with the greatest care. The first result of this examination was to prove that two forms of the species existed side by side, one with the area immediately above the orbits smooth, the other with a 
definite ridge running along the upper limit of each orbit and produced in front into a short, horn-like structure measuring in adult specimens from $2-4 \mathrm{~mm}$. in length. I cannot detect any other peculiarity that seems to be correlated with the presence of this horn, and Capt. I loyd tells me that horned and homless individuals are taken together in the same haul of the trawl. I therefore propose to name the horned form Myliobatis nienhofi, var. comifera, var. nov. (P1. ii, fig. 4.)

The presence or absence of horns has been considered a specific character in other species of the genus, but Jordan and Snyder ${ }^{2}$ suggest that these structures are deciduous in a Japanese species ( $M$. tobijei). This is not the case as regards the Indian species. In an embryo in the collection of the Indian Nuseum which measures I $5 \mathrm{~mm}$. across the disk, the horns are already apparent, but they are absent from several other embryos of about the same size; unfortunately I have not been able to obtain a gravid female of the variety comitera. In some half-grown and old specimens they are absent, in others present. In some horned individuals the denticles on the hack are rather more strongly developed than is usually the case in the typical form.

The hornless form is much commoner than the lorned one, but the latter is not rare. Both have been taken in large numbers off the coasts of Orissa, Chittagong and Burma, and less abundantly off the mouth of the Ganges. Apparently the species prefers a rocky bottom, on which it is possible that it finds more food in the way of molluses. Its diet is not confined to molluses, however, as both fish and prawns have been found in its stomach. These are swallowed whole and are not crushed by the teeth.

The following measurements are interesting as illustrating the variation that occurs as regards the teeth in this species :-

\begin{tabular}{|c|c|c|c|c|c|c|c|c|}
\hline \multirow{2}{*}{ No. } & \multirow{2}{*}{\multicolumn{2}{|c|}{$\begin{array}{c}\text { Breadth of teeth of upper } \\
\text { jaw. }\end{array}$}} & \multicolumn{2}{|c|}{ Number of small teeth. } & \multicolumn{2}{|c|}{ Measurements } & \multirow{2}{*}{\multicolumn{2}{|c|}{ of central tooth. }} \\
\hline & & & Left. & Right. & Brea & ith. & & \\
\hline I & $20^{\circ} 01$ & $111 \mathrm{~m}$. & 3 & 3 & I 355 & mu11. & $2 \cdot 2511$ & 111111. \\
\hline 2 & $x()^{\circ} 0$ &, & $\therefore$ & 3 & II'O &, & $2: 25$ & ,. \\
\hline 3 & I0) 5 & , & 3 & 3 & $\mathrm{I} 20$ & $"$ & $I \cdot 75$ &, \\
\hline 4 & $I 7^{\circ}$ & , & $3-4$ & $2-3$ & II'O & & $I^{*} 5$ &, \\
\hline $5 *$ & $I 0.5$ & , & 2 & 3 & $12 \cdot 0$ & 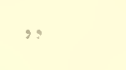 & $2 \cdot 25$ & , \\
\hline 6) & 120 & , & 3 & 3 & $7 \cdot 5$ & ". & $I \cdot 25$ &,$"$ \\
\hline 7 & 230 & , & 3 & 2 & II 0 & $"$, & $3^{\circ} 0$ &, \\
\hline 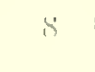 & I广・ & , & 3 & 3 & $10 \cdot 5$ &, & $I \cdot O$ & ., \\
\hline 9 & $1 f^{\circ}(0)$ & s, & $\therefore$ & 3 & 10.5 & ", & $2 \cdot 25$ & , \\
\hline 10 & 270 & ,. & 3 & 3 & $20^{\circ} 0$ & , & $2 \cdot 25$ & ,. \\
\hline
\end{tabular}




\begin{tabular}{|c|c|c|c|c|c|}
\hline \multirow{2}{*}{ No. } & \multirow{2}{*}{$\begin{array}{c}\text { Breadth of tecth of upper } \\
\text { jaw. }\end{array}$} & \multicolumn{2}{|c|}{ Number of small teeth. } & \multicolumn{2}{|c|}{ Measurements of central tooth } \\
\hline & & I.eft. & Right. & Breadth. & Length. \\
\hline II* & I9.5 $\mathrm{mm}$. & 3 & 3 & $12.5 \mathrm{~mm}$. & I'5 $\mathrm{mm}$. \\
\hline$I_{2} *$ & I $8 \cdot 0$ & + & 3 & $1 I \cdot 2.5$, & 200 \\
\hline 13 & $2 \mathrm{I} \cdot \mathrm{O}$ & 2 & 2 & $I T 0 \quad$, & $3.0 \quad$, \\
\hline If & 20.0 & 3 & 3 & I6.0 , , & I.75 , \\
\hline
\end{tabular}

The numbers marked with a * refer to the specimens of the variety comifora, the remainder to those of the typical form of the species.

The measurements printed above show how little reliance can be placed on exact relative proportions in diagnosing the species of the Myliobatidre. Palrontologists in particular have attempted to separate the species of Myliobatis and even Aêtobatis by examining the relative length and breadth of the teeth. Of one species only (. $\mathrm{H}$. nicuhofii) have I been able to examine a series of adult teeth. The measurements speak for themselves. So far as the other Indian representatives of the family are concerned, most of the jaws I have examined have been those of immature specimens. So far as evidence founded on such specimens goes, however, there is every indication that variation is no less wide in the allies of $M$. nicuhofi than it is in that species.

\section{Myliobatis maculate, Gray and Hardwick.}

This species may be distinguished from.$M$. nimhofi by (I) its large size, (2) its coloration, (3) the arrangement and nature of its denticles, and (4) the shape of the snout.

(I) The size of the adult appears to be nearly twice that of the adult of,$U$. nieuhofii.

(2) The young (which are often as large as the adult of the other species) have the dorsal surface of a deep bronze or greenish grey colour with rather large bluish spots scattered profusely on the posterior part of the lisk. 'These spots are a sign of immaturity, although exactly the contrary is the case as regards Aetobutis punctata. The adult . M. muculut has the back of a minform dark slate-grey.

(3) The most conspicuous feature of the scaling in this species is a longitudinal band, consisting of several closely adjacent rows, of flat denticles situated on the mid-line of the scapular region. The small star-shaped denticles in the skin of the back are also as a rule better developed in.$M$. muculut than in $M$. nienhofii.

(4) The snout in.$M$. maculatu appears to be decidenly more prominent than it is in M. nieuhofii, but this is largely due to the fact that its sides form a more acute angle.

I have seen comparatively few fresh specmens of this species, and only one that appeared to be an adult. It was taken by the "Golden Crown" oft the Orissa coast, 
but unfortunately only the head and tail were preserved. The teeth of the upper jaw measure $28 \mathrm{~mm}$. in transverse diameter, but there is some evidence to show that the mouth is relatively smaller in this species than it is in M. nieuhofii. Judging from the analogy of the few young examples of $M$. maculata I have examined in detail, the adult specimen (a female) must have measured about $78 \mathrm{~cm}$. across the disk, but in making this statement I take it for granted that there is little difference in proportions between the adult and the young of the species.

I have not seen any specimen of $M$. maculata with a superciliary horn, ${ }^{1}$ or of either of the Indian species of the genus with a caudal spine.

\section{Genus Aётоватіs, Müller and Henle.}

This genus is separated from Myliobatis by the character of the teeth. In all the specimens I have seen those of the lower jaw project from the mouth in the form of a plate with parallel sides and an obtusely pointed tip. The nasal flap in these specimens is deeply emarginate. Day says that the tip of the lower tooth-band is sometimes broken off and that the free edge of the nasal flap is then straight as it is in Myliobatis (Fishes of India, ii, p. 7+3), but it is clear from specimens named by him that he confused Aëtobatis guttata with Mvliobatis maculata in some cases.

Great confusion still exists as regards the species of Aëtobatis. Most recent authors, following Günther (Cat. Fishes, viii, p. 492), recognize only one species, namely $A$. narinuri; but at least two distinct forms occur in Indian seas and it is clear that neither is the same as the American and African species.

As regards the last point, there is of course no positive proof that there are not two forms (or even more) in the Atlantic Ocean (one or more of which may be rare), as there are in the Bay of Bengal. But figures published by Duméril (Arch. Mus., x, pl. 20, Paris, r86r) and by Jordan and Eiverman (Bull. U. S. Nat. Muts., No. 47, vol. iv, pls. 37 and 38, Ig0o) represent a species which differs in at least two charactersnamely, the shape of the snout and coloration-from any Indian specimen I have seen. Duméril shows, moreover, that the adult of the form he called Aettobatis latirostris, the type specimens of which came from the mouth of the Gaboon, does not differ materially from the young as regards coloration.

Jordan, who examined specimens from Florida (Guide to the Study of Fishes, vol. i, fig. 349, I905) as well as from the West Indies and Mazatlan (Bull. U. S. Nat. Muts., No. 47 , vol. iv, p. 2753) and found no difference between them, decided with Everman that "this species" [i.e., Aëtobatis laticeps, Gill] " is probably not different from A. narinari.....

There is little doubt that Aetohatis laticcps, Gill, is a synonym of A. latirostris, I)uméril, while Euprasen (Kong. Svens. Vet. Akad. Ny't Handl., xi, p. 2I8, I790) says regarding the species he described as Raju narinari:- "Habitat in India occidentali, juxta Insulas Caribæas, in portu Carenage Insulæ St. Bartholemei."' The figure

'In a half-grown specinen taken in a seine-net on the beach at Puri in March there is a distinct but low rounded eminence on either side just in front of the eye. 
(p1. $\mathrm{x}$ ) accompanying the paper from which this quotation is taken is by no means accurate but shows the white spots extending as far forwards as the spiracles and, moreover, represents the snout as exceedingly short.

It seems indisputable, therefore, that the name Aetobatis narmari belongs to the American form, which there is every reason to think was redescribed by Dumeril as A. latirostris and by Gill as A.laticeps. For the common Indian form, on the other hand, the name A. guttata (Shaw)' is available. 'There is, however, a second Indian form, much rarer than the first in the Bay of Bengal, which, in Mr. Boulenger's opinion, is identical with Bloch and Schneider's Raja flagellum, and corresponds very closely with the description of that species given by Müller and Henle (" Plagiostomen,"' p. I80). I therefore recognize the following species in the genus: Aetobatis narinari (Euprasen), A. guttata (Shav) and A. Aagellum (Bloch and Schneider). Possibly others exist.
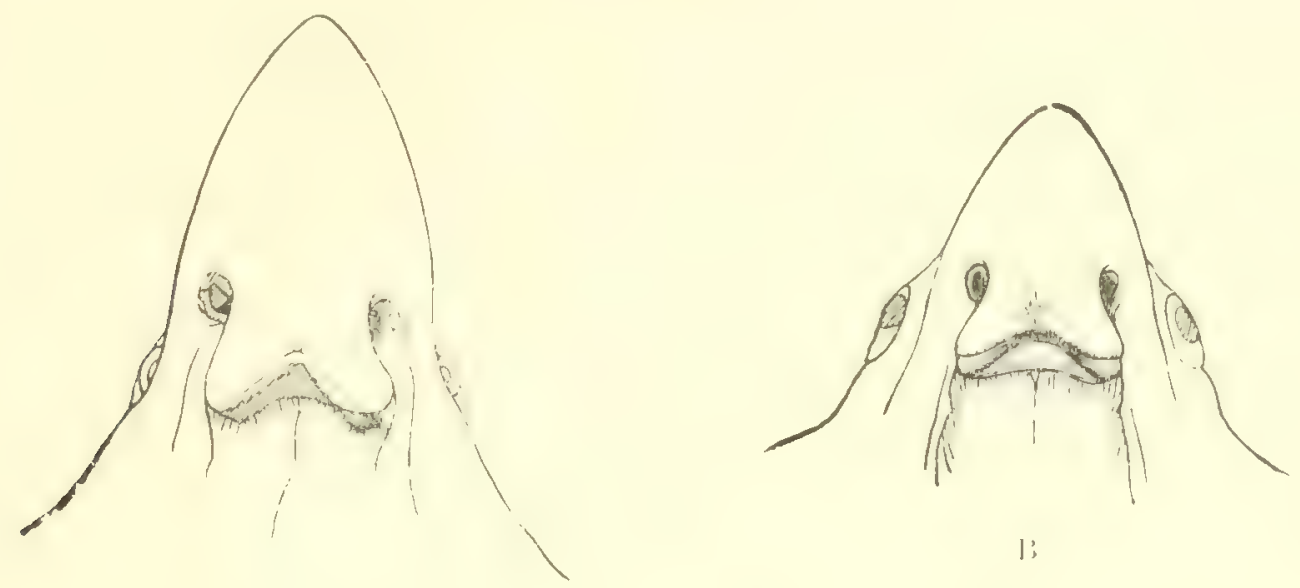

l;

1.

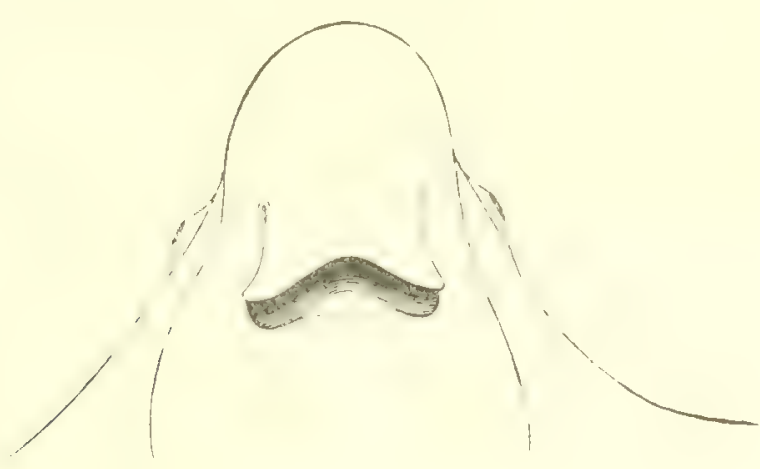

C.

FIG. Io.-Heads of Aztobatis: A, A. Alagellum; B, A. guttata: C, A. narinari (enlarged from Jordan and Everman's figure).

'See Shaw's General Zoology or Systematic Natural History, vol. v, part ii, p. 285 (I8o4). Shaw did not distinguish the Atlantic from the Oriental species, and his figure of "Raja guttata " is quite indefinite: but as he clearly meant to include the common Indian species in his description, his name tnay stand. 
Granted that there are three species of Actobatis,' it is necessary to inquire how they can be distinguished from one another. If only dried specimens are examined, the diagnosis is very difficult, if not impossible, and as regards the Atlantic form I an wholly dependent on published figures and descriptions. The following table gives the differences that are apparent from careful examination on the one hand of these figures and descriptions and on the other of fresh specimens of the Indian forms :-

Character.

1. guttate.
A. narinari.

1. flagelium.
Snont

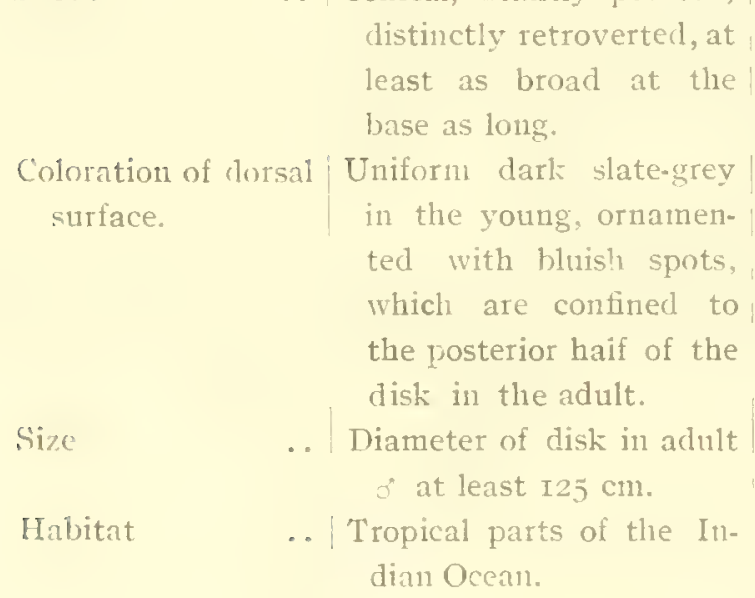

Rounded at the tip, much broader at the base than long, straight (?).

The whole disk including the head covered with whitish spots both in the young and the aduit.
Pointed, straight, much longer than broad at the base.

Disk in the adult of a uniform dark greenish bronze colour, without spots.

Diameter of disk ${ }^{2}$ in adult 1 Diameter of disk in adult 5 I cm. $\quad$ o $47 \mathrm{~cm}$.

Both sides of the Atlantic ; / Red Sea, Bay of Bengal. Gulf of Guinea, American coast as far north as Virginia, West Indies.

\section{Aëtobatis guttata (Shaw).}

Size considerable (adult male $125 \mathrm{~cm}$. across the disk).

Disk shaped much as in Myliobutis nienhofi, but quite naked.

Tail much longer than disk, always hearing at least one serrated spine, often two, sometimes three.

Colom.-Dorsal surface of young of a uniform dark slate-grey, without a trace of spots. 'The spots on the disk of the adult are confined to the posterior half. They are of a bluish tint and are edged with a faint greenish halo. Their size varies considerably. The ground colour of the back of the adult has, in fresh specimens, a beautiful greenish refulgence.

This is a very common species in the Bay of Bengal and, like Myliobatis nicuhofi, is evidently gregarious and probably also migratory in habits, at least while it is young.

I I am much indebted to Messrs. Boulenger and Tate Regan for examining a photograph and drawings of Indian specimens of tetobatis and for comparing them with the original figures of 1 . Ahagellum, which I have not been able to consult.

Gilbert and Statks (Mcm. Calif. Acad. Sci., iv, P. IS, I904) give the width of the disk of a specimen from Panama Bay as $6.5 \mathrm{~mm}$. but do not state its sex. 
Adults are seldom caught even in the trawl and may be solitary. I have only seen one large specimen, which was taken off the Orissa coast. Its measurements are given below.

$$
\text { Aëtobatis Hagellum (Bloch and Schneider). (P1. iv, fig. 5.) }
$$

A. flagellum, Mïller and. Henle, Syst. Beschr. d. Plag., p. I80.

The differences between this species and the preceding one are noted in the table showing the specific characters of the three species of the genus. I have not been able to discover any other points that call for notice. Perhaps the tail is longer in proportion to the body; but in most large specimens of Myliobatidre the tail is mutilated.

Müller and Henle's description is accurate, as is always the case in the work of these authors, whose monograph, in spite of the fact that it contains a certain number of specific descriptions that refer actually to the young stages of forms described as distinct, is still by far the most reliable guide as regards the identification of the Oriental Batoidei.

A. Alagellum is apparently rare in the northern part of the Bay of Bengal. I have only seen two examples, a male taken by the "Golden Crown' off the Orissa coast in November, and a severed head brought from the mouth of the Chilka Iake on the same coast in December by Dr. Jenkins.

\section{Measurements of Indian species of Myliobatis and Aëtobatis.}

\begin{tabular}{|c|c|c|c|c|c|c|c|c|c|c|c|c|c|c|c|c|}
\hline & Spec & cies. & & & Sex. & $\begin{array}{r}\text { Acr } \\
\text { dis }\end{array}$ & & $\begin{array}{l}\text { Mout } \\
\text { ver }\end{array}$ & $\begin{array}{l}\text { hi to } \\
\text { it. }\end{array}$ & Nasal fl & lap. & $\begin{array}{l}\text { Bre } \\
\text { of } s 1 \\
\text { at } b\end{array}$ & $\begin{array}{c}\text { adth } \\
\text { hout } \\
\text { gase. }\end{array}$ & $\begin{array}{l}\text { Lengt } \\
\text { snot }\end{array}$ & $\begin{array}{l}\text { th of } \\
\text { it. }\end{array}$ & Tail. \\
\hline & batis ni & ienho & & . & q & $470+$ & $\mathrm{mm}$ & Igo & mil. & $36 \times 2 I 1$ & $\mathrm{~nm}$. & 5 I 1 & $\mathrm{~nm}$. & 231 & $\mathrm{~mm}$. & Broken. \\
\hline & &, & &. .1 & व & 354 & , & I 45 & , & $130 \times I_{7}$ & , & | 37 & , & 25 & , & $563 \mathrm{~mm}$. \\
\hline & & , & & & 9 & 600 & , & 245 & , & $4.5 \times 2.5$ & ", & 55 & , & $4^{\circ}$ & ", & Broken. \\
\hline & & & & & & 540 & ", & 220 & ," & $40 \times 20$ & , & 50 & , & 32 & & \\
\hline & & $"$ & & .. 1 & 4 & 360 & , & $I_{40}$ & , & $26 \times 17$ & & $4^{2}$ & ," & 25 & .. & $505 \mathrm{~mm}$. \\
\hline & & , & & . & $\varepsilon$ & 510 & . & 205 & , & $35 \times \mathrm{I} 7$ & & 50 & , & 35 & & Broken. \\
\hline & & , & & . & 운 & 340 & , & 133 & , & $30 \times 15$ & ,. & 42 & , & 25 & & \\
\hline & & , & & . I & त & 640 & ," & 260 & & $45 \times 23$ & , & 56 & ,. & 40 & . & $555 \mathrm{~mm}$. \\
\hline & $\begin{array}{l}\text { iellhofii } \\
\text { a. }\end{array}$ & var. & corm & & 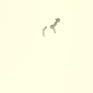 & 420 & ," & 165 & & $135 \times 20$ & , & +5 & & 26 & ," & 560 \\
\hline ", & $"$ & ", & ", & $\cdots$ & द & 445 & ," & $I 68$ & , & $35 \times 20$ & , & 45 & ," & 27 & $"$ & 620 \\
\hline " & ", & , & $"$, & & 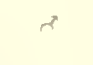 & 390 & , & I35 & & $25 \times 20$ & , & fo & ," & $2 Y$ & ," & $685 \quad$. \\
\hline "? & , & ", & $"$. & & त & 416 & ," & I53 & , & $32 \times 17$ & ," & $4^{2}$ & ," & 20 & ," & Gin \\
\hline , & , & ", & , & . 1 & 8 & $44 I$ & ," & I 70 & ," & $30 \times 2 I$ & ," & 47 & :" & 30 & ," & 840 \\
\hline
\end{tabular}


Measurements of Indian species of Myliobatis and Aëtobatis-Contd.

$\begin{array}{cccc}\text { Species. } & \text { Across } \\ \text { disk. } & \begin{array}{c}\text { Iouth to } 1 \\ \text { vent. }\end{array} & \text { Nasal flap. } \begin{array}{c}\text { Beadth } \\ \text { of snout } \\ \text { at base. }\end{array} & \begin{array}{c}\text { I, ength of } \\ \text { snout. }\end{array}\end{array} \mid$ Tail.

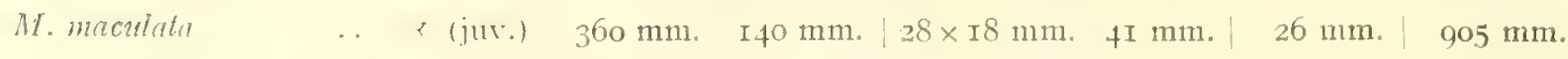

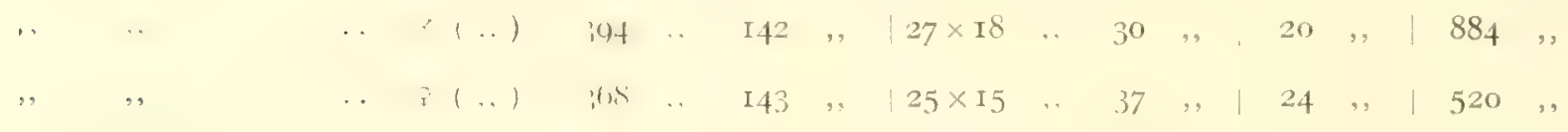

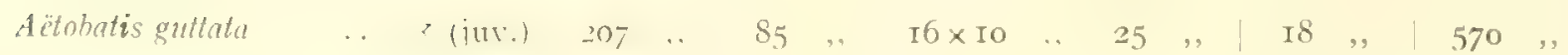

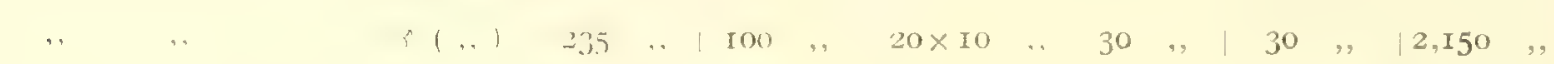

,

A. Hagellum

470

$205,, \quad 38 \times 22$

$68,, \quad 985$,

In a future report on the Selachians of the "Golden Crown," the distribution of the Indian Elasmobranchs will be discussed. As Capt. I,loyd ' has recently made use of all the information at present available in India regarding the Ceratopteridæ, it is unnecessary for me to discuss the species of that family, especially as no specimens have been taken by the "Golden Crown." I may say, however, that an examination of the specimens in the Indian and Madras Museums fully confirms Lloyd's remarks as to the peculiarities of the Ceratopterid skull.

$$
\text { 'Rec. Ind. Mus., ii, P. I75 (I908). }
$$




\section{APPIENDIX.}

\section{ANALYSIS OF THE OILS PRODUCED BY CERTAIN INDIAN RAYS AND OTHER AQUATIC VERTEBRATES. \\ By D. Hooper, F.C.S., Industrial Section, Indian Musenm.}

Among the specimens of fish captured by the "Golden Crown "' and handed over to the Indian Museum for determination have been several species which yield large quantities of oil. The collection and use of marine animal oils in some parts of the world constitute important industries, but in India these fats are very rarely utilised, and their chemical composition and properties have never been studied. Whale and seal oils are occasionally imported for leather dressing and other purposes, and it does not appear that any serious attempt has been made to exploit the oils of Indian fish.

The first oil examined was that of the Gangetic Dolphin (Platanista gangetica). This animal is called susu, sehu and sisur, and the oil is locally used as an embrocation for rheumatism and as an illuminating agent. The oil is yellowish-brown becoming reddish-brown on keeping, has a faint fishy smell, and deposits no solid fats at the winter temperature of Calcutta ( $8-22^{\circ} \mathrm{C}$.).

The following constants were obtained :-

\begin{tabular}{|c|c|c|c|}
\hline Specific gravity at $15^{\circ} \mathrm{C}$. & & . & $02 \mathrm{I}$ \\
\hline Acid value $\quad \ldots$ & . & . & $2 I \cdot 36$ \\
\hline Saponification value & & . & . $\operatorname{Ig} 8 \cdot 8$ \\
\hline Iodine value $\quad$. & & . & .. $106 \cdot 0$ \\
\hline Reichert-Meissl value & . & . & $7 \mathrm{I}$ \\
\hline Fatty acids, per cent. & . & . & $9+0$ \\
\hline Melting point of & . & . & $255^{\circ} \mathrm{C}$ \\
\hline Acid value of & . & . & . $205^{\circ} \mathrm{O}$ \\
\hline Iodine value of & . & . & $\ldots \quad$ II6.5 \\
\hline
\end{tabular}

Although it is allied to the sperm whale, the oil of this animal contained no spermaceti. There is a lair amount of free fatty acids, but there is only a small proportion of the more volatile fatty acids. The solid fatty acid, calculated as palmitic acid, amounted to about I6 per cent. Such an oil would be of value for currying purposes, for burning and for lubricating fine machinery. The other oils examined were those of the livers of certain large fish brought from the Bay of Bengal, and identified by Dr. Annandale. The livers were from the following species :-

I. White Sting-Ray (Trygon microps).

2. Common Saw-Fish (Pristis perottetii).

3. Spotted Shark (Stegostoma tigrimum).

4. Shark Ray (Rhamphobatis ancylostomus). 
The livers of these animals were of an enormous size; that of the Sting-Ray weighing $89 \frac{1}{2}$ pounds and that of the Saw-Fish IO $2 \frac{3}{4}$ pounds. These livers were very rich in oil ; that of the Sting-Ray afforded $7 I^{\circ} 6$ parts of oil, $17^{\circ} 7$ parts of water and $10^{\circ} 7$ parts of hepatic tissue in Ioo parts. The hepatic tissue contained over 5 per cent. of nitrogen and would form a valuable manure. All the oils deposited varying amounts of white fats, chiefly palmitin, at the cold weather temperatures. When freshly expressed the oil has a not unpleasant odour, similar to cod-liver oil, and a colour varying from light yellow to reddish-yellow.

The following constants were obtained :-

\begin{tabular}{|c|c|c|c|c|c|}
\hline Specific gravity at $50^{\circ}$ & C. & $\begin{array}{cc} & \text { I. } \\
\ldots \quad & 9 I_{4}\end{array}$ & $\begin{array}{l}2 . \\
900\end{array}$ & $\begin{array}{l}3 . \\
9 \text { IO }\end{array}$ & $\begin{array}{l}4 . \\
909\end{array}$ \\
\hline Melting point & & $\ldots 22^{\circ} \mathrm{C}$ & $27^{\circ}$ & $26.5^{\circ}$ & $255^{\circ}$ \\
\hline Acid value & . & .. 98 & $I \cdot O$ & $I \cdot I 6$ & $I \cdot 13$ \\
\hline Saponification value & . & . I $94^{\circ} \mathrm{O}$ & $I 87^{\circ} \mathrm{I}$ & $185^{\circ}+$ & I $87^{\circ} 4$ \\
\hline Iodine value & . & $\ldots 1247$ & $92 \cdot 9$ & $I 23^{\circ} 2$ & II $8 \cdot 5$ \\
\hline Reichert-Meiss1 & . & .. $\quad 26$ & $\cdot 28$ & $\cdot 2 I$ & $\cdot 23$ \\
\hline Fatty acids, per cent. & . & . $93 \cdot 2$ & 947 & $94^{\circ} 2$ & $94^{\circ} 6$ \\
\hline Melting point of & . & . $37^{\circ} 5^{\circ} \mathrm{C}$. & $39^{\circ}$ & $39^{\circ}$ & $39^{\circ}$ \\
\hline Acid value of & . & .2034 & $192 \cdot 2$ & I 89.9 & $\mathrm{IgO}_{4}$ \\
\hline
\end{tabular}

All these oils contained a cholesterol affording a rose-red or purplish-red colour with sulphuric acid. The slight acidity of these oils is much in their favour should they be employed for edible purposes. According to Hosmann the presence of free acids is characteristic of fresh cod-liver oil. Comparatively neutral oils such as these would be much more suitable for medicinal purposes. The large quantity of solid fats would render these oils useful for soap manufacture, while the liquid oil, separated from the palmitin, would be serviceable for leather dressing, lighting and lrubicating purposes.

The livers of various fish have not the same uniform composition as the above.

The small skate known as Tryoon gerrardii in a fresh state possessed a liver weighing only $37^{\circ} 5$ grams. This was composed as follows in one hundred parts :-

$\begin{array}{llllll}\text { Water } & \ldots & \ldots & \ldots & \ldots & 56 \cdot 5 \\ \text { Oil } & \ldots & \ldots & \ldots & \ldots & 28 \cdot 3 \\ \text { Tissue } & \ldots & \ldots & \ldots & \ldots & 15 \cdot 2\end{array}$

The hepatic tissue contained II 48 per cent. of nitrogen, an amount equal to that found in dry blood. 



\section{EXPLANA'TION OF PLATE I.}

FIG. I. - Photograph of a female specimen of the typical form of Trygon marnak which measured $5 \mathrm{ft} .3$ in. across the disk.

,. 2.-Photograph of a female specimen of T. uamak var. variegatus which measured about $5 \mathrm{ft}$. across the disk.

, 3.-Photograph of the type specimen (\&) of Trygon favus. This specimen measured $+\mathrm{ft}$. + in. across the disk. 

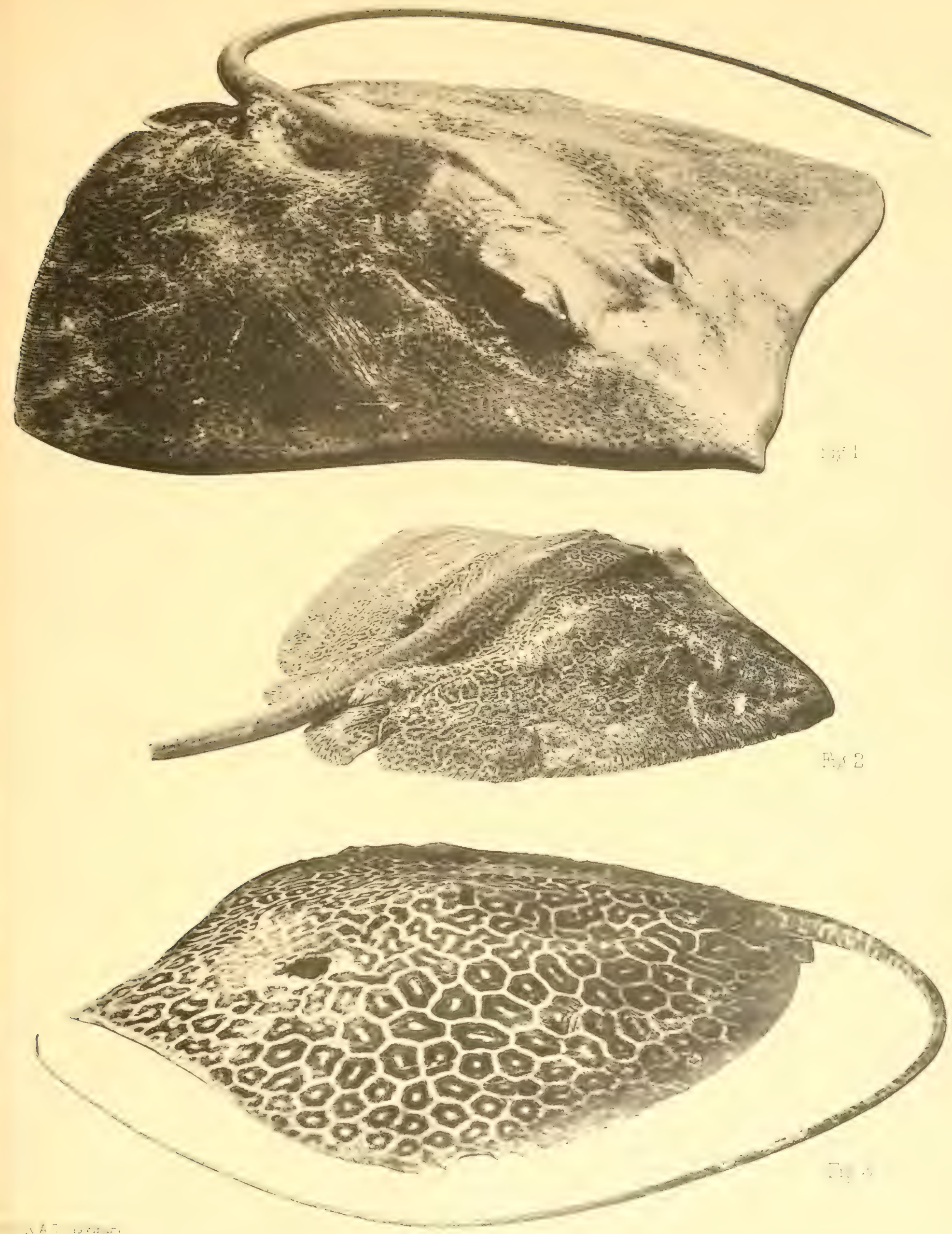




\section{EXPLANATION OF PLATE II.}

FIG. I. - Trygon mamak var. variegatus (adult female). Scale about $\frac{1}{15}$.

, Ia.-Trygon narnak (young). Scale $\frac{1}{4}$.

,, 2.-Trygon gerrardii (adult female). Scale $\frac{1}{6}$.

, 3.-Denticles on upper surface of tail of Trygon microps (nat. size).

, 3a.-Denticles on centre of back of same species, $\times 2$.

.. 4.-Head of Myliobatis nieuhofii var. comifera (nat. size).

.. $4 a$.-Denticles on back of same species, much enlarged. 


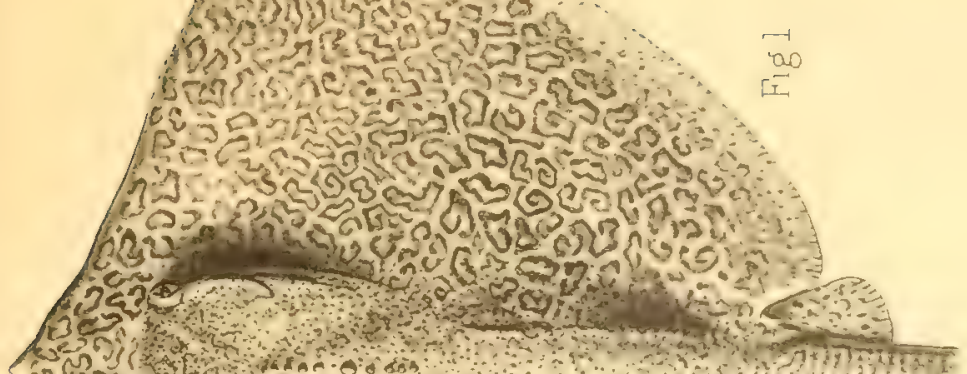

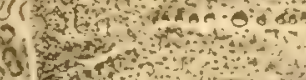

490
30

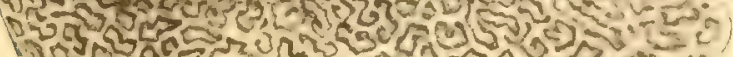

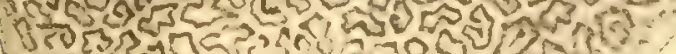

151

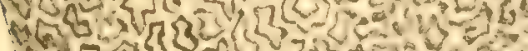

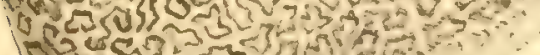

Tus

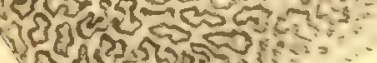

n
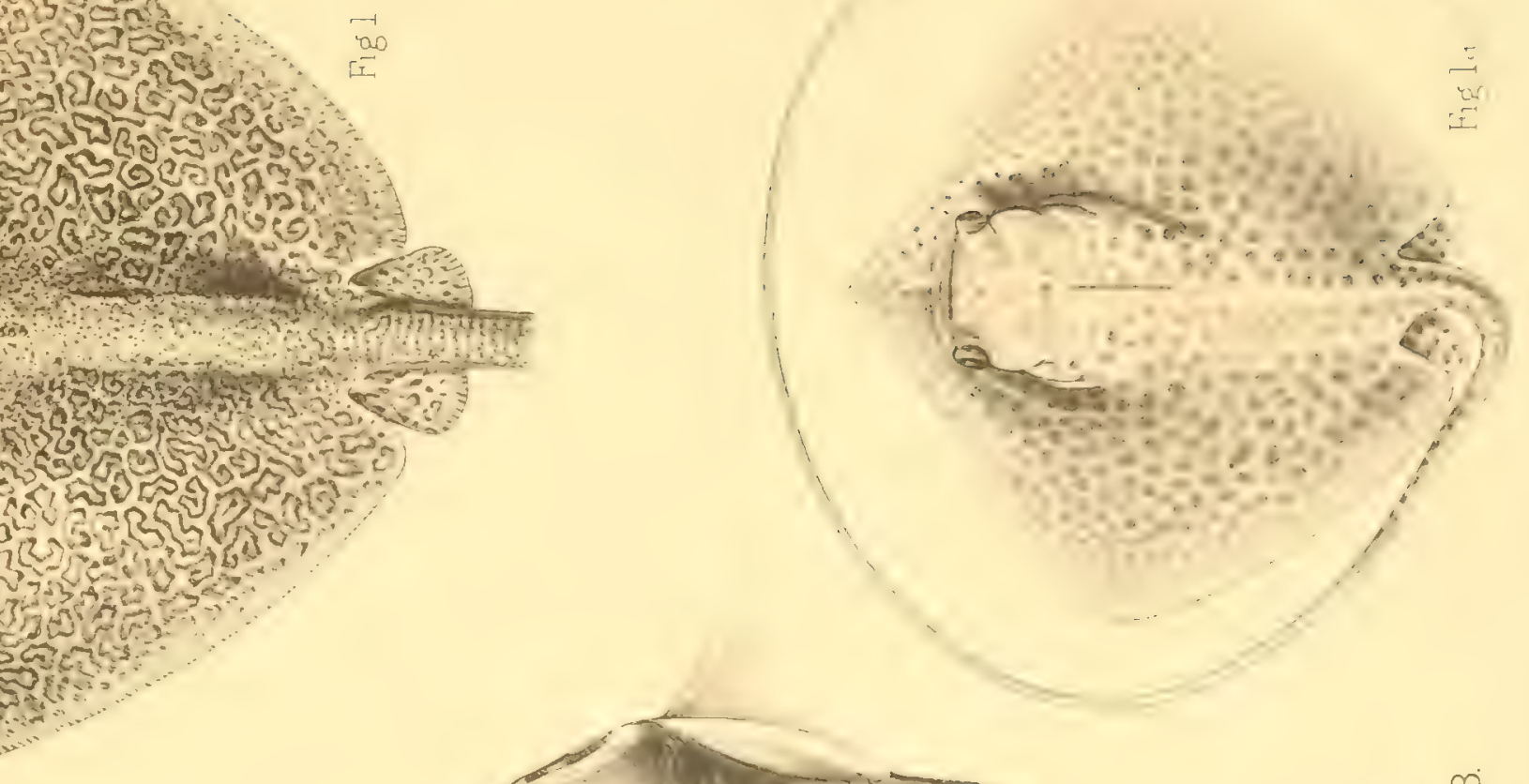

3

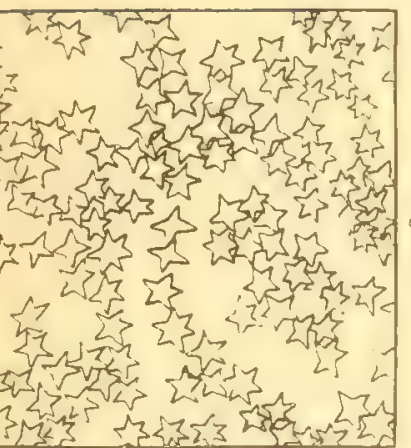
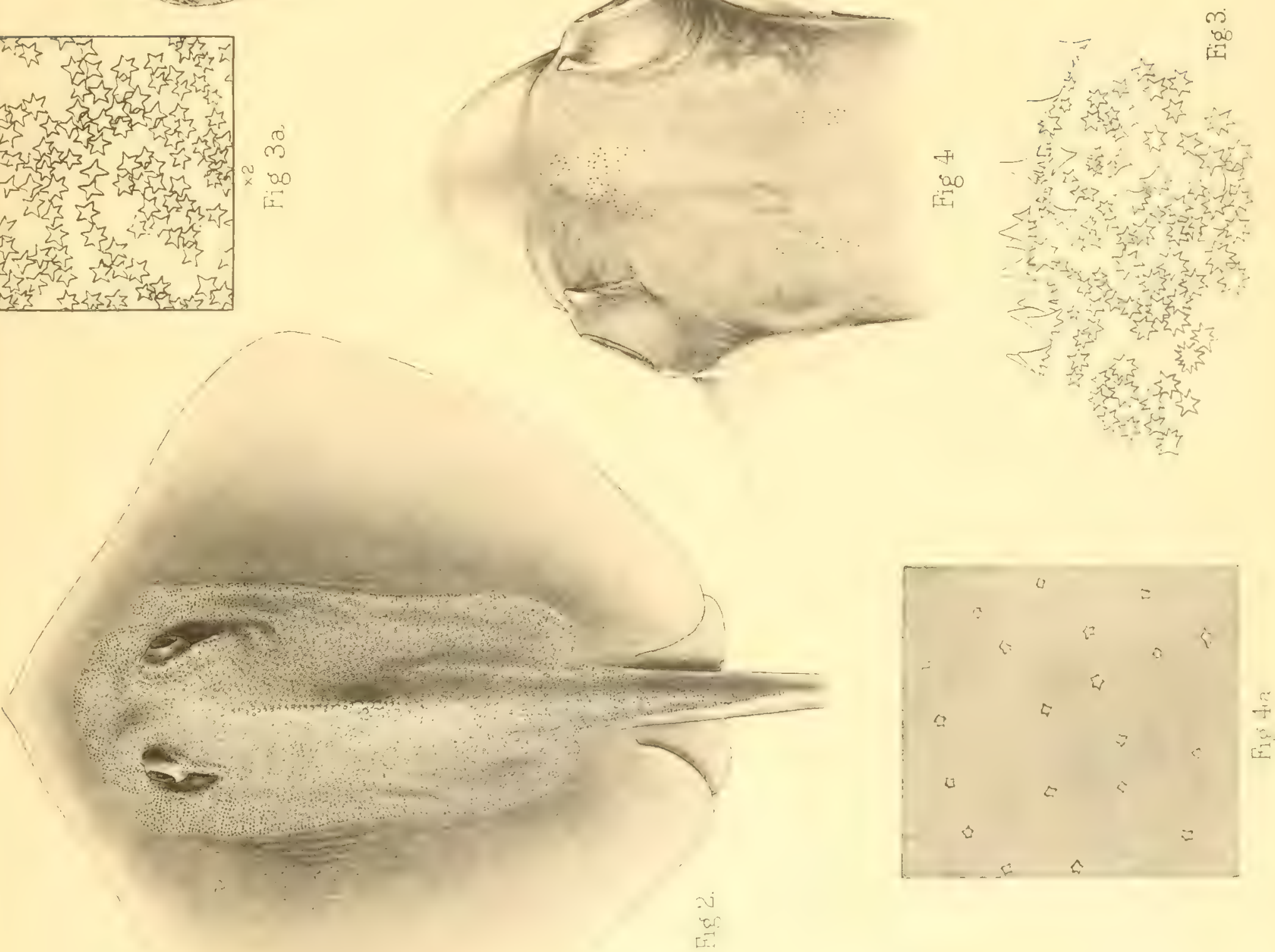


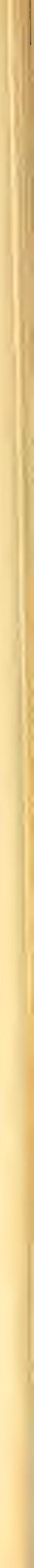





\section{EXPIANATION OF PLATE III.}

\section{MOUTHS OF INDIAN TRYGONIDE.}

IIIG. I. - Internal view of mouth of Trygon microps (much reduced).

\begin{tabular}{|c|c|c|c|}
\hline $1,2$. & , & , & ,, T. uarnak (much reduced). \\
\hline , 3 & .. & ., & , Hypolophus sephen (much reduced). \\
\hline t. & . & . & "Trygon kuhlii. \\
\hline 5 & , & , , & ,, ,, imbricata or walga. \\
\hline 6. & $\cdots$ & & gorrardii. \\
\hline 7. & . & , & , , , zugei. \\
\hline S. & $\because$ & . & ,' Urogymmus asperrimus (much reduced) \\
\hline $9 \cdot$ & ", & ," & ," Trygon bleekeri (reduced). \\
\hline 10. & & " & ," $\quad$, favus (much reduced). \\
\hline & ", & , & ,' , marginatus (much reduced). \\
\hline
\end{tabular}


Mem. Ind. Mus. Vol. If, 1909.
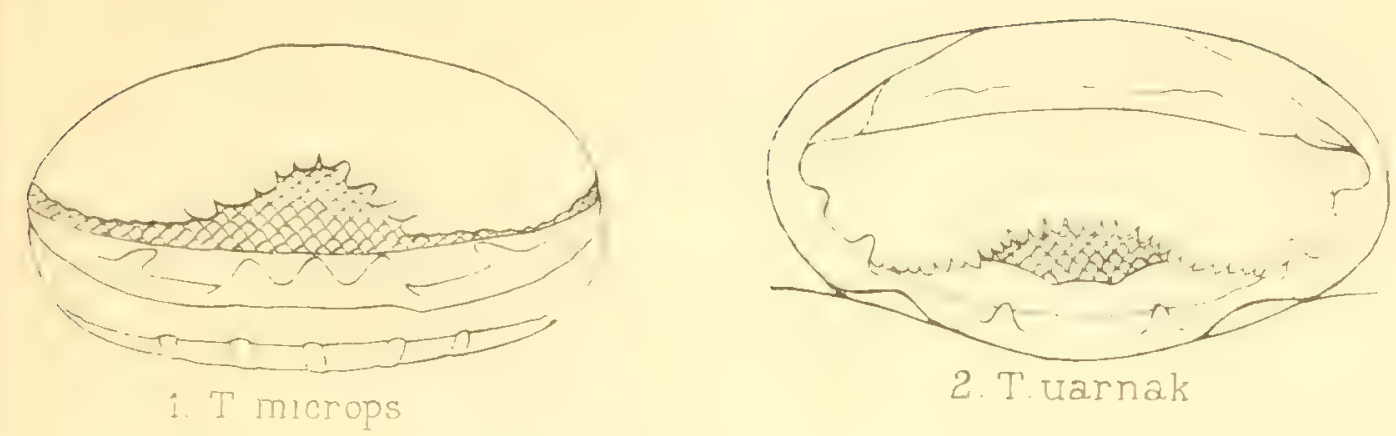

Plate!'.

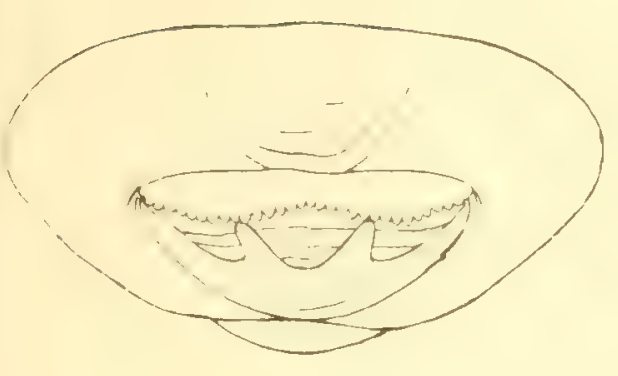

$\because+r_{2}^{\prime}+1$

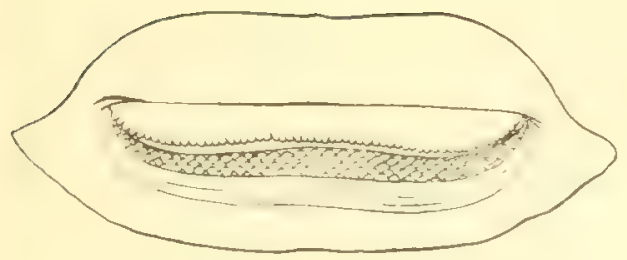

$T=\cdots+\cdots$

15.

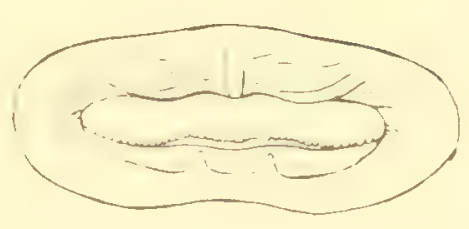

5 'T walga

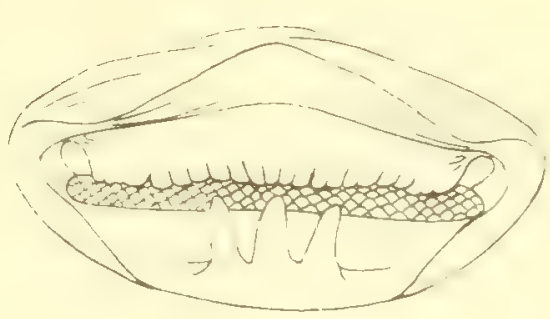

$c \quad 100, \therefore, \ldots+\ldots \ldots$

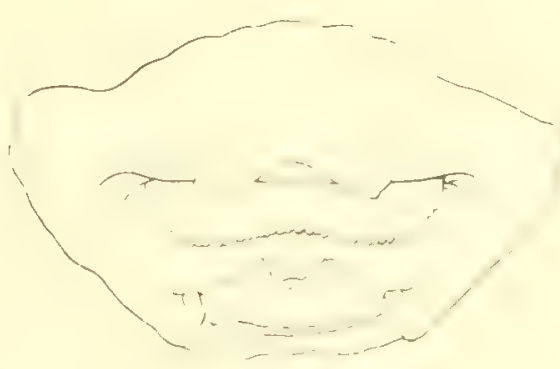

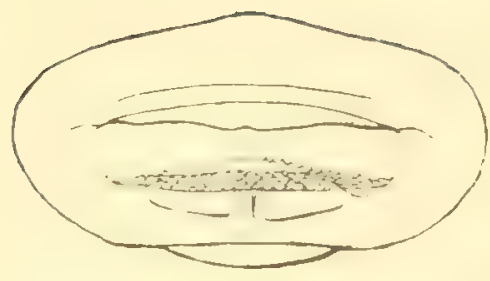

3. T stephen

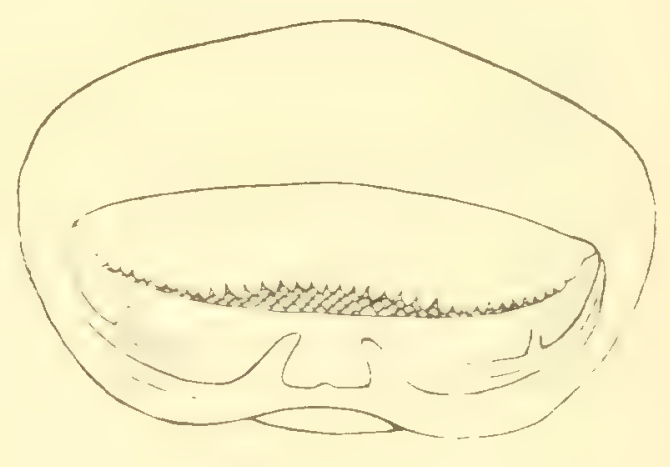

$6 \mathrm{~T}$ gerrardi

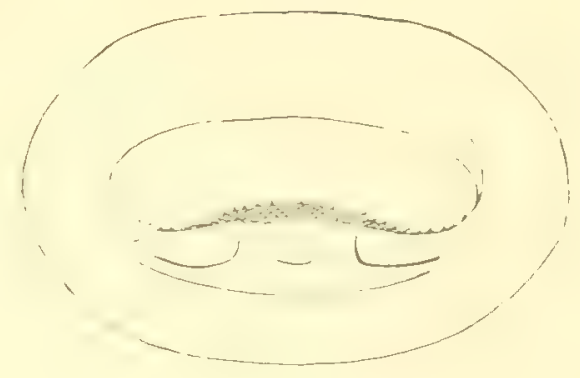

Ga. T.gerrardi

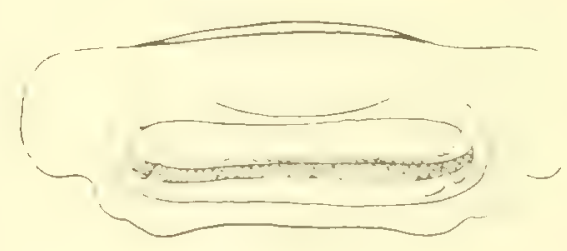

9. T bleaker

MOUTHS OF INDIAN TRYGONIDAE 



\section{EXPLANATION OF PLATE IIIA.}

MOUTHS AND TeETH OF INDIAN TORPEDINID

[All the teeth are drawn from preparations monnted in canada batsum.]

Firg. I.-Internal view of the mouth of Narcine timlei, $x+$.

,$\quad$ I $a$.-Teeth of the same, $\times 75$.

,. 2.- Internal view of the mouth of Narcine brmmea, $\times 4$.

,2 $2 a$.-Teeth of the same, $\times 75$.

, 3.- Internal view of the mouth of Narcine mollis, $\times 6$.

, $3 a$ - Teeth of the same, $\times 75$.

, 4.-Teeth of Torpedo mamorata, $\times 20$.

, 5.-Mouth of Benthobatis moresbyi, $\times 8$.

, 5 a. - Teeth of the same, $\times 75$.

, 6. -Mouth of Astrape dipterygia, $\times 6$.

, 6a.-Teeth of the same, $\times 75$.

, 7.-Mouth of Bengalichthys impennis, $\times 6$.

- $7 a$. Teeth of the same, $\times 75$. 

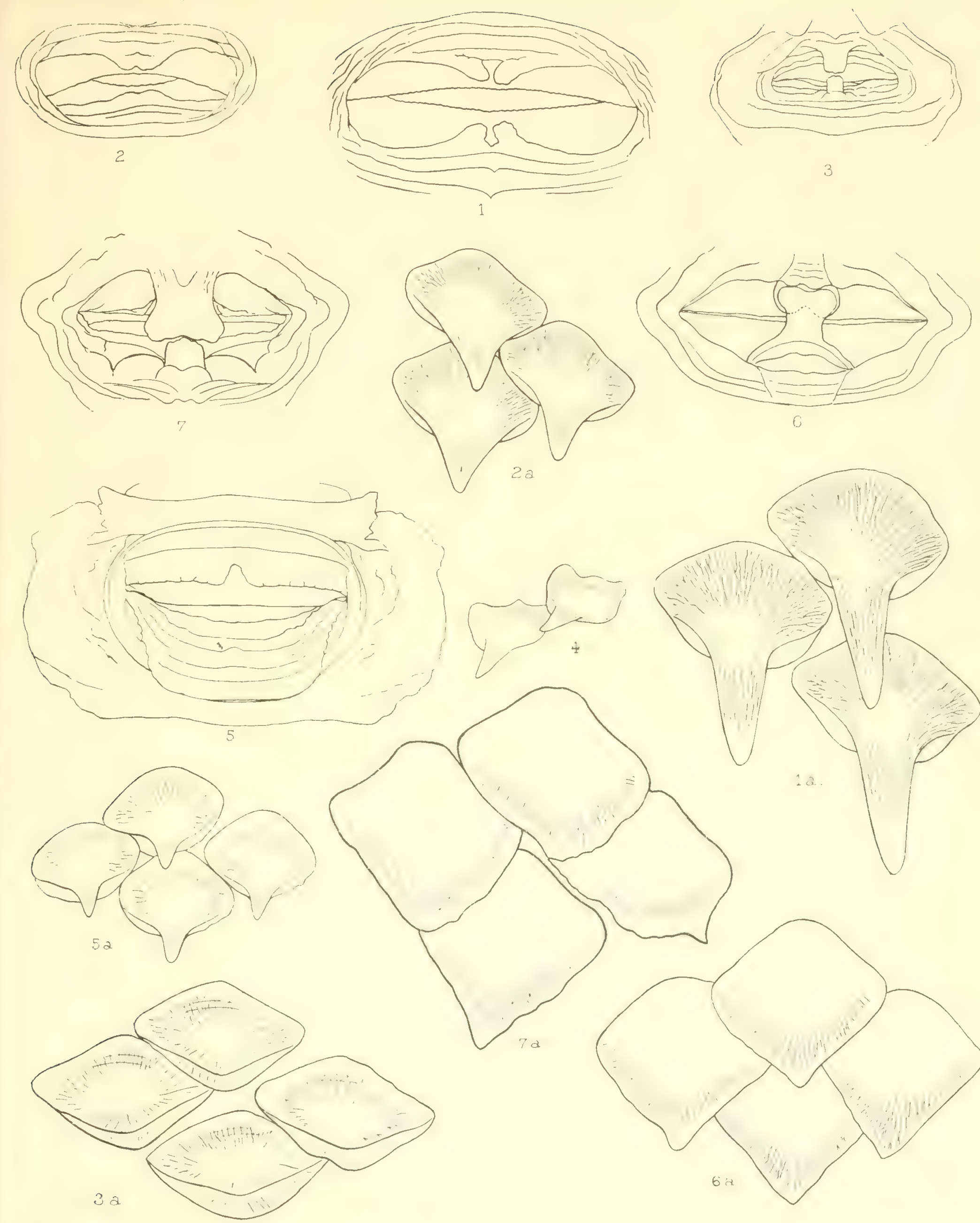



\section{EXPLANATION OF PLATE IV.}

FIG. I.-Photograph of type specimen(q) of Trygon microps. This specimen measured $6 \mathrm{ft} .6 \mathrm{in}$. across the disk.

. 2.-Photograph of female specimen of $T$. zugei, $\times \frac{3}{10}$.

,. 3.-Photograph of female specimen of Pteroplatea zomura (considerably reduced).

. 4.-Photograph of young specimen of Pt. tentaculata, $\times c . \frac{1}{2}$. A piece of white paper has been placed beneath the left tentacle.

. 5.-Photograph of a male specimen of Aëtobatis flagcllum, $\times$ c. $\frac{1}{5}$. 


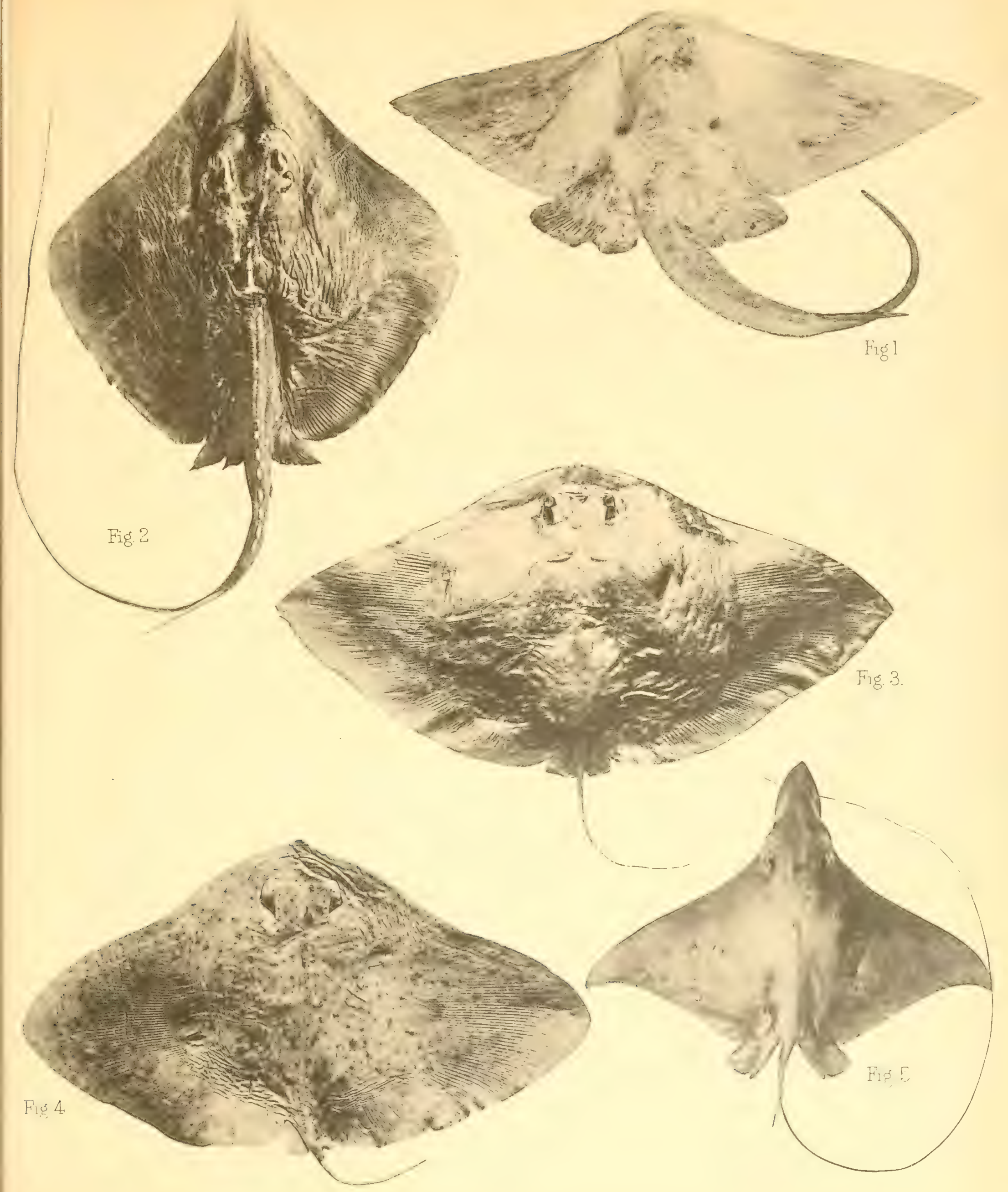




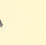




\section{EXPLANATION OF PLATE $V$.}

FIG. I.-Photograph of a male specimen of Hypolophus sephen in which the end of the tail has been lost (much reduced).

,, 2, 2a.-Photographs of a large female specimen of Urogymms asperrimus in which the tail had been mutilated (much reduced). In fig. 2 the base of the disk is considerably foreshortened.

, 3.-Photograph of a female specimen of Torpedo marmorata from the Orissa coast, $\times$ c. $\frac{2}{5}$

, 4.-Cast of the type specimen ( $*$ ) of Pristis annandalei, Chaudhuri, $x \frac{1}{14}$.

, 5.-Photograph of a male specimen of Rhamphobatis ancylostomus, $\times$ c. $\frac{1}{15}$. 


\section{RECORDS}

\section{of the \\ INDIAN MUSEUM}

('A JOURNAL OF INDIAN ZOOLOGY)

\section{Vol. I, 1907.}

Pari I.-Contributions to the Fauna of the Arabian Sea. Records of Hemiptera and Hymenoptera from the Himalayas. Further notes on Indian Freshwater Entomostraca. The Fauna of Brackish Ponds at Port Canning, Lower Bengal, I-III. A Sporozoon from the Heart of a Cow. Miscellanea.

Part 11.-Revision of the Oriental Stratiomyidx. Description of an Oligochæte Worm allied to Chelogaster. The Fauna of Brackish Ponds at Port Canning, Lower Bengal, IV. Further Note on a Polyzoon from the Himalayas. Reports on a collection of Batrachia, Reptiles and Fish from Nepal and the Western Himalayas. The Fauna of Brackish Ponds at Port Canning, Iower Bengal, V. Notes on Oriental Diptera, I, II. Miscellanea.

Part III.-Report on the Mariue Polyzon in the collection of the Indian Museum. The Fauna of Brackish Ponds at Port Canning, Lower Bengal, VI. A third note on Earwigs (Dermaptera) in the Indian Museum, with the descrip. tion of a new species. Notes on Oriental Diptera, III. Description of a new snake from Nepal. Notes on a col. lection of marketable fish from Akyab, with a description of a new species of Laclarius. Description of two fresh. water Oligochæte Worms from the Punjab. Notes on Phosphorescence in Marine Amimals. Notes on the rats of Dacca, Eastern Bengal. Notes on Freshwater Sponges, I-V. Miscellanea.

Purt IY - Niediclava monocanthi, the type of a new genus of Hydroids parasitic on Fish. Preliminary descriptions of three new Nycteribiides from India. Annotated Catalogue of Oriental Culicila. Notes on Oriental Diptera, IV. Notes on Iireshwater Sponges, VI, VII. Description of a new Cyprinid Fish of the genus Danio from Upper Burma, Miscellanea.

Table of Contents, List of Plates, List of Authors, Errata and Corrigenda, and Index.

\section{Vol. II, 1908-1909.}

Pay 1 . The retirement of Lieut.-Col. Alcock, with a list of his papers, etc, on Indian Zoology. The Fauna of Brackish Ponds at Port Canning, Lower Bengal, VII. Description of a Nerw Dictyonine Sponge from the Indian Ocean. Notes on Freshwater Sponges, VIII. Remarkable cases of variation, I. Description of a new species of Lizard of the genus Salea, from Assam. The Fauna of Brackish Ponds at Port Canning, Lower Bengal, VIII. Description of a new Cavernicolous Phasgonurid from Lower Siam. Descriptions of new species of Marine and Freshwater Shells in the collection of the Indian Museum. Notes on Oriental Syrphidæ, I. Description of a new variety of Spongilla loricata. Notes on Oriental Diptera, V. Miscellanea.

Part 11.-Gordiens du Musée Indien. The Fauna of Brackish Ponds at Port Canning, Lower Bengal, IX. Description of a new species of Danio from Lower Burma. Rhynchota Malayana, I: Cimex rotundatus, Signoret. Notes on Freshwater Sponges, IX. Fruit Bats of the genus Pteropus inhabiting the Andaman and Nicobar Archipelagos. A new species of Sun-Bird obtained near Darjiling. Three Indian Phylactolæmata. On two new species of EagleRays (Myliobatidx). Description of a new species of the genus Sesarma, Say., from the Andaman Islands. Descriptions of new species of Land, Marine, and Freshwater Shells from the Andaman Islands.

Parl III. - The Fauna of Brackish Ponds at Port Canning, Lower Bengal, X, XI. On some Oriental Solifugre rvith descriptions of new forms. The difference between the Takin (Budorcas) from the Mishmi Hills and that from Tibet, with notes on variation displayed by the former. Caridina nilotica (Roux) and its varieties. Description of a new species of Charaxes from the Bhutan Frontier. First Report on the Collection of Culicidæ and Corethridæ in the Indian Museum, with descriptions of new genera and species. Miscellanea.

Part IV.-Report on a collection of aquatic animals made in Tibet by Capt. F. H. Stervart in I907, I. Notes on Aculeate Hy menoptera in the Indian Museum, I. Indian Psychodidx. Description of a new species of mouse from the Madura District, Madras. Some Cleridæ of the Indian Museum. The Fauna of Brackish Pouds at Port Canning, Lower Bengal, XII. Description of a new species of Saw-Fish captured off the Burma Coast. A new Sting Ray of the genus Trygon from the Bay of Bengal. New Micro-lepidoptera from India and Burma. Notes on some Chrysomelid Beetles in the collection of the Indian Museum. Sis nev Cicindelin from the Orjental Region. Description of a new slug from Tibet.

Part V.-Revision of the Oriental Leptidæ. Revised and annotated Catalogue of Oriental Bombylidæ, with descriptions of new species.

Vol. III, 1909.

Payt I.-The Races of Indian Rats. 


\section{MEMOIRS \\ of the \\ INDIANN MUSEUM}

Vol. I.

No. I.-An account of the Rats of Calcutta. By W. C. Hossack. Rs. 5-8.

No. II.-An account of the Internal Anatomy of Bathynomus giganteus. By R. E. LLOYD. Rs. 2.

No. III A and 13.- The Oligochæta of India, Nepal, Ceylon, Burma and the Andaman Islands, with an account of the anatomy of certain aquatic forms. By W. Michatisen and J. Stephenson. Rs. $4-8$.

No. IV.-Investigator sicarius, a Gephyrean Worm hitherto undescribed, the type of a new order. By.F. H. StewarT. Rs. 2. 


\section{MEMOIRS \\ of the \\ INDIAN MUSEUM \\ Vol. III, No. I.}

Report on the Fishes taken by the Bengal Fisheries Steamer "Golden Crown" (WITH PLATES I-III).

PART II.-Additional Notes on the Batoidei, By

N. ANNANDALE.

PART lil.-Plectognathi and Pediculati, By

N. ANNANDALE and J. T. JENKINS.

PART IV.-Pleuronectidæ, By

J. T. JENKINS.

PUBLISHED BY ORDER OF THE TRUSTEES OF THE INDIAN MUSEUM. Calcutta :

PRINTED AT THE BAPTIST MISSION PRESS.

NOVEMIBER, IgIO.

Price Three Tupees. 


\section{Miscellaneous Zoological Publications.} the R.I.M.S. "Investigator." By A. Alcock, M.B., C.M.Z.S. $\cdots$ of the Deep-sea Madreporaria collected Account of the Deep-sea Madreporaria collected
by the R.I.M.S. "Investigator." By A. Alcock, M.B., C.M.Z.S. .. .. .. . Account of the Triaron. (Hexactinellid) sponges collected by the R.I.M.S. "Investigator." By F. E. Schulze, Ph.D., M.D. .. . . .

Account of the Alcyonarians collected by the R.I.M.S. "Investigator," Part I. By J. Arthur Thomson, M.A., and W. D. Hendersou, M.A. B.Sc.

Account of the Alcyonarians collected by the R.I.M.S. "Investigator," Part II. By J. Arthur Thomson, M.A., and J. J. Simpson, M.A., B.Sc. 20

Aids to the identification of Rats connected witl Plague in India. By W. C. Hossack, M.D.

Catalogue of Indian Crustacea. Part I.-Introduction and Brachyura Primigeuia. By A. Alcock, M.B., L.L.D., F.R.S.

Catalogue of Indian Decapod Crustacea. Part I.Brachyura. Fasciculus II.-The Indian Freshwater Crabs-Potamonidæ. By A. Alcock, C.I.E., M.B., LL.D., F.R.S.

Catalogue of the Indian Decapod Crustacea. Part II.-Anomura. Fasciculus I,-Pagurides. Bv A. Alcock, M.B., L.L.D., F.R.S., C.I.F;

Catalogue of the Indian Decapod Crustacea. Part III.-Macrura. Fasciculus I. - The Prawns of the Peneus Group. By A. Alcock, M.B., I.I.D., F.R.S., C.I.E

Catalogue of Indian Deep-sea Crustacea : Decapoda Macrura and Anomala in the Indian Musenm. By A. Alcock, M.B., LI.D., C.M.Z.S.

Catalogue of Indian Deep-sea Fishes in the Indian Museum. By A. Alcock, M.B., C.M.Z.S.

Catalogue of Mammalia in the Indian Museum, Part I. By J. Anderson, M. D. I.I. D. H.R.S. Part II. By W. I. Sclater, M.A., I.Z.S.

Catalogue of Mantodea in the Indian Museum, Parts I and II, By J. Wood-Mason, F. Z. etc. Catalogue of Motls of India, Parts I to VII. Iy E. C. Cotes and C. Swinloe, F.L.S., F.Z.S., etc.

Echinoderma of the Indian MIuseum: Account of the Deep-sea Holothurioidea collected by the R.I.M.S. "Iuvestigator." By R. Koebler and C. Vaney

Echinoderma of the Indian Museum: Iittora?
As.

The above can be ohtained from the Superintendent of the Indian Museum, Calcutta, and from Messrs. Friedlander \& Sohn, II, Caristrasse, Berlin.
Holothurioidea collected by the R.I.M.S. "Investigator", By R. Koebler and C. Vaney 2 o Lichinoderma ot the Lidian Museum: Deep-sea Ophiuroidea collected by the R.I.M.S. "Investigator:" By R. Koehler Echinoderma of the Indian Museum: Shallow"Investigator" By R, Koehler .

Echinoderma of the Indian Miseum, Part $\mathrm{V}$ : An account of the Deep-sea Asteroidea collected by the R.I.M.S. "Investigator." By R.

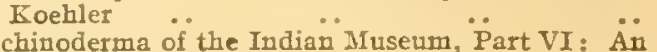
Echinoderma of the Indian Minseum, Part VI: An
account of the Shallow-water Asteroidea. By $R$.

Koehler
Figures and Déscriptions of Nine Species of Squillidæ from the collection of the Indian Museum. By.J. Wood-Masor, F.Z.S., etc., edited by Guide to the Zoological Collections exhibited in the Bird Gallery of the Indian Musenm. By F. Finn, B.A., F.Z.S. ․ …

Guide to the Zoological Collections exhibited in the Fish Gallery of the Indian Museum. By A. Alcock, MI.B., C.M.Z.S.

Guide to the Zoological Collections exhibited in the By A. Alcock, M.B., C.M.Z.S. (Out of print.)

Guide to the Zoological Collections exhibited in the Reptile and Amphibia Gallery of the Indian Museum. By A. Alcock, M.B., C.M.Z.S. (Out of print.)

Hand I, ist of Mollusca in the Indian-Museum, Parts I and II, and Fasciculus IE. By G. Nerill, C.MI.Z.S., etc. Index, Parts I and II. By W. Theobold

Illustrated Catalogue of the Asiatic Horus and Antlers in the Indian Museum. By T. Bentham

List of Batrachia in the Indian Museum. By WV. L. Sclater, M.A., F.Z.S.

Iist of Birds in the Indian Museum. Part I Corvidæ, Paradiseidæ, Ptilonorhynchidæ and Crateropodide. By F. Finn, B.A., F.Z.S.
I, ist of Snakes in the Indian Museum. By W. Sclater, M. A, F.Z.S.

Monograph of the Asiatic Chiroptera and Catalogue of the Species of Bats in the Indian Miuseum. By G. E. Dobson, M.A., M. B., F.R.S. VII. BV W. L. Distant, F.E.S. ... A. Alcock, M.B. C.M.Z.S. .

Monograph of the Oriental Cicadidr, Parts I to

\section{Other I'ublications edited and sold by the Snperintendent of the Im,ion Mastam (uso obtrinable from Messis. Friellander of solun issued by the Director. of the linylel Iudian Mrevime.}

Illustrations of the Zoology of the R.I.M.S. "Investigator," 1892. Fishes, Plates I to VII. Crustacea, Plates 1 to V, ISQ.1. Fishes, Plates VII to XIII. Crustacea, Plates VI to VIII. Fichinoderma, Plates I to III, Isos. Erhinoderma, Plates IT and V. Fishes, Plates IIV to IVI. Crustacea, Ilates IX to XV, ISc6. Crustacea, Plates XVI to XXVI, $187 \%$. Fishes, Plate XVII. Crustacea, Plates XYViII to XIXII. Mollusca, Plates I to VI, 1898. Fishes, Plates XVIII to XXIV. Crustacea, Plates XXXII to XXXV. Mollusca, Plates VII and VIII, r²9. Fishes, Plates XXV aud XXVI. Crustacea, Plates XXXVI to XI, igoo. Fishes, Plates XXVII to XXXV. Crustacea, Plates XIVI to XI,VIII. Index, Part I, I90I. Crustacea, Plates XLIX to LV. Mollusca, Plates IX to XIII, I903. Crustacea, Plates IVI to IXVII. Crustacea, Plates LXVIII to LXXVI. Fishes, Flates XXXVI to XXXVIII, 1905. Crustacea (Malacostraca), Plates LXXVII to IXXIX. Crustacea (Entomostraca), Plates I and II. Mnllusca, lates XIV to XVIII, I907. Fishes, Plates XXXIX to XLIII. Crustacea (Entomostra Ca), Plates III to V. Mollusca, Plates XIX and XX, Ig08.- Re. I per plate. Mlollusca, Plates XXI to XXII, Ig0g.-
As 8 per plate. 


\section{REPORT ON THE FISHES TAKEN BY THE BENGAL FISHERIES STEAIER "GOLDEN CROWN."}

\section{PART II.-ADDITIONAL NOTES ON THE BATOIDEI.

\author{
By N. AnNandale, D.Sc., F.A.S.B., Superintendent, Indian Museum.
}

Since my report on the Batoidei was published (Mem. Ind. Mus., ii, pp. I-60), a considerable number of interesting specimens of this group have been obtained by the "Golden Crown," whose operations have now been brought to a close so far as the Government of Bengal is concerned, and I have had the opportunity of examining some of the Indian rays in the British and the Royal Scottish Museums. It has therefore become advisable in some cases to supplement, and in one to correct my former statements in the light of additional knowledge. I have nothing to add to what I said as regards the Pristidae and Rhinobatidae, but the Trygonidae and Myliobatidae need further comment, while as regards the Torpedinidae I may note that a considerable number of specimens of Bengalichthys imponnis of both sexes have recently been taken in Balasore Bay, and one small female on the shore at Puri.

My great and increased obligations in this work to Dr. J. T. Jenkins must be acknowledged, and also my sense of the courteous assistance which I met in the British Museum at the hands of Mr. G. A. Boulenger.

\section{Family TRYGONIDAE. \\ Trygon uamak (Forskal).}

Mem. Ind. Mus., ii, p. 22.

Bleeker's specimen of $T$. mudulatus (one of the types of that "species") in the British Museum (specimen M in Günther's Catalogue) appears to be a young example of $T$. uarnak in which the spots have already begun to coalesce. At this stage I am unable to distinguish the colour variety varicgatus from the typical form. Several of the synonyms in the Catalogue must undoubtedly be transferred from this species to $T$. gerrardii; but a more careful examination of Bleeker's specimens than I had time to undertake in Europe would be necessary to elucidate this point fully. $T$. pareh seems to me to be distinct from either species, although it is probably identical with my own $T$. alcockii, which of course, should this prove to be the case, must be sunk as a synonym. It may be noted tlat in dried or shrivelled specimens of $T$. alcockii the flat scales on the dorsal surface become more conspicuous than is the 
[VOT. III,

case in fresh specimens. They do not, however, even in a dried skin assume the regular patten with well-defined outlines so characteristic of $T$. gerrardii and T. bleekeri.

The measurements of the disk of the young specimen of $T$. uarmak given on page 30 of my report are unusual, the disk being broader than is commonly the case. The following measurements were taken from a single batch of somewhat older specimens in which the spots had already begun to coalesce and the ground colour of the back to darken:-

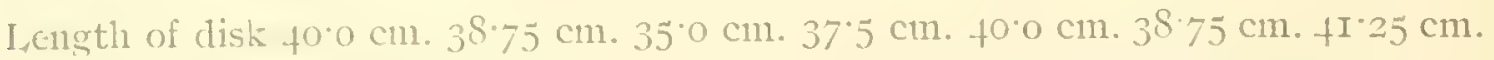
Breadth of disk $\left.50^{\circ} 0,47^{\circ},, 425,40^{\circ} 25,40^{\circ}\right), 48 \cdot 75,, 5 I^{\circ} 25$,,

\section{Trugon gcruardii, Gray.}

Hem. Ind. Mus., ii, p. 24 .

Trwo species are confused under this name in the British Museum Catalogue, a half-grown specimen from Japan being certainly distinct from the types of the species. The latter are young stuffed specimens, but I am pretty sure that they are identical with what I call $T$. gerrardii. In $T$. gerrardii the spots never extend to the anterior half of the disk, as they do in the half-grown Japanese specimen. in which there are traces of a mid-dorsal row of spines resembling those of T. akajei.

A large adult male of $T$. gcrrardii was recently captured off the Madras coast which had the ventral surface suffused with dark pigment. Its measurements were as follows :-

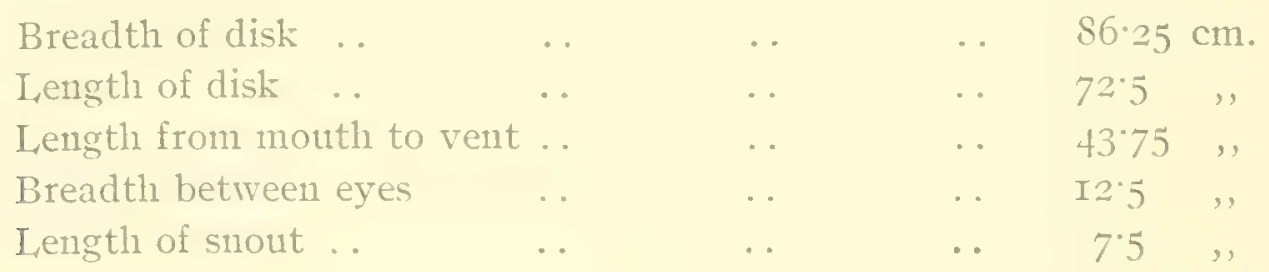

This is by far the largest specimen of the species I have seen, but the pale spots, which were confined to the posterior margin of the disk, were quite distinct.

\section{Trygon fluviatilis (Ham. Buch.).}

(Plate i, fig. I.)

Size fairly large (a female from the sea measured $+\mathrm{ft} .7^{\frac{1}{2}}$ in. across the disk).

Disk slightly broader than long without the pelvic fins, very flat, with the lateral angles very broadly and gradually rounded, so that the whole body, including the

1 But see Dr. Günther's remarks in his "Fische der Siidsee," pt. ir, p. 492 (I9IO). He is of the opinion that the species of these type specimens cannot be recognized. It is only after comparing large numbers of specimens in different conditions of preservation that I renture to differ from him. 
pelvic fins, has an oval, ontline. The snout acutely pointed and much produced, more than twice as long as the distance between the eyes.

Colour.-Dorsal surface a dark livid purplish grey, changing to dull ochraceous in the middle of the disk. Ventral surface white with a broad, irregular, deeply pigmented margin, which is more or less interrupted in front.

Eyes small, not very prominent.

Skin tough; the entire dorsal surface (except that of the pelvic fins) and a considerable part of the ventral covered by small indistinctly stellate scales, the projecting points of which are for the most part blunt. These scales are larger for the most part on the head than on the rest of the disk, but on the posterior half of the body some of them are markedly larger than the rest and bear sharp, straight spines; on the fins and on the ventral surface they are very small.

This species is closely allied to Blyth's T. marginatus, from which its produced and pointed snout will at once distinguish it. It also occurs in the R. Ganges, and is evidently the species named by Hamilton Raja fluvintilis. On this point I shall have more to say on another occasion.

A specimen was taken off the Madras coast from between 20 and 30 fathoms in November, Igog. Its measurements were as follows:-

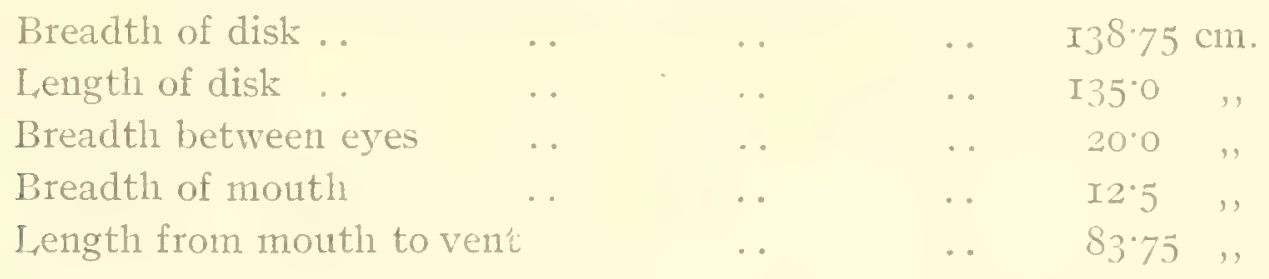

The tail had unfortunately been removed before the specimen was brought to the Museum, but we have recently obtained another specimen in which the tail was apparently complete, but was less than twice as long as the body.

\section{Urogymmus asperrimus, MIiller and Henle.}

(Plate ii, figs. I, I $l, I b$.)

Mem. Ind. Mus, ii, p. 37.

Another large female specimen of this fish was taken off the Madras coast in September, Igog. Curiously enough its tail was mutilated in exactly the same way as was the case in the individual of the same species previously described. Its measurements were as follows:--

Breadth across disk

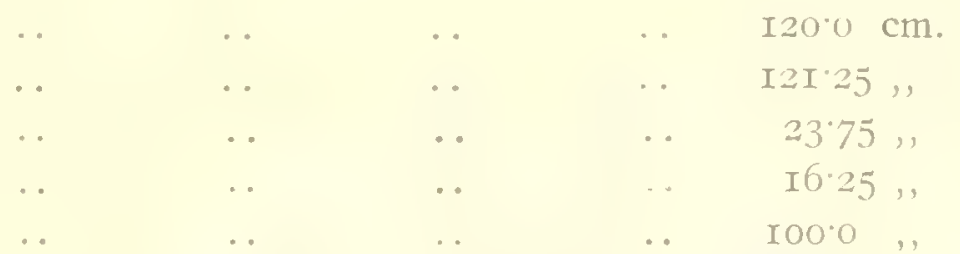

This specimen had on the floor of the mouth, in addition to three finger-like processes in the centre, a shorter process on either side. 
On the same voyage as that on which the large individual was taken, a young one, perhaps horn from it prematurely, was also captured. It differed from the adult in the total absence of scales from the pectoral fins and snout and in possessing only blunt scales on the body and tail. Although there was no trace of a spine on the latter, the place in which it would have been in a Trygon was occupied by a distinct naked groove (p1. ii, fig. Ib)-an interesting piece of evidence as regards the descent of Urogymmus from a genus such as Trygon with a poison-spine on the tail. On the snout a few soft tubercles were visible, which appeared to be developing spines with a flat base.

\section{Family MILIOBATIDAE.}

Aëtobatis narinari (Ëuphrasen).

(Plate ii, fig. 2.)

A. narinari, Mcm. Ind. Mus., ii, p. 55 (\&).

A. guttata, ibid., p. $56(\sigma)$.

It becomes clear from an examination of specimens from localities outside the Bay of Bengal and of individuals taken recently by the "Golden Crown" off the Madras coast, that I was wrong in two particulars as regards the species of Aetobatis; firstly, in thinking that the form I called. A. narinari was peculiar to the Atlantic, and secondly, in regarding it as specifically distinct from the common Indian form. For some reason all the specimens I had examined in a fresh condition were males, in which the snout appears to be normally more pointed than it is in females; and it is evident that the coloration of the species is more variable than I realized. In Edinburgh and London there are Indian specineus that agree closely with American and South Sea specimens in the British . Iuseum, while an old female from the Madras coast differs in more respects than one from all other specimens I have seen. It appears, however, that if very old and very young individuals, in both of which the spots are obscure or absent, are omitted from consideration, three colour varieties may be distinguished as follows :-

Var. A.-Entire dorsal surface of disk, including the snout, spotted.

Var. 13. - Spots on the dorsal surface confined to the post-spiracular part of the disk

Var. C.-Spots confluent into short transverse streaks.

Var. B is the common variety in the northern parts of the Bay of Bengal, but is by no means confined to Indian seas Var. A is found off the Coromandel and Malabar coasts as well as in the Atlantic and South Pacific; while var. C is probably liable to occur in diverse places as an individual sport.

The large female recently taken by the "Golden Crown" is practically devoid of spots, which appear to have become almost obsolete. Very young individuals are also unspotted; but in them the spots are just commencing to appear. For the following measurements of the large specimen I am indebted to Dr. Jenkins 
and Mr. G. H. Tipper. They were taken on the fresh fish, while I have only been able to examine the skin in spirit. Unfortunately the snout was not measured, but it has evidently been extremely broad, short, and blunt. The measurements of young males were taken from two specimens captured together in the Bay of Bengal and preserved in spirit. Unfortunately the snout is much distorted in the smaller of the two, which was probably born prematurely:-

\begin{tabular}{|c|c|c|c|c|c|}
\hline & & & $q$ & $\sigma^{*}$ (juv.) & $\sigma(j u v)$. \\
\hline Breadth of disk & $\cdots$ & . & $205^{\circ} 0 \mathrm{~cm}$ & $23^{\circ} 2 \mathrm{~cm}$. & $20^{\circ}+\mathrm{cm}$ \\
\hline Length of disk & & & I32.5 , & 1377 & I $2 \cdot 4$, \\
\hline Length of tail & & $\cdots$ & $275^{\circ} 0$, & $57^{\circ} \mathrm{O}$ & 47.5, \\
\hline Mouth to vent $\quad$. & . & . & & $9^{6}$ & $8 \cdot 5$, \\
\hline Breadth of snout at base & . & & $\cdots$ & $12 \cdot 7$ & \\
\hline Length of snout . . & . & & . & I $2 \cdot 6$, & \\
\hline
\end{tabular}

The length of disk includes that of the snout.

The large female differs not only in its inconspicuous coloration, very large size and short rounded snout from other specimens sent to the Museum from the "Golden Crown," but also in having the dorsal surface and the whole of the tail covered with small, star-shaped denticles. On the head these are sufficiently close together to form a regular pavement, while on. the tail they have a spinous character. Miiller and Henle have noticed that the tail of very large specimens of A. Aagellum is sometimes rough (Plagiostomon, P. ISo), and I am inclined to think that this is a character denoting extreme old age The teeth in the "Golden Crown" specimen are transverse, and not pointed at the tip in the lower jaw; the nasal flap is nearly straight; there is no trace of a serrated spine on the tail. It is evident therefore, that neither the shape of the tooth-band of the lower jaw, the outline of the snout, that of the nasal flap, nor the number of spines present on the tail can be regarded as characters of specific importance. 


\title{
PART III,-PLECTOGNATHI AND PEDICULATI.
}

\author{
By N. Annandale, D.Sc., F.A.S.B., Superintendent, Indian Museum, and. J. T. \\ JENkins, B.Sc. (Lond.), D.Sc. (Wales), Ph.D. (Kiel), Superintendent, Lanca- \\ shire and Western Sea Fisheries, late Fishery Adviser, Government of Bengal.
}

\section{INTRODUCTION.}

As comparatively few sharks and dog-fish have been taken by the "Golden Crown," and as the collection of Selachians in the Indian Museum is by no means complete, we have thought it best to defer the consideration of this group. Moreover, to describe the 'Teleostei in the collection of the "Golden Crown" in an adequate manner will mean little less than a revision of the Indian representatives of all the families of which specimens have been obtained, and this work cannot yet be undertaken as regards the larger groups. We have therefore decided to deal, in the first instance, with those groups that are compact and of moderate size without reference to their exact systematic position. As a beginning we here discuss the suborders Plectognathi and Pediculati, in our arrangement of which we follow Mr. Boulenger's account of the Teleostei in the Cambridge Natural History, vol. vii (I90.4).

Most of the specimens of these suborders that Day has figured in his Fishes of India are in the collection of the Indian Museum, including the types of several species. In the "Golden Crown'" collection the 'Triacanthidae and Tetrodontidae of the Bay of Bengal are fairly well represented, but the Balistidae, Diodontidae and Pediculati poorly. The Balistidae and Diodontidae are mainly species which frequent coral reefs, but coral reefs do not occur in the northern part of the Bay of Bengal, and it is only near the southern limits of the trawler's cruises, that is to say, off the Madras coast, that Balistidae have been taken. Their presence there is probably due to the large masses formed by molluscs of the genera Siliquaria and Spiroglyphus and almost comparable to coral reefs in growth. The Indian Pediculati, on the other hand, are mostly deepsea forms; the majority of the species that belong to our fauna have been described by Col. Alcock or by Capt. Lloyd from the "Investigator" collections, the types being in the Indian Museum.

We must express our obligations to Prof. Max Weber of Amsterdam for valuable notes on the genera Triacanthus and Halicutaca.

$$
\text { I.-Suborder PLECTOGNATHI. }
$$

\section{LIST OF THE, PLECTOGNATHI OF INDIAN SEAS.}

[The names of species not represented in the collection of the Indian MIuseum are printed in italics. 'Those of species taken by the "Golden Crown' are distinguished 
by $a^{*}$, those of species of which the types are in the Indian Museum with a $\dagger$; and those of species not recorded or recognized as distinct by Day in the "Fauna" with a §.]

\section{SCLERODERMI.}

Fain. TRIACANTHIDAE.

I. Triacanthus brevirostris.*

2 , , oxycephalus. *\$

3. , strigilifer.*

4. ,, weberi.* $\$ \uparrow$

5. Triacanthodes ethiops. $\$$

6. Halimochirurgus centriscoides. $\uparrow$

Fam. 'T'RIOdontidae.

7. Triodon bursarius.

Fam. Baisistidae.

8. Balistes stellaris.**

9. ,, maculatus.

Io. ,, vetula.

II. , niger.

I2. ,, mitis.

I3. Balistes conspicillum.

I4. Balistes viridescens.

I5. , fuscus.

I6. ,, flavimarginatus.

I7. Babistes cllioti.

I8. Balistes aculeatus.

I9. ,, rectangulus.

20. ,, undulatus.

2I. Balistes buniva.

22. Balistes erythrodon.

23. Monacanthus oculatus.\$

2.4. Monacanthus nematophorns.

25. , setifer.

26. Monacanthus choerocephalus.

$27 . \quad$, tomentosus.

28. Aluteres monoceros.*

29. , scriptus. *

30. Aluteres nasicomis.\$

3I. Anacanthus barbatus.
34. Ostracion punctatus.

35. ,, nasus. *

$36 . \quad$, cornutus.

37. Ostracion fornasini.\$

\section{GYMNODONTES.}

Fam. Tetrodontidae.

38. Tetrodon lunaris.*

39. , inermis.*

40. ,, sceleratus.

fI. ,, hypselogenion.

42. ,, oblongus. *

43. , spinosissimus.

4. ,, patoca**

45. . cutcutia.

46. ,, immaculatus.*

47. , nigropunctatus.

f8. ,, stellatus.*

49. ,, reticularis.*

50. , , hispidus.

5I. ,, leopardus. $\dagger$

52. , viridipunctatus. $\dagger$

53. , fluviatilis.

54. Tropidichthys investigatoris, sp. nov. $\uparrow$

55. Tropidichthys valentini.

$56 . \quad$, bennettii.

57. Tropidichthys margaritatus.*

Fam. DIODONTIDAE.

58. Diodon hystrix.

59. Diodon maculatus.

60. Diodon orbicularis.*\$

Fam. MOLIDAE.

6r. Orthagoriscus, sp.

Fam. Ostraciontidafi.

32. Ostracion gibbosus.*

33. ,, cubicus. 
IgIo.] N. AnNANDAlE, and J. T. Jenkins: Plectognathi and Pediculati.

Of the 6 I species in the above list, only I7 have been taken by the "Golden Crown," although 34 of the 54 Batoidei known from Indian seas were obtained. This is evidently due to the fact that the great majority of the Plectognathi are reefhaunting species not found in water suitable for the operations of a trawler. Three species in the list (Triacanthodes ethiops, Halimochinurgus centriscoides and Ostracion formasini) have been added to the Indian fauna by Col. Alcock,' while five have recently been recorded from the south-western limits of the Indian seas by Mr. Tate Regan in his account of the fish taken off the Maldives and in other parts of the Indian Ocean by Prof. Stanley Gardiner. ${ }^{2}$ These five species, only the first of which is represented in the collection of the Indian Museum, are Monacanthus oculatus, M. nematophorus, Aluteres nasicomis, Tropidichthys valentini and T. bemettii. 'Two additional species have recently been taken by the R.I.M.S. "Investigator" in fairly deep water, both new to the fauna, namely, Tetrodon spinosissimus and Tropidichthys investigatoris, sp.nov. The former was described by Mr. Tate Regan from the Saya de Malha Bank in the Indian Ocean, and is represented in the Indian Museum by several specimens from the Gulf of Martaban and from Hongkong. 'Two species of Triacanthus and one of Diodon, not recognized by Day, have been taken by the "Golden Crown." Most of the forms dealt with in this paper are, however, well known; only two new species are described here (Tropidichthys investigatoris and Halientaea indica), while a third (Triacanthus weberi) has recently been described by Mr. B. L. Chaudhuri.

The families and genera of the Plectognathi have so often been discussed that in most cases it will be unnecessary for us to describe their peculiarities, which are fully described in Günther's Catalogue of the Fishes in the British Musenm, vol. viii.

\section{Sclerodermi.}

Key to the Families and Indian Genera of Sclerodermi.

Family I, 'TRIACANTHIDAE.

Skin covered with small scales; body compressed; a spinous dorsal fin consisting of at least two spines; a pair of stout moveable ventral spines.

A.- Snout moderately produced; teeth small, conical, in a double series ... .. . . Triacanthodes.

B.- Snout moderately produced; teeth of the outer series incisor-like $\quad . . \quad \ldots$ Triacanthus.

C. - Snout produced into a long, curved, perfectly tubular organ .. . . . Halimochinurgus.

1 Journ. Asiat. Soc. Bengal (ii), vol. 1xiii, p. I37, pl. vii, fig. 6 (I894), and vol. 1xv, p. 338 (I896); Proc. A siat. Soc. Bengal, I899, p. 78 ; Illustr. Zool. R.I.1I.S. "Investigator," Fishes, pl. xv, fig. 9, and pl. $x x x i$, fig. 3 .

${ }^{2}$ Gardiner's Fauna and Geogr. Maldive and Laccadive Arch., vol. i, p. 279, and Trans. Limn. Soc. London (2), xii, p. 252 . 


\section{Family II, BalistiddaE.}

Skin rongh or with moveable scales; body compressed; not more than three spines in the dorsal; ventral reduced to a single spine or absent.

$$
\begin{aligned}
& \text { A.-Three dorsal spines present } \quad \ldots \quad \ldots \text {. . Balistes. } \\
& \text { B.--One perfect and usually one rudimentary dorsal } \\
& \text { spine. } \\
& \text { (b) Ventral spine present or absent; no barbel ; less } \\
& \text { than fo rays in the anal fin .. . Monacanthus. } \\
& \left(b^{\prime}\right) \text { No ventral spine; no barbel; more than fo rays } \\
& \text { in the anal fin .. . . . Aluteres. } \\
& \left(b^{\prime \prime}\right) \text { No ventral spine; a fleshy barbel on the lower }
\end{aligned}
$$

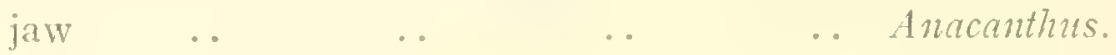

The scales modified into a firm and inflexible carapace formed of mosaic-like scutes; spinous dorsal and ventral fins absent.

Teeth small, slender, in a single series _.. . . Ostracion.

The above key is based on the one given by Guinther in his Catalogue (vol. viii, p. 208), but only Indian forms are included and certain modifications have been rendered necessary by more recent work on Oriental ichthyology.

$$
\begin{aligned}
& \text { Family 'TRIACANTHIDAE. } \\
& \text { Genus TRIACANTHUs, Cuvier. } \\
& \text { Key to the Indian species of Triacanthus. }
\end{aligned}
$$

A.- Second dorsal spine much more than half as long as the first.

First dorsal spine shorter than the head; membrane of the dorsal fin tipped with black .. T. strigilifer.

B.-Second dorsal spine less than half as long as the first.

(b) Membrane of dorsal fin entirely pale; first dorsal spine distinctly longer than the head; snout fairly stout; dorsal profile of head sinuous ..

T. oxycephalus.

(b') Membrane of dorsal fin black; first dorsal spine not longer than the head; snout stout, with. the dorsal profile nearly straight 
$\left(b^{\prime \prime}\right)$ Membrane of dorsal fin edged with black; first dorsal spine not or barely longer than the head; snout slender, with the dorsal profile distinctly concave and the ventral profile sinuous .. T. weberi.

\section{Triacanthus strigilifer, Cantor.}

Day, Faun. Brit. Ind., Fishes, vol. ii, p. 472.

This species, which does not appear to be quite so common in the Bay of Bengal as $T$. brevirostris, is easily distinguished by the length of the second dorsal spine. Should this spine be broken, as is sometimes the case, the characteristic form of the snout, midway between that of $T$. brcvirostris and $T$. vebcri, will serve as diagnostic.

$T$. strigilifer has been taken on both sides of the Bay by the "Golden Crown" and is represented in Day's collection.

\section{Triacanthus oxycephalus, Bleeker.}

Bleeker, Atlas Ichthyologique, vol. v, p. 90, p1. ccxx, fig. 3.

This species is regarded by Gunther as synonymous with $T$. biaculeatus, but is apparently distinguished from the latter not only by the outline of its snout and the great length of the anterior dorsal spine, but also by distinct differences in coloration and in form of body. Prof. Max Weber has been kind enough to compare a specimen with Bleeker's original specimens.

$T$. oxycephalus is not represented in Day's collection. It has been taken off the coast of Orissa by the "Golden Crown" and also occurs off that of Lower Burma as well as in the Malay Archipelago.

\section{Triacanthus brevirostris, Temm. and Schleg.}

Day, Famn. Brit. Ind., Fishes, vol. ii, p. 47 I.

$T$. brevirostris is perhaps the commonest species of the genus in the Bay of Bengal. In Lake Chilka it occurs in brackish water. It is easily distinguished from other species by its comparatively stout snout and by the almost complete blackness of the membrane of the dorsal fin.

\section{Triacanthus zecberi, Chaudhuri.}

T weberi, Chandhuri, Journ. Asiat. Soc. Bengal (N.S.), vol. vi, p. 497, p1. xxxii (I9Io).

This species is not represented in Day's collection; indeed, all the specimens in the collection of the Indian Musenm were taken by the "Colden Crown." Possibly it inhabits rather deeper water than the other species.

The peculiar form of the snout, which it is difficult to express accurately by means of meastrements, will at once distinguish the species. The dark pigment on the snout, moreover, forms a narrower and hetter defined band on the sides than is the case in $T$. strigitifer, $T$. brevirostris or $T$. oxycephalus. 
Family BALISTIDAE.

Genus BAListes, Lacépède.

Balistes stellaris, Bloch and Schneid.

This is the only species of the genus that has been taken by the "Golden Crown." It is apparently not uncommon on the Siliquaria grounds off the Madras coast at a depth of from 20 to 30 fathoms.

\section{Genus Monacanthus, Cuvier.}

No species of this genus (sensu stricto) has been taken by the "Golden Crown." As, however, two new species have recently been added to the Indian fauna, the following key may prove useful. All the Indian species are fully described in Günther's Catalogue:-

Key to the Indian species of Monacanthus.

A.-Ventral spine moveable; the ventral protuberance not extending beyond it.

(a) Upper profile of snout concave; scales minute, each with four or five spines on the margin ..

$\left(a^{\prime}\right)$ Upper profile of snout concave; scales minute, not very rough, sometimes mixed with minute cirri $\quad \cdots \quad \ldots$.

$\left(a^{\prime \prime}\right)$ Upper profile of snout nearly straight; skin velvety, with long fringed filaments .. M. nematophorus.

B.-Ventral spine absent.

Body subcircular, marked with purplish ocelli .. M. oculatus.

Genus AlutERES, Bleeker.

Key to the Indian species of Aluteres.

A.-Dorsal spine not in front of the orbit.

(a) Dorsal profile of snout convex; caudal fin much shorter than the head $\quad \cdots$

$\left(a^{\prime}\right)$ Dorsal profile of snout concave; caudal fin nearly as long as or longer than the head .. A. scriptus.

B.-Dorsal spine distinctly in front of the orbit.

Dorsal profile of snout convex; dorsal spine nearly as long as the head...

.. A. nasicomis.

\section{Aluteres monoceros (Osbeck).}

Monacanthus monoceros, Day, Faun. Brit. Ind., Fishes, vol. ii, p. 482.

'This species has been taken by the "Golden Crown"' on several occasions. It appears to be not uncommon, together with Balistes stcllatus, on the Siliquaria grounds off the Madras coast. 
igro.] N. Annandale and J. T. Jenkins: Plectognathi and Pediculati.

An abnormal specimen in the collection, while agreeing in other respects with typical examples, shows no trace of the dorsal spine.

\section{Aluteres scriptus (Osbeck).}

Monacanthus scriptus, Day, op. cit., p. 483

At least one specimen was taken by the "Golden Crown" on the same grounds as the last species.

\section{Family OS'TRACIONTIDAE.}

\section{Genus Ostracion, Artedi.}

The only species of this genus taken by the "Golden Crown' are O. gibbosus (the O.turritus of Day's books) and O. nasus. The two species do not appear to have quite the same distribution in the Bay of Bengal, for while $O$. nasus has been taken in considerable numbers in the muddy waters opposite the mouths of the Ganges, O. gibbosus appears to be characteristic rather of the Siliquaria grounds off the Madras coast and the rocky bottom off Arakan. Both species occur, however, in the Andamans.

Alcock (Joum. Asiat. Soc. Bengal (ii), vol. 1xv, p. 338) has added O. fomasini, a species widely distributed in the Indian Ocean, to the fauna of British India; but we have been unable to find his specimen, which was taken off Ceylon in 34 fathoms, in the collection of the Indian Museum. The species is easily distinguished from its ally $T$. comutus by its much shorter superciliary spines, which are parallel or slightly convergent, and by the fact that it possesses a large, conical, compressed spine in the middle of the back.

\section{Gymnodontes.}

The families here recognized are clearly distinguished by Day as "groups," except that he does not separate the Diodontidae, which have only a single tooth in each jaw, from the Tetrodontida, which have two.

\section{Family TETRODONTIDAE}

Considerable difference of opinion exists among ichthyologists as to the number of genera that should be recognized in this family. We are able to distinguish three among the Indian forms, as follows:-

A.-Back rounded or flat; nostrils conspicuous.

(a) Dorsal and anal fins with more than 20 rays $\begin{array}{lllllll}\text { each } & \ldots & \ldots & \ldots & \ldots & & \ldots\end{array}$

$\left(a^{\prime}\right)$ Dorsal and anal fins with not more than 16 rays

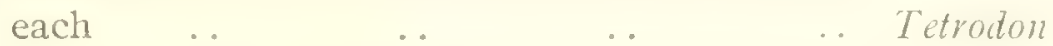

B.-Back compressed into a ridge; nostrils very inconspicuous.

Dorsal and anal fins with not more than I6 rays

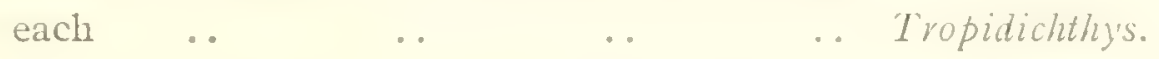


Genus TETRODON, Linn.

Tetrodon inemis, Schlegel.

A specimen of this species was taken by the "Golden Crown" off the mouth of the Eastern Channel ( R. Hughli), in November, Igog. The sides of the fresh specimen are of a bright golden-green colour.

\section{Tetrodon hmaris, Bloch and Schneid.}

There seems to be every gradation between $T$. hunaris and $T$. spadicens, Richardson. The only difference is the extent to which the spines on the dorsal surface extend backwards. T. Innaris is one of the commonest species in the Bay and was frequently taken on the "Golden Crown." Young individuals from $2 \mathrm{~cm}$. in length were taken in large numbers on the shore at Puri at the commencement of Fiebruary, Igog. In fresh specimens the back is dark bluish or greenish grey, sometimes obscurely marbled with a paler shade. The sides and belly are white.

\section{Tetrodon oblongus, Bloch.}

A common species in the Bay of Bengal frequently recorded on the "Golden Crown.'

The length of the largest specimen is $28 \mathrm{~cm}$.

\section{Tetrodon spinosissimus ('Tate Regan).}

(Plate i, fig. 2.)

Spheroides spinosissimus, Tate Regan, Trans. Limn. Soc. Lond. (2) Zool., voí. xii, part iii, p. 253, p1. 3I, fig. 5 .

There are two specimens in the collection of the Indian Museum from the Gulf of Martaban, taken by the "Investigator" from a depth of Ioo fathoms. 'They differ from Tate Regan's figure in having very much shorter spines, and one of them has numerous small black dots on the tail.

Several specimens from Hongkong agree closely with the original figure.

The species may be distinguished from all those lescribed by Day, in the group with two nasal apertures on each side, by the uniform pale brown coloration of its dorsal surface.

\section{Tetrodon patoca, Hanl. Buch.}

'Two large specimens were taken by the "Golden Crown," one off the Orissa coast in August, Igo8, the other off Gopalpur (Martas Presidency) in September, rgon, the latter measuring $\mathrm{I}_{2}^{1}$ inches in length. The species is common in the estuaries of the Cranges.

There are also several small specinens from Karachi in the collection. In these the pale spots are somewhat obscure. This, however, may be die to the fact that they were originally preserved in formalin. 
igTo.7 N. AnNANDAlE and J. T. JENkins: Plectognathi and Pediculati.

\section{Tetrodon viridipunctatus, Day.}

'This appears to be a species of doubtful validity, as Day's descriptions and figures differ from those of $T$. patoca mainly as regards rnarkings. The type is a painted skin, and no other example is known; moreover, the artificial markings on the type do not at all agree with Day's figure. The specimen, therefore, is hardly even of historical value.

\section{Tetrodon immaculatus, Bloch and Schneid.}

Several specimens have been recorded from both sides of the Bay. The largest specimen in the collection is $2 \mathrm{I}^{\circ} 5 \mathrm{~cm}$. long. The spines in this species are covered with a thick cuticular investment. None of the specimens in the collection have barred sides.

\section{Telrodon migropunctatus, Bloch and Schneid}

This species was not recorded on the "Golden Crown."

There are two specimens in the collection. One is covered with fairly long spines, the other almost naked. In the latter the skin is covered with small, closely set, soft tubercles.

The spiny specimen has no history: the other is from Port Blair in the Andamans.

Tetrodon stellatus, Bloch and Schneid.

Recorded from the "Golden Crown'" on several occasions.

In a series of specimens it does not seem possible to draw any real distinction between Ginther's varieties " and $\beta$, except that variety a probably consists of old and variety $\beta$ of young individuals.

Of Günther's var. $\gamma$ (the Crayracion astrotaenia of Bleeker), we have examined two small specimens; but we do not feel justified in expressing an opinion, in the absence of intermediate forms, as to its distinctness.

\section{Tetrodon fluviatilis, Ham. Buch.}

This species, which appears to be entirely littoral, estuarine and fluviatile, rvas not obtained by the "Golden Crown," but a large series of specimens has been examined.

There are two well-marked varieties in the river Ganges and on the Indian coasts.

In var. A (figured by Hamilton in his Fishes of the Ganges) there are welldefined pale bars across the back, and the caudal fin is more or less definitely spotted or barred. The ventral surface is usually unpigmented.

In var. B (figured by Day in his Fishes of India) the markings are much less distinct, the dorsal surface being marbled rather than barred. The ventral surface is usually pigmented.

Var. B has not yet been examined by us from fresh water, but var. A occurs on the Orissa coast as well as far up the Ganges (Sara Ghat). 
The two varieties were taken together in a trawl on December 6th, I909, in brackish water in the Sattermukhi River, Ganges delta.

Genus 'Tropidichthys, Bleeker.

Key to the Indian species of Tropidichthys.

A.-A large black ocellus present at the base of the dorsal fin.

(a) Pale ocelli on the snout, sides and caudal fin .. T. margaritatus.

$\left(a^{\prime}\right)$ Pale ocelli absent from the caudal fin .. T. bennettii.

B. - No dark ocellus at the base of the dorsal fin.

(b) Dark markings consisting solely of delicate longitudinal and transverse lines; no pale ocelli $T$. investigatoris.

$\left(b^{\prime}\right)$ Somewhat irregular dark bands present; sides with pale ocelli $\quad . \quad \ldots \quad \ldots$ T. valentini.

Bieeker in I 854 referred those species with ridged back and inconspicuous nasal organs to a genus Tropidichthys. In I 865 he called the species with these characters Psilonotus. Günther regarded them as a subgenus of Tetrodon under the name of Anosmins, Peters, I855; and Day treated them as a division of Tetrodon.

\section{Tropidichthys margaritatus, Rüpp.}

(Plate i, fig. 3.)

There are four specimens in the Museum, all taken by the "Golden Crown" off the Madras coast. The lines under the eye are nearly horizontal, and not radiating. There are no horizontal lines on the lower part of the head, and the small ocelli on the tail show a tendency to run together and form ventral bars. Those on the ventral surface are very faint, if they can be distinguished at all.

Tropidichthys investigatoris, sp. nov.

(Plate i, fig. 4.)

Two specimens from the Andamans (St. 239 of the "Investigator") at a depth of 55 fathoms.

$$
\text { D. O-I0. P. Iร. A. IO. C. II. }
$$

Outline of back distinctly angular, the highest point being just above the gillopening. Depth of body very variable. The whole of head and body, except the tail, covered with small spines which lie parallel to the skin. Each spine with two roots.

No dark spot at base of dorsal fin. Fins practically colourless. Back and sides pale brown. Three narrow somewhat sinuous dark lines crossing the snout in front of the eye, the two posterior ones bending inwards towards the orbit; a fourth line joining the orbits near the centre; at least one similar line across the 
back; two or three transverse lines on upper part of each side behind the pectoral; several short vertical lines beneath the eye. Ventral surface cream-coloured.

\section{II.-Suborder PEDICULATI.}

\section{LIST OF THE PEDICULATI OF INDIAN SEAS,}

Fam. Lophidda.

I. Lophins indicus. $t \S$

2. , gracilimanus $\uparrow \S$

3. ,. mutilus. $+\$ 1$

4. , , lugubris. $\uparrow \$$

5. .. triradiatus. $\uparrow \S$

Fam. Ceratimati

6. Lophodolus indicus. $+\S$

7. Melanocoetus sp. $\$$

8. Ceratias bispinosus $\$$

9. Oneirodes glomerosus. $\dagger \$$

Fam. Anteinnaritida.

Io. Chatmax pictus."

Ii. , apus. + s
I2. Antennarius hispidus."

I3. , nummifer.

I4. ", commersonii.s

Fam. Malthidae.

I5. Malthopsis lutea. $†$

I6. ,. triangularis.ts

I7. Halientaed indica.* $+\S$

I8. , nigra t\$

I9. ., coccinea.

20. , stellata."

2I. ,, fumosa.ts

22. Halicmetus ruber. $+\$$

23. Dibranchus nasutus. t\$

$24 . \quad$, micropus. $t \$$

25. , , nudiventer. 4 \$

Of the Indian Pediculati, out of a total of 25 species, 20 are deep-sea forms. Only three have been taken by the "Golden Crown," viz., Antennurius hispidus, Halicutaea stellata and H.indica. The last is described as a new species. All the Indian species are, however, represented in the collection of the Indian Minseum. The deep-sea forms of which the types are in this collection are fully described either in Col. Alcock's Descriptive Catalogue of Deep-Sea Fishes in the Indian. IInsenn, or in Capt. Lloyd's appendix, ${ }^{2}$ and are figured in the Illustrations of the Zoology of the R.I.M.S. "Intestigator.

irey to the Indian Families and Genera of Pedianduti.

I.-Head and body depressed, more or less disk-like.

A.-Gill opening in lower axil of pectoral.

Family I, Lophidar.

Genus Lophinus.

\footnotetext{
1 This and other species of Itopliidae which hare the second portion of the spinous dorsal olsoles. cent are placed by ('oode and Bean in a new genus Lophindes: ser "()ceanic Ichthyology," I3ull. U. S. Nat. Mus., r895, p. 537 .

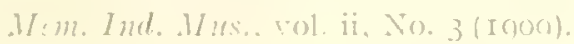


B.-Gill opening above pectoral.

Family II, MAL,THIDAE.

a.-A soft dorsal present.

(a) Palate edentulous; 2 gills .. Dibranchus.

$\left(a^{\prime}\right)$ Palate edentulous; $2 \frac{1}{2}$ gills ... .. Halientaea.

$\left(a^{\prime \prime}\right)$ Teeth on palate and vomers .. . . Malthopsis.

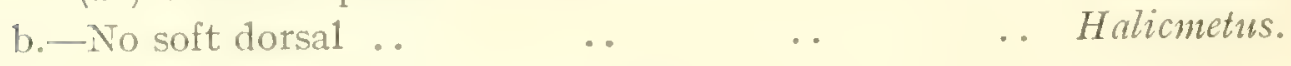

II.-Head and body compressed or rounded.

A.-Pectoral fin straight.

Family III, CERATIIDAE.

a.-Skin smooth.

(a) A pair of cephalic spines; a jointed dorsal filament situated behind the head .. . Lophodolus.

(a') Dorsal filament on snout ... . . Melanocoetus.

$\left(a^{\prime \prime}\right)$ Two dorsal filaments .. .. Oncirodes.

b. - Skin covered with minute prictles .. $\quad \ldots$ Ceratias.

B.-Pectoral fin distinctly elbowed.

Family IV, ANTENNARIIDAE.

(a Body not much compressed; spinous dorsal consisting of I or 2 unprotected tentacles ..

(b) Body compressed and elevated; spinous dorsal

Channax. consisting of 3 spines, of which the first is tentacular

. Antennarins.

Family MAL,THIDAE,

Genus Halieutaea, Cuv. \& Val.

Key to the Indian species of Halieutaea.

I.-Under surface of disk covered with perfectly smooth, glandular, nearly transparent skin.

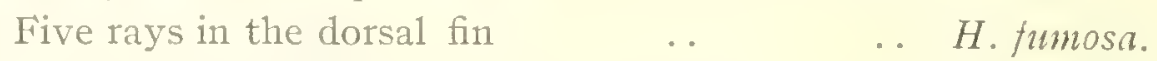

II.--Under surface of disk bearing minute stellate spines or granules covered with skin which is opaque or slightly translucent.

A.-Four rays in the dorsal fin.

(a) Roof of tentacular cavity extending forward as far as the edge of the disk; caudal and pectoral fins not edged with black .. H. indica. 
$\left(a^{\prime}\right)$ Roof of tentacular cavity not extending to the margin of the disk; caudal and pectoral fins edged with black

B.-Five rays in the dorsal fin.

(b) Disk flat $\quad \ldots \quad$. $\quad \ldots \quad H$. nigra.

(b') Disk distinctly convex in front .. H. coccinea.

Halieutaea indica, sp. nov.

(Plate ii, fig. 4.)

H. stellata, Day (nec Kïhl), Faun. Brit. Ind., Fishes, p. 234, fig. 85 .
D. 4. V. I, 5 .
A. 4 .
P. I3.
C. 9 .

Tail, excluding the caudal fin, from $\frac{1}{4}$ to $\frac{1}{3}$ length of disk. Caudal usually slightly longer than the tail, occasionally of the same length. Length and width of disk approximately equal. Dorsal surface covered with numerous strong subequal spines, many of which are bifid; at the edge many are trifid. Most of the spines have four roots; at the edge of the disk they project freely and are accompanied by delicate cuticular processes. The anterior extremity of the ron of the tentacular cavity reaches or is slightly in advance of the anterior extremity of the disk, and the aperture of the cavity is vertical, so that the cavity is concealed from above. The strong spine at each side of it projects beyond the margin of the disk. Superciliary ridge with strong spines. Interorbital space equals or slightly exceeds diameter of eye. The ventral surface with minute scattered spines.

Colour (in spirit). Dorsal surface white, densely covered with very minute black dots, which are grouped together in places to form thin lines and reticulated patterns. Ventral surface white (somewhat translucent) with scattered minute black and opaque white dots. Pectoral fins colourless, caudal fin clouded with grey, occasionally with white, vertical bands. Colour of dorsal surface of living specimens pink.

This is undoubtedly the species figured by Day as $H$. stellata of Kühl, but it differs from the latter species, amongst other characters, in the following points:-

(I) The spines on the dorsal surface are less strongly developed.

(2) The extremity of the roof of the tentacular cavity extends at least as far forwards as the edge of the disk.

Professor Max Weber, who has been kind enough to examine a specimen, agrees with us in regarding this species as distinct.

$$
\begin{aligned}
& \text { Halientaca stellata, Kühl. } \\
& \text { (Plate ii, fig. 3.) } \\
& \text { D. 4. V. I, 5. A. 4. P. I3. C. } 9 .
\end{aligned}
$$

Tail, excluding the caudal fin, $\frac{1}{3}$ length of disk. Caudal fin nearly the same length as the tail. 
1)isk distinctly broader than long. Dorsal surface covered with stout stellate spincs, most of which have more than four roots. They vary considerably in size, but none are very smali. Over the greater part of the disk the spines are single At the edge, where they are accompanied by numerous cuticular processes, they have at least four sharp pcints. The anterior extremity of the roof of the tentacular cavity does not reach the alge of the disk. The aperture of the cavity slopes downwards and forwards, so that it is partly visible from above. The disk is much flatter than in $H$. coccinea. Superciliary ridge with strong simple spines. Interorbital space distinctly broader than diameter of eye. Ventral surface with very minute and widely scattered spines.

Colour (in spirit). Dorsal surface pinkish grey with numerous black spots, the centre of each of which is much darker than the periphery. These spots tend to be arranged in eight groups, four on each lateral half of the disk. The most marked group is that on each sicle of the centre of the mid-dorsal region. 'The whole of the dorsal surface is covered with minute pigment cells; the ventral surface white. In life the ground colour of the dorsal surface is a deep red.

Pectoral and caudal fins white, broadiy edged with black. Dorsal fin black, edged with white.

This species appears to reach a much larger size than $H$. indica. In some respects it resembles $H$. coccinca, but the disk is much flatter, the spines on the dorsal surface are stouter, and those on the ventral surface are smaller or more widely scattered. The coloration is also different, and there are only + rays in the dorsal.

WV had proposed to describe this species as new, but notes that Prof. Max Weber has been kind enough to send convince us that we would have been wrong in so doing.

$$
\begin{aligned}
& \text { Family ANTENNARIDDAE. } \\
& \text { Genus ANTENNARIUs, Cuv. } \\
& \text { Fey to the Indian species of Antennarius. }
\end{aligned}
$$

T.-Skin devoid of spines

Skin bearing numerous foliaceous processes _. . marmoratus.

II.-Slin covered with ninute spines.

1. - Sicles pale with numerous clark streaks, which

radiate from the eye and from the pectoral fin.. A hispidus.

I3. - Sides variously mottled or spotted.

(b) First dorsal spine (tentacle) longer than the second

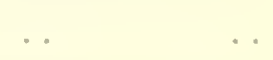

A. commersonii.

$\left(b^{\prime}\right)$ First dorsal spine not longer than the second

A. nummiter.

Antenurius hispidus, Bloch and Schneid.

Two specimens have been taken hy the "Golden Crown" off the Ganjam coast. There are several others in the collection of the Indian Museum, one of which from 
Dhappa near Calcutta (if the locality is correct) must have been taken in brackish water.

The series examined exhibit considerable variation as regards marking, but all the specimens differ from Günther's figure, 'in that the markings on the posterior part of the sides of the body take the form of streaks instead of spots. There is considerable variation in the length of the tentacles and in the form and size of the tuft at its extremity. Day's figure is taken from a shrivelled and distorted specimen still in the collection of the Indian Museum. The body is much deeper than he represents it.

\section{Antennarius mummifer, Cuv.}

(Plate i, fig. 5.)

If Günther is correct as to the synonymy of this species, Day's figure in the Fishes of India" represents not it but a variety of $A$. commorsonii, Güth. "There is, however, a specimen in the collection of the Indian Museum that agrees fairly well with Bleeker's figure of 4 . coccinens, which Ginther regards as a representation of the true $A$. nummifer. It is by no means improbable that these three forms, as well as several others, will ultimately prove to be conspecific.

\section{Antennarius commersonii (Lacép.).}

Day's specimen in the collection of the Indian Nuseum, although apparently not the one he figured as $A$. nummifer in the Fishes of India, belongs perhaps to Günther's A. commersonii var. B. The spots, however, are less numerous than in the individuals figured by the latter author. There are several young specimens in the collection (length from 28 to $42 \mathrm{~mm}$.) which agree fairly well with the definition and figure of var. A of the same species, except that the first dorsal spine is distinctly shorter than the second. Perhaps they are the young of that form. These specimens are from Bombay.

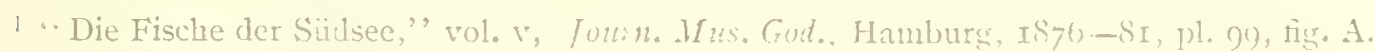

2 Ibid., p. I63, pls. [Ou-Iob.

s late lix, fig. 2 .

+ Atlas lchthyologique, rol. v, pl. cxevii, fig. 2 (IS65).

b Notably A. tridens (Schlegel); see I'ietschmann in Ann. h. k. Vutuh. Hojmus., vol. xxiii. 1). I, pl. i (Vienna, Igog). 


\title{
PART IV.-ON A COLLECTION OF INDIAN PLEURONECTIDAE.
}

\author{
By J. T. Jenkins, D.Sc. (Wales), Superintendent, Lancashive and Western Sea \\ Fisheries.
}

This collection was for the most part obtained by the Bengal Government's steam trawler the "Golden Crown" in the Bay of Bengal during Igo8-og. A few specimens from the 'Trivandrum Museum, from the Indian Marine Survey collection, and several collected by Dr. Annandale on Puri beach are also included. Nost of the species figured in the accompanying plate (pl. iii) have been described in the Records of the Indian Museum, vol. v, pp. I23-I 40 (Igro).

So far as the observations of the "Golden Crown" extended it would appear that the Pleuronectidae are not so abundant in the Bay of Bengal between ro and 35 fathoms as they are on similar ground in British waters. The genus Plenronectes, which is frequently taken in enormous quantities in the seas of Northern Europe, and is a valuable commercial fish, is entirely absent in the Bay, and its place is apparently taken by the genera Psendorhombus and Psettodes. At any rate these genera are found in localities which would in England be inhabited by Plewronectes. The habitat of the two common species of Pseudorhombus, $P$. arsins and P. javanicus, is similar to that of the Dab (Pletronectes limanda), while Psettodes crmmei may be taken to be the representative of the Flounder (Plentronectes flesis) in Indian waters.

Of the "soles," the genera Cynoglossius and Synaptura are characteristic of depths between Io and 35 fathoms, while Plagusia, which was rarely taken on the "Golden Crown," would appear to frequent shallower areas since it is commonly taken by the beach fishermen at Puri. The commonest sole in the Bay is Cynoglossus macrolepidotus, and this species formed the bulk of the commercial "sole" of the "Golden Crown." So far as the limited observations in the Sunderbuns extended, it seems that Cynoglossus extends well into the estuaries, at any rate specimens were captured at Morrelganj and Kan Rondighee. At the latter place the salinity is very slight, the reading with the Kiel araeometer being $r^{\circ}$ oogo.

\section{PLEURONECTIDAE.}

$$
\text { PSETTODES, Bennett. }
$$

Psettodes entmei, Bloch and Schneid.

Numerous specimens of this species were obtained by the "Golden Crown." It is especially abundant on the muddy grounds off the entrance to the Eastern Channel (mouth of the Hughli). 
Three specimens were added to the IInseum collection from the "Golden Cromn.

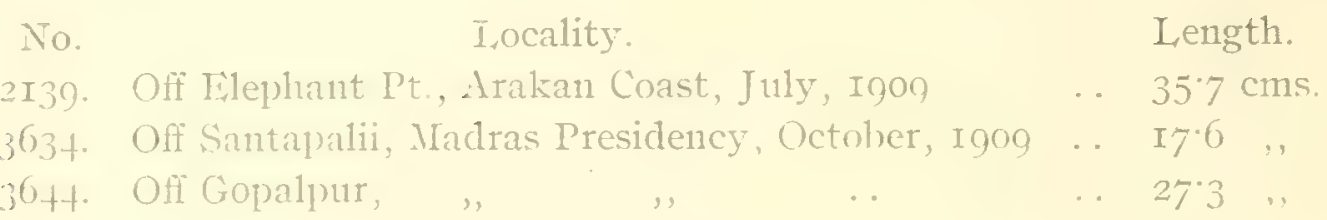

PSEUdORHOMBus, Bleeker.

Three species of Pscudorhombus are represented in the coilection, siz.:-

I'seudorhombus arsins, Bleeker.

Psendorhombus javanicus, Bleeker.

Psendorhombus messellii, Gray.

As is the case in British Pleuronectidae, there is a considerable variation in colour and marking within the limits of a single species. This is especially noticeable in the case of the specimens of Psendorhombus arsins. The presence of intermediate specimens hetween the extreme colour varieties, however, renders it certain that only one species is represented.

\section{Psendorhombus arsius, Bleeker.}

This species is distinguished from the nearly related $P$. jaiminas by the larger number of dorsal fin rays (over 7o) and the enlarged anterior teeth.

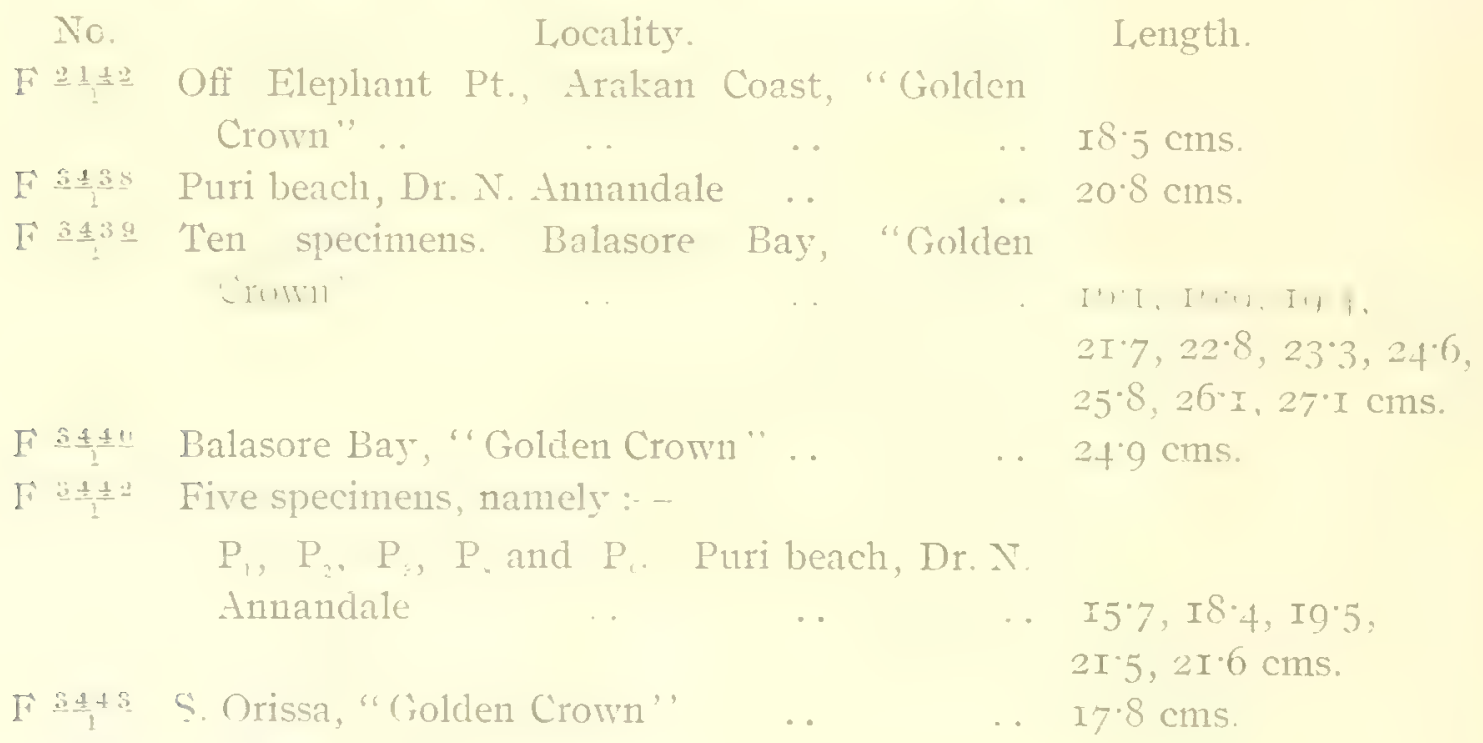

\section{I'sendorhombus juranicus, Bleeker.}

Day in his description of this species says "A well-developed pre-anal spine." whereas in $P$. arsius the "pre-anal spine, when present, is but slightly apparent."

According to my observations this spine is occasionally well-developed (vide

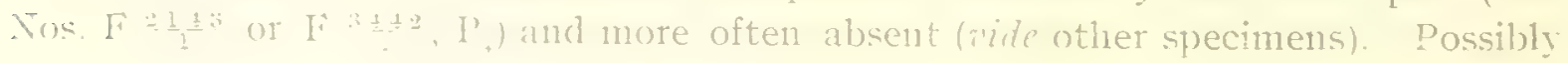


this is a sexual difference; at any rate it does not serve as a specific distinction from $P$. arsins. It will be noticed that the specimens of $P$. javanicus are on the arerage smaller than those of $P$. arsins.

No. Locality. Length.

F $21+\frac{1}{1}$ Off Elephant Point, Arakan Coast, "Golden

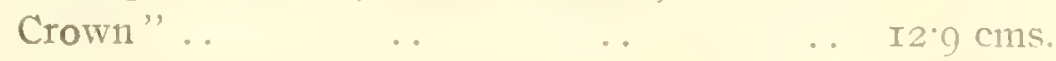

F $\frac{34}{1} 1$ Puri beach, Dr. N. Annandale .. . I $6.6 \mathrm{cms}$.

F $33_{1}^{4} 2$ Four specimens- $\mathrm{P}_{4}, \mathrm{P}_{5}, \mathrm{P}_{6}, \mathrm{P}_{7}$. Puribeach, Dr. N. Annandale . $\quad \ldots \quad \quad \ldots \quad I I 4, I 33, I 3 \%$, and $16^{\circ}+$ chis.

Pseudorhombus russellii, Gray.

Day evidently regards this species as identical with $P$. arsius, but from an examination of this collection I am convinced that the species are distinct.

I2242. Off Orissa Coast, Marine Survey.

The Indian species of Psendorhombus may be distinguished by the following characteristics:-

Anterior teeth enlarged $\{$ Dorsal fin rays over $70 \ldots P$. arsizs, Bleeker.

Teeth minute $\quad \cdots\left\{\begin{array}{l}\text { Longest dorsal rays at com- } \\ \text { mencement of posterior } \\ \text { half of fin } \ldots \text {. Prellit, Gray. } \\ \text { Anterior dorsal rays elevated P. triocellatus, B1. Sch. }\end{array}\right.$

The following table gives the height, length, ratio of height to length of hody (inclusive of caudal) and the number of dorsal and ventral fin rays in the various specimens of Pseudorhombus examined:-

\begin{tabular}{|c|c|c|c|c|c|c|}
\hline No. & Length; $\mathrm{mm}$. & Height. & Ratio H. to L. & Dorsal fin raỵs. & $\begin{array}{l}\text { Ventral fin } \\
\text { rays. }\end{array}$ & Species. \\
\hline $2 I_{4} 2$ & $18_{5}$ & 83 & $2: 2$ & 74 & 6 & $P$. arsius. \\
\hline 3438 & 208 & 90 & $2 \cdot 3$ & $7 \mathrm{I}$ & 6 &, \\
\hline $3439_{15}$ & $27 I$ & 120 & $2 \cdot 2$ & 74 & 6 & ," \\
\hline$\therefore 15 \pi$ & 246 & I04 & 24 & 75 & 6 & , \\
\hline, $15 b$ & 258 & I08 & $2 \cdot 4$ & 75 & 6 & \\
\hline,$\quad 15 c$ & $26 I$ & $\mathrm{II}_{5}$ & $2 \cdot 3$ & 73 & 6 & ", \\
\hline, $15 d$ & 233 & 95 & $2 \cdot 5$ & 74 & 6 & , \\
\hline , 15e & I94 & $8 \mathrm{I}$ & $2 * 4$ & 76 & 6 & , \\
\hline
\end{tabular}




\begin{tabular}{|c|c|c|c|c|c|c|}
\hline No. & Length, mm. & Height. & Ratio H. to $I_{1 \cdot}$ & Dorsal fin rays. & $\begin{array}{c}\text { Ventral fin } \\
\text { rays. }\end{array}$ & Species. \\
\hline $343915 f$ & 228 & 94 & $2 \cdot 4$ & 74 & 6 & $P$. arsius. \\
\hline$\therefore 15 q$ & 217 & 92 & $2 \cdot 3$ & 73 & 6 & ", \\
\hline,, $35 h$ & I6I & 69 & $2 \cdot 3$ & 75 & 6 & ", \\
\hline, $215 i$ & I69 & $7 x$ & $2 \cdot 4$ & 73 & 6 & $"$ \\
\hline $344^{\circ}$ & 249 & 105 & 24 & 76 & 6 & ", \\
\hline $344^{2} \mathrm{pl}$ & I57 & 63 & $2 \cdot 5$ & 74 & 6 &, \\
\hline$\because p^{2}$ & 216 & 89 & $2 \cdot 4$ & 73 & 6 & ", \\
\hline,$n$ & I 84 & 83 & $2 \cdot 2$ & 75 & 6 & $"$ \\
\hline,$n s$ & 215 & $9^{\mathrm{r}}$ & $2 \cdot 4$ & $7 I$ & 6 & $"$ \\
\hline,$p 9$ & 195 & 87 & $2 \cdot 2$ & $?$ & 6 & , \\
\hline 3443 & 178 & 73 & $2: 4$ & 76 & 6 & ", \\
\hline 2143 & 129 & 53 & $2 \cdot 4$ & 69 & 6 & P. javanicus. \\
\hline $344 \mathrm{I}$ & I66 & 70 & $2 \cdot 4$ & 70 & 6 & $"$, \\
\hline $3442 \mathrm{pt}$ & I33 & 56 & $2 \cdot 4$ & 68 & 6 & $"$ \\
\hline,$p j$ & I 37 & 58 & 24 & 69 & 6 & $"$, \\
\hline,$p 6$ & I64 & 69 & $2 \cdot 4$ & 68 & 6 & ", \\
\hline,$p 7$ & II 4 & $4^{8}$ & $2 \cdot 4$ & 69 & 6 & , \\
\hline 12242 & 107 & 45 & $2 \cdot 4$ & 69 & 6 & P. russellii. \\
\hline
\end{tabular}

Platophrys, Swainson.

Platophrys was sparingly obtained by the "'rolden Crown." Occasionally it was met with in rough ground off the Arakan Coast in the neighbourhood of Oyster Island. One species only was taken.

\section{Platophrys pantherimes, Rüpp.}

2622. Arakan Coast, January, Igog. Length, $9.6 \mathrm{cms}$.

Rномпвогдіснжну, Bleeker.

At least two species are met with in the "Golden Crown" collection, both being obtained off the Arakan Coast in January, I9o9, in the same locality as Platophrys pantherimus. Neither species had previously been recorded from the Arakan Coast.

Rhomboidichthys valderostratus, Alcock.

2623. Mrakan Coast, January, I909. Length, $8 \cdot 2$ and $7 \cdot 5 \mathrm{cms}$.

2624. ", , , , , $\quad 6 \cdot 2,7^{\circ} 1,7^{\circ} 7$ and $7^{\circ} 7 \mathrm{cms}$. 
Rhomboidichthys azureus, Alcock.

2625. Arakan Coast, January, Igog. Length, $7 \cdot 6 \mathrm{cms}$.

BRACHYPL,EURA, Günther.

Brachypleura xanthosticta, Alcock.

This species was recorded from the Ganjam Coast, whence Alcock's type specimens were obtained, and also off the entrance to the Eastern Channel at the mouth of the Hughli.

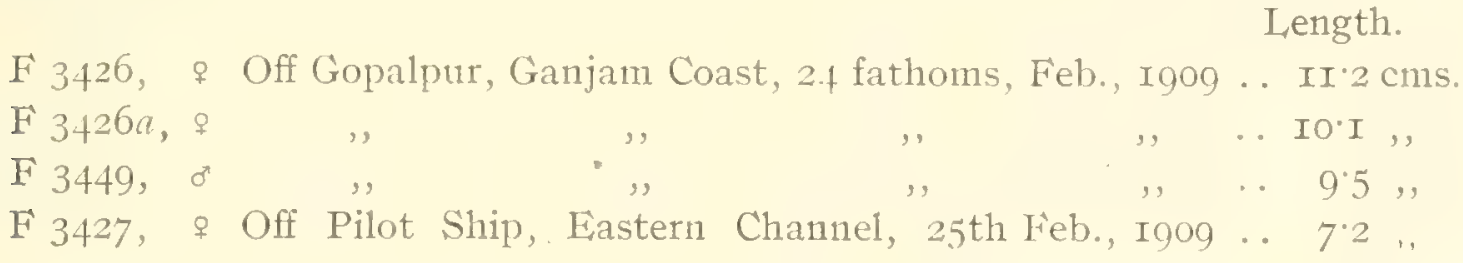

\section{PSE'TTYLIS, Alcock.}

This genus was established by Alcock' in I 890 for a number of Pleuronectids allied to Rhomboidichthys. One of the generic characters as given by Alcock is "no scales" " but I agree with Johnstone " that the body is covered with scales which are cycloid, except at the bases of the dorsal and anal fins, on the ocular side, where they are ctenoid. The single specimen in the collection is Psettylis ocellata.

\section{Psettylis ocellata, Alcock.}

$\mathrm{F} \pm 1 \frac{1}{1} \underline{3}$, Indian Marine Survey Station $387,49-$ fo fathoms. I at. X. $15^{\circ} 25^{\prime}$. Isong. E.. $933^{\circ}+5^{\prime}$.

\section{SCIANECTES, Alcock.}

Scianectes macrophthalmus, Alcock.

This species was described by Alcock" from a specimen taken at a depth of roo fathoms off Akyab. It was obtained in much shallower water by the "Golden Crown ' off Puri on March I5th, Igog.

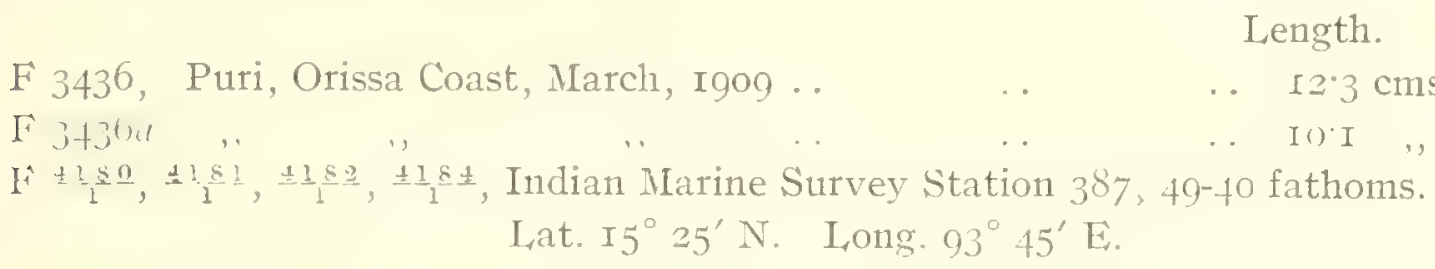

${ }^{1}$ Amm. Mag. Nat. Hist. (6), vi, I8go, p. 436 .

'Ibid., p. 437, and Descriptive Catalogue of the Indian deep-sea Fishes in the Indian Musenm, Calcutta, I899, p. I24.

${ }^{3}$ Rep. Ceylon Pearl Oyster Fish., pt. ii, p. 207 (Roy. Sac. Lond., 1904).

+ See Journ. As. Soc. Beng., vol. 1viii, pt. ii, No. 3, I889. 
SOLEA, Klein.

When fishing off the Ganjam Coast on the "Golden Crown," the trawl brought up a specimen of what at first sight appeared to be a Synaptura zebra or allied species. 'The caudal fin was, however, distinctly separate from the vertical fins. Subsequently another specimen was obtained in the same locality.

The term "Symaptura" was first applied by Cantor,' to distinguish a subgenus of Solea, in which the caudal, dorsal and anal fins are all united. In other respects the subgenus has the general structure of Solea.

Subsequently, when looking through some of the "Investigator" Pleuronectidae, three specimens were found provisionally labelled "Symaptura quagga," one of which was undoubtedly Synaptura commta (Kaup) (see below), and the other two showed the same distinction of the caudal fin, and are consequently referred, together with the two "Golden Crown" specimens, to a new species of Solea, here described as Solea syncupturoides.

Solea synapturoides, sp, nov. (Plate iii, figs. $4,4 a, 4 b$.

Type specimen Fi is $\frac{1}{3}$ ?

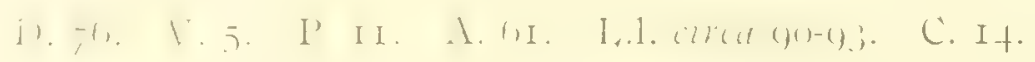

I. ength of head $5 \frac{1}{2}$, height of body 3 in total length inclusive of caudal.

The eyes are situated close together less than half a diameter apart, the upper being slightly in advance of the lower. Diameter 5 in length of head and about a diameter or slightly more from end of snout.

Nostrils on coloured sicle at end of tube, which is situated just anterior to the lower orbit.

Fins.--Dorsal and anal rays unbranched. Both pectorals present.

Colour.--Slate-coloured, with nine dark transverse unbranched bands on body and seven or eight on head.

Locality.-Off Ganjam Coast, $24 \cdot 30$ fathoms. Obtained on the Steam Trawler "Golden Crown."

Achirus, Lacépède.

One specimen of this genus was identified in the "Golden Crown" collection, namely, Achims maculatus, B1. Schn., taken off the Ganjam district of the Madras Presidency in March, Igog.

Achims maculatus, Bloch and Schneid.

Ii 3428. Ganjan Coast, off Sonapur, March, I9o9. Length ro.o cms.; depth 20 to 25 fathoms.

\section{SynAPTURA, Cantor.}

There are four species of Synaptur represented in the collection, and of these "wo were recorded on the "Golden Crown."

"Catalogue of Mralityan Fishes," Joum. As. Soc. Bengal, vol. xviii, p. I204. 
Symaptura commersomiana, Iracép.

F 2328. Off Burmese (Arakan) Coast, I7th November, Igo8. I, ength, $23^{\circ} 4$ cms. "Golden Crown."

Symaptura altipinnis, Alcock.

A specimen of this species was taken by the "Golden Crown" off the Ganjam Coast in from 2t-30 fathoms. Alcock's type was recorded from the Vizagapatam Coast from similar depths (25 fathoms).

F 2472. Ganjam Coast, 24-30 fathoms, February, I909. I ength, I $8 \cdot 0$ cms. "Golden Crown."

Synaptura orientalis, Bloch and Schneid.

F $\pm \frac{1}{1} \frac{9}{1}$, Quilon, Trivandrum Museum, R. S. N. Pillay coll.

$\mathrm{F} \pm \frac{1}{1} \frac{86}{6}$, Trivandrum ,

Synaptura comuta (Kaup).

A specimen of this species occurs in the collection. It had been labelled provisionally "Synaptura quagga." There can, however, be no doubt, from the cycloid scales and the first dorsal ray being thickened and prolonged, that the specimen belongs to this species.

F $\frac{82}{1} \frac{5}{2}$, Off Malabar Coast, 68 fathoms, Marine Survey _. I $2 \cdot 6 \mathrm{cms}$.

Plagusia, Cuvier.

The genus Plagusia appears to be an inshore genus At any rate, it is far commoner on Puri beach than in the "Golden Crown" hauls. P. bilineatu was occasionally taken on the "Golden Crown." Both species are represented in the collection.

\section{Plagusia bilineata, Bloch.}

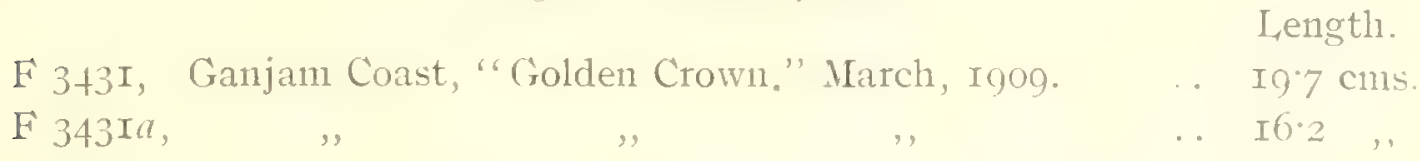

Plagusia marmorata, Bleeker.

F $\pm \underline{1} \mathbf{1}$, young specimen, Puri beach, Dr. Annandale.

\section{ApHoristia, Kaup.}

There is one damaged Plentonectid in the collection which is referable to the above genus. In this specimen the head is badly damaged, and it is not possible to determine the extension of the month-cleft with reference to the eyes. Both sides of the body are coloured, and there are no cross-bands, consequently the species is either Aphoristia wood-musoni, Alcock, or Aphoristin gilesii, Alcock. The fact that 
the anal fin commences a little way behind the ventral and not closely adjacent to it leads me to place this specimen in the former species, which has previousiy been recorded from the Andaman Sea.'

Aphoristia wood-masoni, Alcock.

$\mathrm{F} 11 \pm 0$, Station 332, Indian Marine Survey, 279 fathoms.

Lat. N. $10^{\circ} 2 I^{\prime}$. Long. E. $92^{\circ} 46_{4}^{1}$.

Cynoglossus, Ham. Buch.

At least three species were obtained on the "Golden Crown" and of these Cynoglossus macrolepidotus was by far the commonest, this species being the commercial "sole" of the "Grolden Crown."

Cynoglossus macrolepidotus, Bleeker.

F 3648, Off Pilot Ship, Eastern Channel, mouth of Hughli, I, ength.

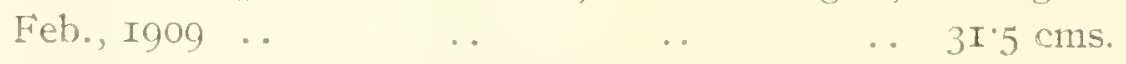

F 3445, Off Puri, Orissa Coast, September, Igo8 ․ 230 ,"

F $3445^{a}$, , , , , , . . 2 $23^{\circ} 0$,"

Cynoglossus semifasciatus, Day.

F 3437, Puri Coast, "Golden Crown," March, Igog .. Length, II*4 cms.

Cynoglossus quatrilineatus, Bleeker.

F 3444, Elephant Pt., Arakan Coast, "Golden Crown,"

July, $\operatorname{Igo8} \quad \ldots \quad \ldots \quad$ Length, $26.7 \mathrm{cms}$.

Cynoglossus puncticeps, Richardson.

$\mathrm{F} \pm \frac{1}{1} \frac{5}{5}$, Trivandrum, Trivandrum Museum.

Ii $\pm \frac{1}{1} \leq 1, \quad$, , , .

Cynoglossus lida, Bleeker.

There are two specimens in the collection from the Trivandrum Museum which more nearly resemble this species than any other. The number of rows of scales between the lateral lines on the coloured side is slightly higher than that given by Day as characteristic for the species, being from I6 to I7 instead of I3. In other respects the resemblance is very close. One of the specimens $\left(\mathrm{F}^{ \pm} \underline{1} \underline{1}, \underline{8}\right)$ has the coloured side marked with blackish dots. There is, however, a great amount of colour

1 See Alcock, Journ. As. Soc. Beng., vol. 1viii, part ii, No. 3, IS89, p. 294. 
IgIo.]

variation amongst Pleuronectids, and consequently it would be safer to regard both these specimens as belonging to the same species.

$\vec{F} \pm 1$, 토, Trivandrum, Trivandrum Museum.

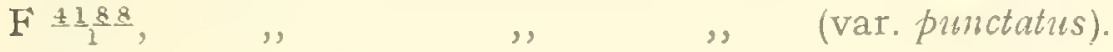




EXPLANATION OF PLATE I.

I'I(;. I.-Trygon fluviatilis (much reduced).

2.-Tetrodon spinosissimus, $\times \quad I \frac{1}{2}$.

. 3.-Tropidichthys margaritatus, $\times \quad \mathrm{I} \frac{1}{2}$.

. 4.- ,, investigatoris, sp. nor., $\times \quad \mathrm{I} \frac{1}{2}$.

,. 5-Antennarius nummifer, $\times \mathrm{I} \frac{3}{2}$. 


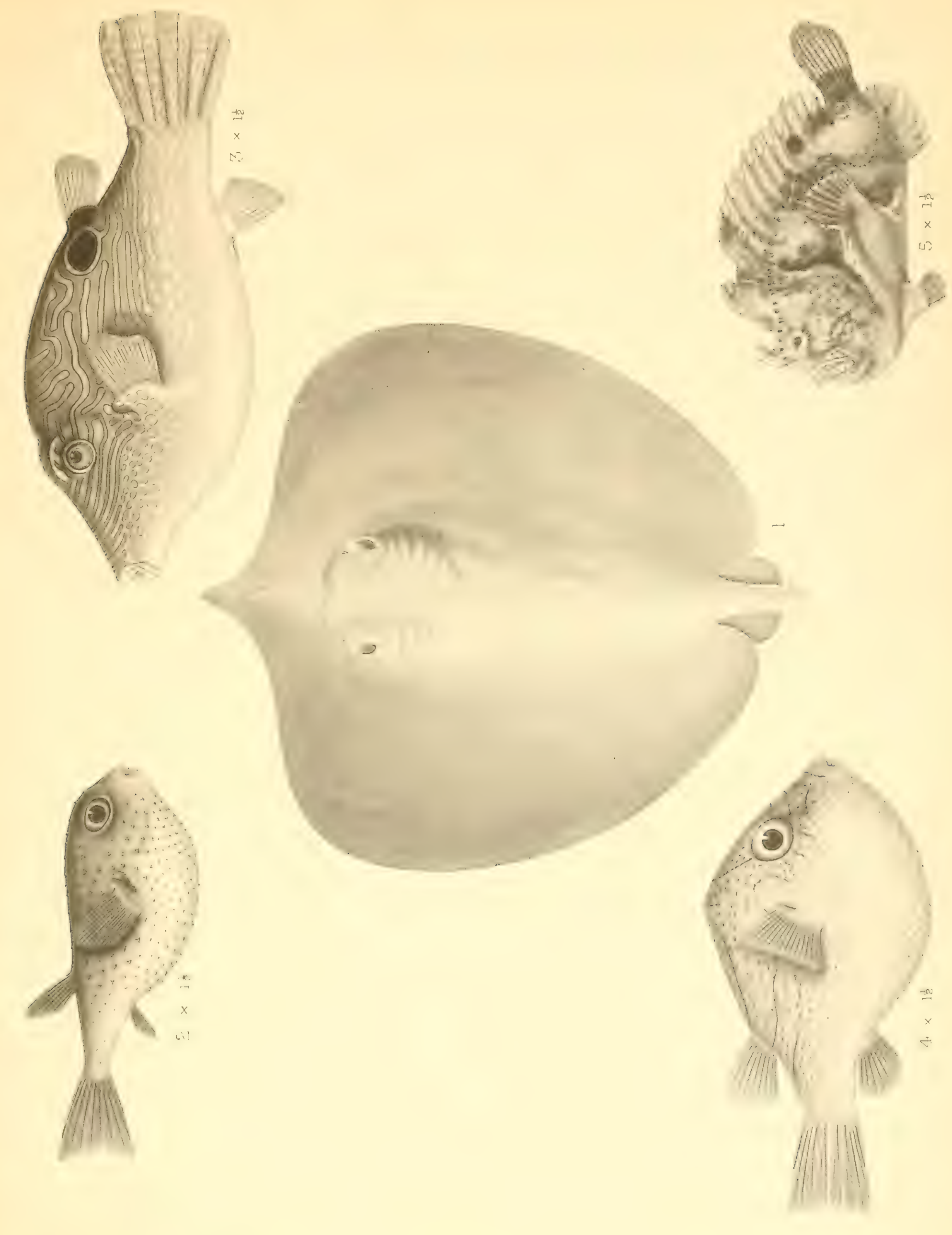




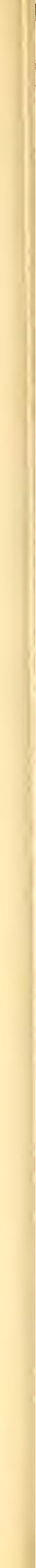


EXPLANATION OF PLATE II.

Figs. I, I $a$, Ib.-Cogymms asperimus (young $c^{\prime}$ ): I, I $a$, reduced; Ib, nat. size.

IIIG. 2.-Aetobatis namari (young o), reduced.

,, 3.-Halientaea stellata, reduced.

, 4.- " indica, sp. nov., nat. size. 




\section{EXPLANATION OF PLATE III.}

Fig. I.-Plagusia obscura, Jenkins. (Described Rec. Ind. Mus., v, p. I34.)

, ra.- ", , scale from coloured side of body.

, I $b$. - , , ," , blind ," ,"

, 2.- Solea sindensis, Jenkins. (Described ibid., p. I33.)

, $2 a$ and $2 b$. - Scales from coloured and from blind side of body of Solea sindensis, $\times \mathrm{I} 6$.

, 3.-Cynoglossus acinaces, Jenkins. (Described, ibid., p. I30.)

,$\quad 3 a$ and $3 b$. - Scales from coloured and from blind side of body of Cynoglossus acinaces, $\times \mathrm{I} 6$.

"4. Solea synapturoides, sp. nov.

, $4 a$ and $4^{b}$. - Scales from coloured and from blind side of body of Solea synapturoides, $\times 8$.

,. 5.-Cynoglossus deltae, Jenkins, $\times$ 2. (Described ibid., p. I30.)

,$\quad 5 a$ and $5 b$. - Scales from coloured and from blind side of body of Cynoglossus deltae, $\times$ I6. 

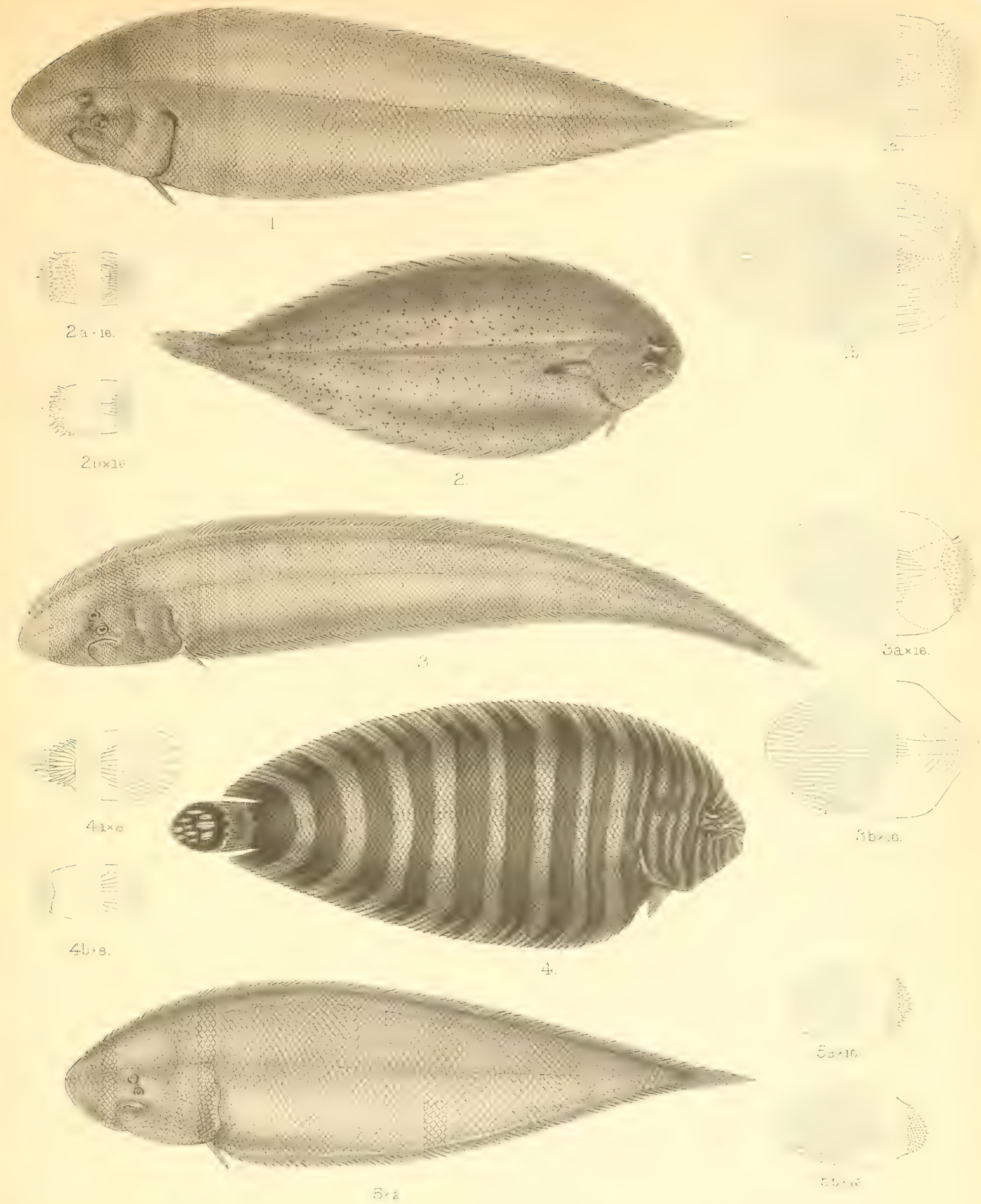



\title{
INDIAN MUSEUM
}

\author{
( A JOURNAL OF INDIAN ZOOLOGY)
}

Vol. I, 1907.

P.drl $I$-Contributions to the Fauma of the Arabian Sea. Records of Hemiptera and Hymenoptera from the Himalayas. Further notes on Indian Freshwater Entomostraca. The Fauna of Brackish Ponds at Port Canning, Lower Bengal, I-III. A Sporozoon from the Heart of a Cow. Miscellanea.

Part II.-Revision of the Oriental Stratiomyidæ. Description of an Oligochæete Worm allied to Chatogaster. The Fauna of Brackish Ponds at Port Canning, Lower Bengal, IV. Further Note on a Polyzoon from the Himalayas. Reports on a collection of Batrachia, Reptiles and Fish from Nepal and the Western Himalayas. The Fauna of Brackish Ponds at Port Canning, Lower Bengal, V. Notes on Oriental Diptera, I and II. Miscellanea.

Part I11.-Report on the Marine Polyzoa in the collection of the Indian Museum. The Fauna of Brackish Pouds at Port Canning, Lower Bengal, VI. A third note on Earwigs (Dermaptera) in the Indian Museum, with the descrip. tion of a new species. Notes on Oriental Diptera, III. Description of a new suake from Nepal. Notes on a collection of marketable fish from Akyab, with a description of a vew species of Lactarius. Description of two fresh. water Oligochæte Worms from the Punjab. Notes on Phosphorescence in Marine Animals. Notes on the rats of Dacca, Eastern Bengal. Notes on Freshwater Sponges, I-V. Miscellanea.

Pavi IV.-Nudiclava monocanthi, the type of a new genus of Hydroids parasitic on Fish. Preliminaty descriptions of three new Nycteribiide from India. Annotated Catalogue of Oriental Culicidæ. Notes on Oriental Diptera. Notes on Freshwater Sponges; VI, VII. Description of a new Cyprinid Fish of the genus Danio from Upper Burma. Miscellanea.

\section{Vol. II, 1908-1909.}

Part I.-The retirement of Lieut.-Col, Alcock, with a list of his papers, etc., on Indian Zoology. The Fauna of Brackish Ponds at Port Canning, Lower Bengal, VII. Description of a New Dictyonine Spcnge from the Indian Ocean. Notes 'on Freshwater Sponges, VIII. Remarkable cases of variation, I. Description of a vew species of Lizard of the genus Salea, from Assam. The Fanna of Brackish Ponds at Port Canning, Lower Bengal, VIII. Description of a new Carernicolous Phasgonurid from Lower Siam. Descriptions of new species of Marine and Freshwater Shells in the collection of the Indian Museum. Notes on Orieutal Syrphidæ, I. Description of a new variety of Spongilla loricata. Notes on Oriental Diptera, V. Miscellanea.

Part II.-Gordiens du Musée Indien. The Fauna of Brackish Ponds at Port Canning, Lower Bengal, IX. Description of a new species of Danio from Lower Burma. Rhynchota Malayana, I. Cimex rotundatus, Signoret. Notes on Freshwater Sponges, IX. Fruit Bats of the genus Pteropus inhabiting the Andaman and Nicobar Archipelagos. A new species of Sun-Bird obtained near Darjiling. Three Indian Phylactolæmata. On two new species of EagleRays (Myliobatidæ). Description of a new species of the genus Sesarma, Say,, from the Andaman Islands. Descriptions of new species of Land, Marine, and Freshwater Shells from the Audaman Islands.

Part II1. - The Fauna of Brackish Ponds at Port Canning, Lower Bengal, $\mathbf{X}, \mathbf{X I}$. On some Oriental Solifugæ with descriptions of new forms. The difference between the Takin (Budorcas) from the Mishmi Hills and that from Tibet, with notes on variation displayed by the former. On Caridina nilotica (Roux) and its varieties. Description of a new species of Charaxes from the Bhutan Frontier. First Report on the Collection of Culicidæ and Corethridæ in the Indian Museum, with descriptions of new genera and species. Miscellanea.

Part IV.-Report on a collection of aquatic animals made in Tibet by Capt. F. H. Stewart n 2907 , I. Notes on Aculeate Hymenoptera in the Indian Museum, I. Indian Psychodidæ. Description of a new species of mouse from the Madura District, Madras. Some Cleridæ of the Indian Museum. The Fauna of Brackish Ponds at Port Canning, Lower Bengal, XII. Description of a new species of Saw-Fish captured off the Burma Coast. A new Sting Ray of the genus Trygon from the Bay of Bengal. New Micro-lepidoptera from India and Burma. Notes on some Chrysomelid Beetles in the collection of the Indian Museum. Six new Cicindelina from the Oriental Region. Description of a new slug from Tibet.

Part V.--Revision of the Oriental Leptidæ. Revised and annotated Catalogue of Oriental Bombylidæ, with descriptions of new species.

Pari I. - The Races of Indian Rats.

Vol. III, 1909.

Part II.-Notes on Freshwater Sponges, $\mathbf{X}$. Report on a collection of aquatic animals made in Tibet by Capt. F. H. Stewart in I907, II. Note on some amphibious Cockroaches. Description de quelques nouvelles Cécidomyies des Indes. Description of new land and marine shells from Ceylon and S. India. Description of two new species of Caranx from the Bay of Bengal. Remarks on some little known Indian Ophidia. Remarks on some forms of Dipsadomorplus. A pelagic Sea-Anemone without tentacles. Rhynchota Malayana, II.

Part 111. - Notes on the Neuroptera in the collection of the Indian Museum. Ner Indian Leptidæ and Bombylidæ, with a note on Comastes, Os. Sac., v. Heterostylum, Macq. Notes on the Trichoptera in the collection of the Indian Museum. Diagnoses of new species and varieties of Freshwater Crabs, I-3. Report on a small collection of Lizards from Travancore. Description of three new Cicindeline from Borneo. The relation between fertility and normality in Rats. Description of a Barnacle of the genus Scalpellum from Malaysia. The Hemipterous family Polyctenidæ. Notes on Freshwater Sponges, XI. Descriptions of two new shells from S. India. Preliminary note in a new geilus of Phylactolæmatous Polyzoa. Miscellanea.

IV.-Description of a minute Hymenopterous insect from Calcutta. The Insect Fauna of Tirhut, No. 1. Descripons of new species of Botia and Nemachilus. New Oriental Sepsina. A new species of. Fredericella from Indian kes. Diagnoses of new species and varieties of freshwater crabs, No. 4. On some new or little-known Mygalo-
jorph spiders from the Oriental region and Australasia. 


\section{Vol. IV, 1910 .}

No. I. - Second report on the collection of Cuficidx in the Indian Museum, with descriptionis of new genera and species.

Nos. II and III:-The Indian species of Papataci Fly (Phlebotomus). Taxonomic values in Culicidæ.

No. IV.-Revision of the Oriental bload-sucking Muscidæ (Stomoxine, Philamatomyia, Aust, and Pristirhynchomyia, gen. nov.).

Vol. V, 1910.

Part T.-The Hydroids of the Indian Museum, I. Notes on Freshwater Sponges, XII. Descripticns of new shells in the collection of the Indian Museum from Burma, Siam and the Bay of Bengal. Materials for a revisicn of the Phylactolæmatous Polyzoa of India. Studies on the aquatic Oligocheta of the Punjab. An undescribed Burmese Frog allied to Rania tigrina. Miscellanea:

Part II,-Description d'Ophiures nouvelle; provenant des dernières campagnes de "I'Investigator" dans l'Océau -Indien. Description d'Holothuries nouvelles appartenant au Musée Indien. The rạces of Indian rats; II. Descriftion of a new species of jculpellumi from the Andaman Sea. Deșeriptions of five neis species of marine shells from the Bay of Bengal. Notes on fish from India and Persia, with descriptions of tow species.

Part III.-A new genus of Psycholid Diptera frcm the Himalayas and Travancore. The Indian barnacles of the sub genus Smilium, with remarks on the cilassification of the genus Scalpellum. On a subspecies of Scutigerella ungniculata. Hausen, found in Cilcutta. The distribution of the Oritntal Scolopendrida. Notes on Decapoda in the Indian Iuseum, I. Description of a new species of Nemachilus from Northern India. Notes on the larve of Toxorhynchiles immisericors, IVlk. Description of a South Indian frog allied to Rana corrugala of Ceylon. Contributions to the fauna of Yunnan, Introduction aru Part. I. Miscellanea:

\section{MEMOIRS \\ of the \\ INDIAN MUSEUM}

Vol. I.

No. I.-An account of the Rats of Calcutta. By W. C. Hossack. Rs. 5- $\delta$.

No. 2.-An account of the Internal Anatomy of Bathynomus giganteus. 'By R. E. LLOYD. Rs. 2.

No. 3, A and B.-The Oligochrta of India, Nepal, Ceylon, Burma and the Andaman Islands, with an account of the anatomy of certain aquatic forms. By W. MICHAELSEN and J. STEPHENSON. Rs. $4-8$.

No. 4.--Investigator sicarins, a Gephyrean Worm hitherto undescribed, the type of a new order. By F. H. STEWART. Rs. 2.

\section{Vol. II.}

No. I.-Report on the Fishes ta'sen by the Bengal Fisheries Steamer "Golden Crown." Part I.-Batoidei. By N. Annandale. Rs. 2.

No. 2.-An account of the Indian Cirripedia Pedunculata. Part I.-Family Lepadidæ. (sensu stricto). By N: ANNANDALE., Rs.2.

No. 3.-A description of the deep-sea fish caught by the R.I.M.S. Ship "Investigator." since the year. Igoo, with supposed evidence of mutation in Malthopsis, and Illustrations of the Zoology of the R.I.M.S. Ship "Investigator," Fishes Plätes XLIV-L, I909. . By R. E. LLOYD.. Rs. 4-8.

No. 4.-Ètude sur les Chironomides des Indes Orientales, avec description de quelque: nouvelles espèces d'Egypte. Par J. J. KIEFfFer. Rs. 2. 



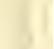





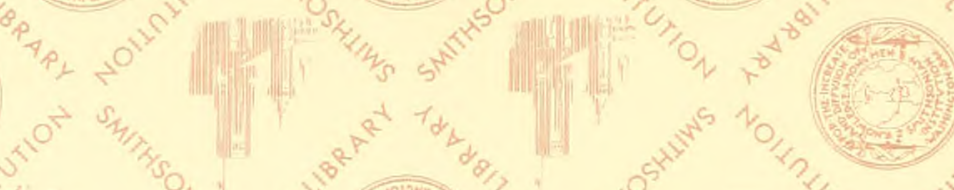

2
+2 -

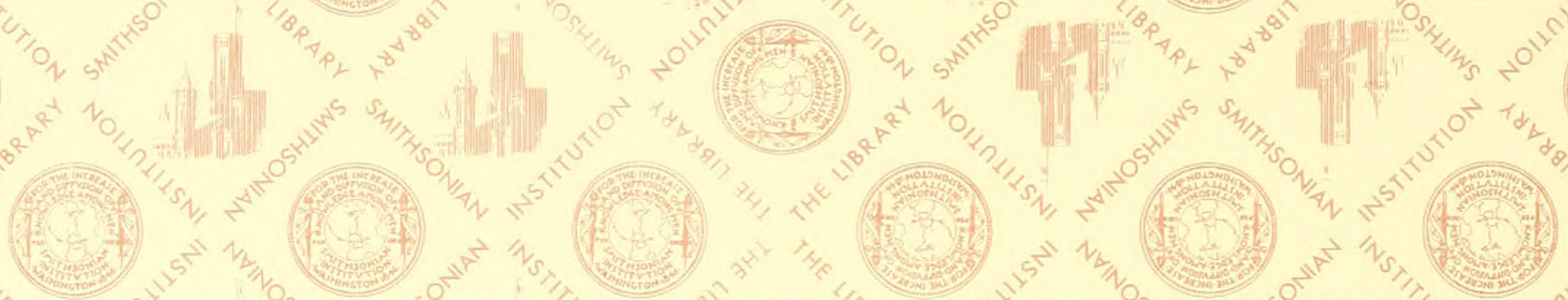

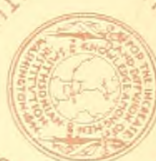
कर 



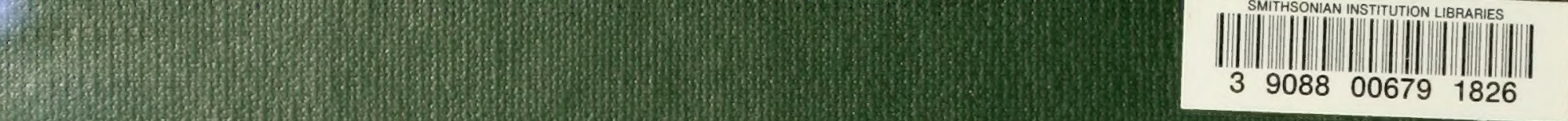

